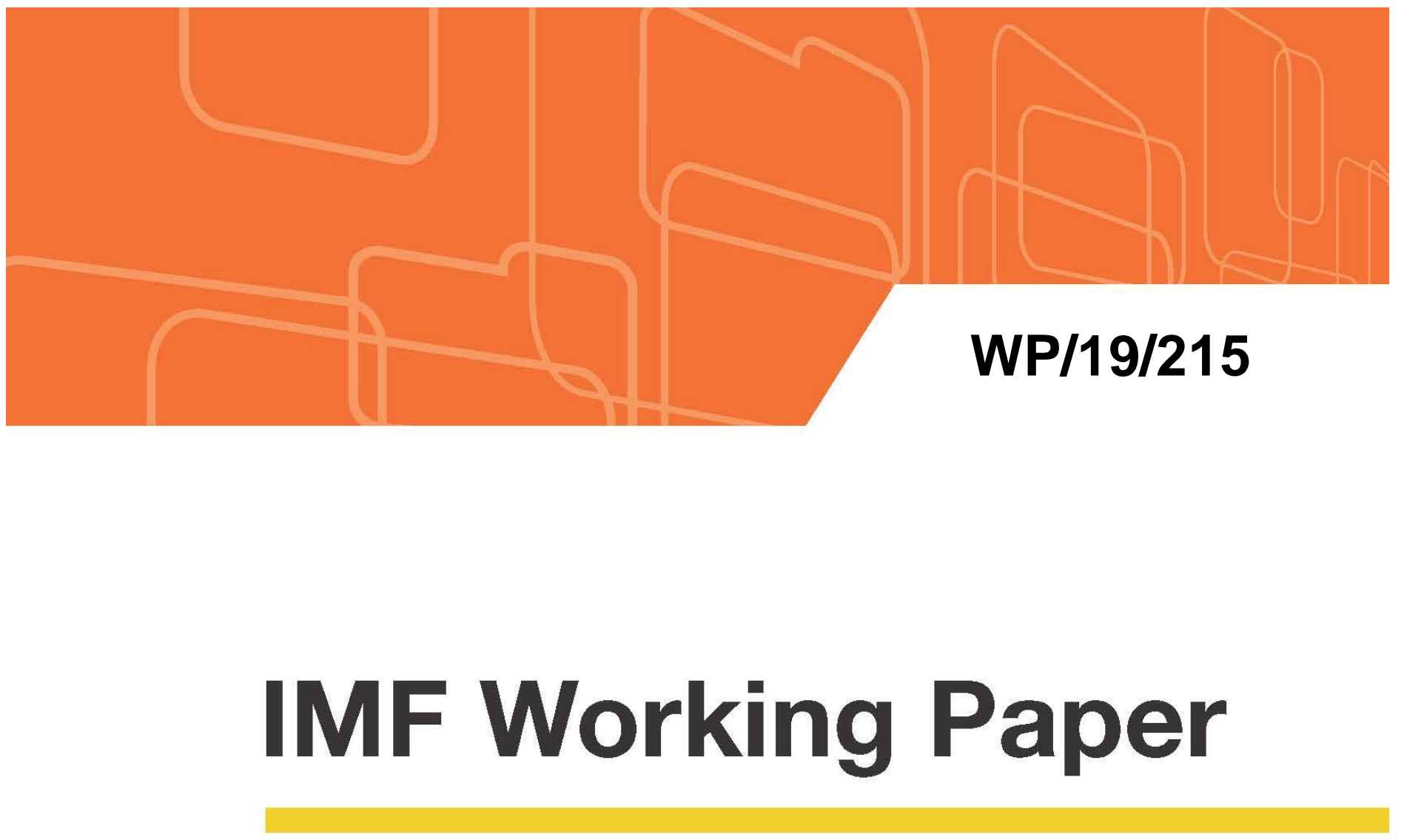

\title{
Long-Term Macroeconomic Effects of Climate Change: A Cross-Country Analysis
}

by Matthew E. Kahn, Kamiar Mohaddes, Ryan N. C. Ng, M. Hashem Pesaran, Mehdi Raissi and Jui-Chung Yang

IMF Working Papers describe research in progress by the author(s) and are published to elicit comments and to encourage debate. The views expressed in IMF Working Papers are those of the author(s) and do not necessarily represent the views of the IMF, its Executive Board, or IMF management.

$$
\text { I N T E R N A T I O N A L M O N E T A R Y F U N D }
$$


IMF Working Paper

Fiscal Affairs Department

\title{
Long-Term Macroeconomic Effects of Climate Change: A Cross-Country Analysis*
}

\section{Prepared by ${ }^{* *}$ Matthew E. Kahn, Kamiar Mohaddes, Ryan N. C. Ng, M. Hashem Pesaran, Mehdi Raissi and Jui-Chung Yang}

Authorized for distribution by Catherine Pattillo

October 2019

\begin{abstract}
IMF Working Papers describe research in progress by the author(s) and are published to elicit comments and to encourage debate. The views expressed in IMF Working Papers are those of the author(s) and do not necessarily represent the views of the IMF, its Executive Board, or IMF management.
\end{abstract}

\begin{abstract}
We study the long-term impact of climate change on economic activity across countries, using a stochastic growth model where labor productivity is affected by country-specific climate variables - defined as deviations of temperature and precipitation from their historical norms. Using a panel data set of 174 countries over the years 1960 to 2014, we find that per-capita real output growth is adversely affected by persistent changes in the temperature above or below its historical norm, but we do not obtain any statistically significant effects for changes in precipitation. Our counterfactual analysis suggests that a persistent increase in average global temperature by $0.04^{\circ} \mathrm{C}$ per year, in the absence of mitigation policies, reduces world real GDP per capita by more than 7 percent by 2100 . On the other hand, abiding by the Paris Agreement, thereby limiting the temperature increase to $0.01^{\circ} \mathrm{C}$ per annum, reduces the loss substantially to about 1 percent. These effects vary significantly across countries depending on the pace of temperature increases and variability of climate conditions. We also provide supplementary evidence using data on a sample of 48 U.S. states between 1963 and 2016, and show that climate change has a long-lasting adverse impact on real output in various states and economic sectors, and on labor productivity and employment.
\end{abstract}

JEL Classification Numbers: C33, O40, O44, O51, Q51, Q54.

Keywords: Climate change, economic growth, adaptation, counterfactual analysis.

Author's E-Mail Address: mkahn10@jhu.edu; km418@cam.ac.uk; rncn2@cam.ac.uk; pesaran@usc.edu; mraissi@imf.org; jc.yang@mx.nthu.edu.tw.

\footnotetext{
${ }^{*}$ We are grateful to Nicoletta Batini, Paul Cashin, Kamil Dybczak, Stephanie Eble, Daniel Garcia-Macia, Stephane Hallegatte, Zeina Hasna, John Hassler, Beata Jajko, Florence Jaumotte, Roland Kpodar, Per Krusell, Anne L. Moses, Peter Phillips, Saad Quayyum, Margit Reischer, Christiane Roehler, Ron Smith, Richard Tol and seminar participants at the IMF, Bank of Lithuania, Bank of Canada, EPRG, Cambridge Judge Business School, the ERF 24th Annual Conference, the 2018 MIT CEEPR Research Workshop, and the Keynes Fund Research Day for comments and suggestions. We also thank Matthew Norris for help with constructing the global climate dataset. We gratefully acknowledge financial support from the Keynes Fund. Part of this work was done while Jui-Chung Yang was a Postdoctoral Research Fellow at the USC Dornsife INET. An earlier draft of this paper was presented at the IMF when Kamiar Mohaddes was a visiting scholar at the Asia and Pacific Department.

*** Kahn: Johns Hopkins University. Mohaddes and Ng: University of Cambridge. Pesaran: University of Southern California and Trinity College, Cambridge, UK. Yang: National Tsing Hua University, Taiwan Province of China.
} 


\section{TABLE OF CONTENTS}

CONTENT

PAGE

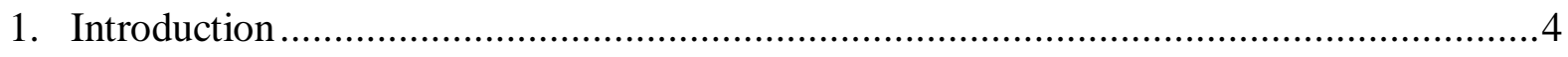

2. A Multi-Country Stochastic Growth Model with Climate Effects ..................................11

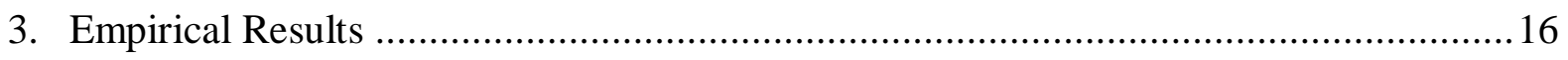

3.1. Climate Change: Historical Patterns .................................................................. 16

3.2. Long-Term Impact of Climate Change on Economic Growth..................................20

3.3. Robustness to the Choice of Historical Norms …………......................................2 28

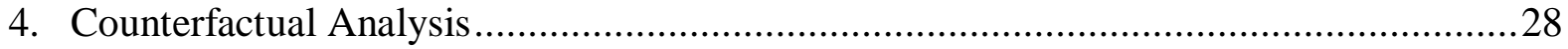

5. Evidence from an Advanced Economy: The Case of the United States ...........................37

5.1. Long-Run Impact of Climate Change on U.S. Economic Growth .............................38

5.2. Further Evidence from U.S. Sector Level Data........................................................4

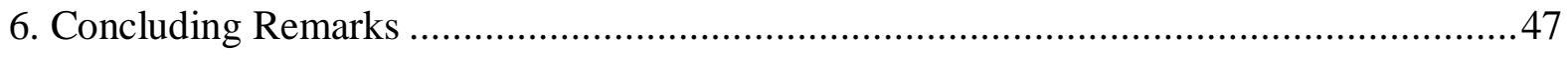

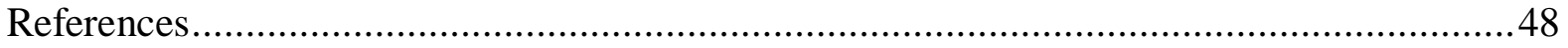

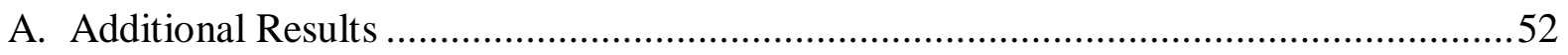

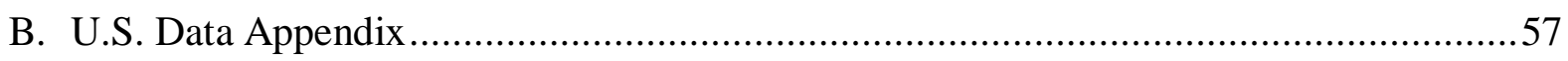

Figures

1. Global Temperature Projections (Deviations from 1984-2014) ….................................. 8

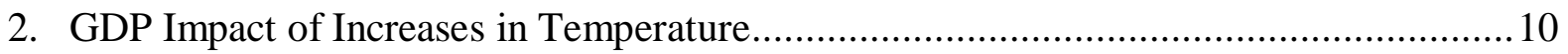

3. GDP Per Capita Losses from Increases in Temperature: Cold vs. Hot ..............................10

4. Global Land-Surface Air and Sea-Surface Water Temperatures (Degrees Celsius,

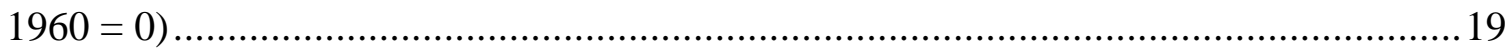

5. Temperature Increase per year for the 174 Countries, 1960-2014 ……........................ 19

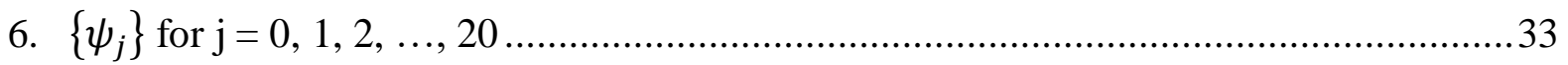

7. Percent Loss in GDP per capita by 2100 in the Absence of Climate Change Policies

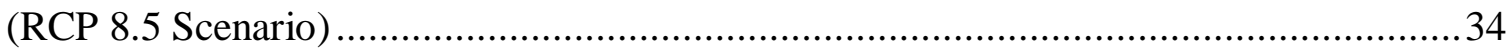

8. Percent Loss in GDP per capita by 2100 Abiding by the Paris Agreement (RCP 2.6

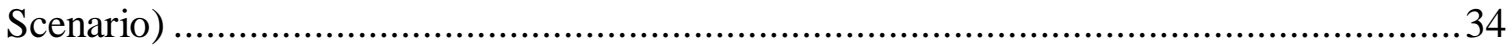

9. Long-Run Effects of Climate Change on per capita Real GSP Growth in the United States, 1963-2016.

A.1. Global Land-Surface Air and Sea-Surface Water Temperatures (Degrees Celsius, $1960=0)$ 
Tables

1. Individual Country Estimates of the Average Yearly Rise in Temperature Over the Period 1960-2014

2. Long-Run Effects of Climate Change on per Capita Real GDP Growth, 1960-2014 (Historical Norms as the Moving Averages of Past 30 Years).

3. Long-Run Effects of Climate Change on per Capita Real GDP Growth, 1960-2014 (Using Absolute Value of Deviations of Climate Variables from their Historical Norm) .25

4. Long-Run Effects of Climate Change on per Capita Real GDP Growth, 1960-2014 (Historical Norms as the Moving Averages of Past 20 Years).

5. Long-Run Effects of Climate Change on per Capita Real GDP Growth, 1960-2014 (Historical Norms as the Moving Averages of Past 40 Years)

6. Effects of Climate Change on per Capita Real GDP Growth, 1960-2014

7. Percent Loss in GDP per capita by 2030, 2050, and 2100 under the RCP 2.6 and RCP 8.5 Scenarios...

8. Percent Loss in GDP per capita by 2030, 2050, and 2100 under the RCP 8.5 Scenario: the Role of Climate Variability.

9. Individual U.S. State Estimates of the Average Yearly Rise in Temperature Over the Period 1963-2016.

10. Long-Run Effects of Climate Change on the Growth Rate of Major Economic Indicators for the United States, 1963-2016

11. Long-Run Effects of Climate Change on the Growth Rate of Major Economic Indicators for the United States, 1976-2016

12. Long-Run Effects of Climate Change on the Output Growth of Various Sectors in the United States, 1963-2016.

A.1. Individual Country Estimates of the Average Yearly Rise in Temperature Over the Period 1900-2014

A.2. Percent Loss in GDP per capita by 2030, 2050, and 2100 under the RCP 2.6 and RCP 8.5 Scenarios.

B.1. Division (SIC) and Sector (NAICS) Classifications.... 


\section{Introduction}

Global temperatures have increased significantly in the past half century and extreme weather events, such as cold snaps and heat waves, droughts and floods, as well as natural disasters, are becoming more frequent and severe. These changes in the distribution of weather patterns (i.e., climate change ${ }^{1}$ ) are not only affecting low-income countries, but also advanced economies - in September 2017 while Los Angeles experienced the largest fire in its history, Hurricanes Harvey and Irma caused major destruction in Texas and Florida, respectively. A persistent rise in temperature, changes in precipitation patterns and/or more volatile weather events can have long-term macroeconomic effects by adversely affecting labour productivity, slowing investment and damaging human health; something that is usually overlooked in the literature owing to the focus of existing studies on short-term growth effects.

This paper investigates the long-term macroeconomic effects of climate change across 174 countries over the period 1960 to 2014. Climate change could affect the level of output (by changing agricultural yields, for example) or an economy's ability to grow in the longterm if the changes in climate variables are persistent, through reduced investment and lower labour productivity in most sectors of the economy. We focus on the latter and develop a theoretical growth model that links deviations of climate variables (temperature and precipitation) from their historical norms to changes in labour productivity and, hence real output per capita. In our empirical application, we allow for dynamics and feedback effects in the interconnections of climate change and macroeconomic variables. Also, by using deviations of climate variables from their respective historical norms, while allowing for nonlinearity ${ }^{2}$ we avoid the econometric pitfalls associated with the use of trended variables, such as temperature, in output growth equations. As it is well known, and is also documented in our paper, temperature has been trending upward strongly in almost all countries in the world, and its use as a regressor in a growth regression can lead to spurious estimates.

To measure the damage caused by climate change, economists have sought to quantify how aggregate economic growth is being affected by rising temperatures and changes in rainfall patterns; see a recent survey by Dell et al. (2014). Macroeconomic-climate estimates are a key input in the design of optimal Pigouvian taxes or carbon pricing. These taxes should reflect the social cost of carbon (SCC), which represents the damage caused by the release of one ton of carbon dioxide (Nordhaus 2017). To calculate the SCC, one must obtain estimates of three distinct relationships. First, environmental scientists must measure the relationship between carbon dioxide emissions and ambient carbon dioxide concentrations

\footnotetext{
${ }^{1}$ IPCC (2014) defines 'climate change' as "a change in the state of the climate that can be identified (e.g., by using statistical tests) by changes in the mean and/or the variability of its properties, and that persists for an extended period, typically decades or longer."

${ }^{2}$ Non-linearity arises because growth is only affected when temperature (or precipitation) goes above or below a time-varying historical threshold (i.e., the norm). It is due to this feature that future growth is affected not only by warming (or cooling if that was the case) but also by its variability.
} 
(Pacala and Socolow 2004). Second, atmospheric scientists need to estimate the relationship between ambient carbon dioxide concentrations and temperature (this is the so called climate sensitivity parameter, see Weitzman 2009). ${ }^{3}$ Third, economists should estimate the causal effects of rising average temperature on measures of economic activity.

The literature which attempts to quantify the effects of climate events (temperature, precipitation, storms, and other aspects of the weather) on economic performance (agricultural production, labour productivity, commodity prices, health, conflict, and economic growth) is relatively recent and mainly concerned with short-run effects - see Stern (2007), IPCC (2014), Hsiang (2016), Cashin et al. (2017) and the recent surveys by Tol (2009) and Dell et al. (2014). Moreover, there are a number of grounds on which the econometric evidence of the effects of climate change on growth may be questioned. Firstly, the literature relies primarily on the cross-sectional approach (see, for instance, Sachs and Warner 1997, Gallup et al. 1999, Nordhaus 2006, and Dell et al. 2009), and as such does not take into account the time dimension of the data (i.e., assumes that the observed relationship across countries holds over time as well) and is also subject to the endogeneity (reverse causality) problem given the possible feedback effects from changes in output growth onto the climate variable.

Secondly, the fixed effects (FE) estimators used in more recent panel-data studies implicitly assume that climate variables are strictly exogenous, and thus rule out any reverse causality from economic growth to rising average temperatures - see Burke et al. (2015), Dell et al. (2012), Dell et al. (2014), and Hsiang (2016), and the references therein. At the heart of the Nordhaus DICE model is the need to account for this fundamental issue (see, for instance, Nordhaus 1992). In his computable general equilibrium work, Nordhaus accounts for the fact that faster economic activity increases the stock of greenhouse gas (GHG) emissions and thereby the average temperature. At the same time, rising average temperature could reduce real economic activity. This equilibrium approach has important implications for the econometric specification of climate change-economic growth relationship.

In fact, recent studies on climate science provide strong evidence that the main cause of contemporary global warming is the release of greenhouse gases to the atmosphere by human activities (Mitchell et al. 2001 and Brown et al. 2016). Consequently, when estimating the impact of climate change on economic growth, temperature $\left(\mathcal{T}_{i t}\right)$ may not be considered as strictly exogenous, but merely weakly exogenous/predetermined to income growth; in other words economic growth in the past might have feedback effects on future temperature. While it is well known that the FE estimator suffers from small- $T$ bias in dynamic panels (see Nickell 1981) with $N$ (the cross-section dimension) larger than $T$ (the time series dimension), Chudik et al. 2018 show that this bias exists regardless of whether the lags of the dependent variable are included or not, so long as one or more regressor is not strictly exogenous. In

\footnotetext{
${ }^{3}$ In recent work, Phillips et al. (2019) find that the climate sensitivity parameter with respect to ambient GHG concentrations is even larger than has previously been recognised.
} 
such cases, inference based on the standard FE estimator will be invalid and can result in large size distortions unless $N / T \rightarrow 0$, as $N, T \rightarrow \infty$ jointly. Therefore, caution must be exercised when interpreting the results from studies that use the standard FE estimators in the climate change-economic growth literature given that $N$ is often larger than $T$.

Thirdly, econometric specifications of the climate change-macroeconomic relation are often written in terms of real GDP per capita growth and the level of temperature, $\mathcal{T}_{i t}$, and in some cases also $\mathcal{T}_{i t}^{2}$; see, for instance, Dell et al. (2012) and Burke et al. (2015). But if $\mathcal{T}_{i t}$ is trended, which is the case in almost all countries in the world (see Section 3.1), inclusion of $\mathcal{T}_{i t}$ in the regression will induce a quadratic trend in equilibrium log per capita output (or equivalently a linear trend in per capita output growth) which is not desirable and can bias the estimates of the growth-climate change equation. Finally, another major drawback of this literature is that the econometric specifications of the climate change-growth relation are generally not derived from or based on a theoretical growth model. Either an ad hoc approach is used, where real income growth is regressed on a number of arbitrarily-chosen variables, or a theoretical model is developed but not put to a rigorous empirical test.

We contribute to the climate change economic growth literature along the following dimensions. Firstly, we extend the stochastic single-country growth models of Merton (1975), Brock and Mirman (1972), and Binder and Pesaran (1999) to $N$ countries sharing a common technology but different climate conditions. Our theoretical model postulates that labour productivity in each country is affected by a common technological factor and countryspecific climate variables, which we take to be average temperature, $\mathcal{T}_{i t}$, and precipitation, $\mathcal{P}_{i t}$, in addition to other country-specific idiosyncratic shocks. As long as $\mathcal{T}_{i t}$ and $\mathcal{P}_{i t}$ remain close to their respective historical norms (regarded as technologically neutral), they are not expected to affect labour productivity. However, if climate variables deviate from their historical norms, the effects on labour productivity could be positive or negative, depending on the region under consideration. For example, in a historically cold region, a rise in temperature above its historical norm might result in higher labour productivity, whilst for a dry region, a fall in precipitation below its historical norms is likely to have adverse effects on labour productivity. ${ }^{4}$ Secondly, contrary to much of the literature which is mainly concerned with short-term growth effects, we explicitly model and test the long-run growth effects of persistent increases in temperature. Thirdly, we use the half-panel Jackknife FE (HPJ-FE) estimator proposed in Chudik et al. (2018) to deal with the possible bias and size distortion of the commonly-used FE estimator (given that $\mathcal{T}_{i t}$ is weakly exogenous). When the time dimension of the panel is moderate relative to $N$, the HPJ-FE estimator effectively corrects the Nickel-type bias if regressors are weakly exogenous, and is robust to possible feedback

\footnotetext{
${ }^{4}$ Our focus on the deviations of temperature and precipitation from their historical norms also marks a departure from the literature, as changes in the distribution of weather patterns (not only averages of climate variables but also their variability) are modeled explicitly.
} 
effects from aggregate economic activity to the climate variables.

We start by documenting that the global average temperature has risen by 0.0181 degrees Celsius per year over the last half century (1960-2014), with positive country-specific trend estimates in 169 out of 174 countries in our sample (97.1\% of cases), and statistically significant estimates at the $5 \%$ level in 161 out of 169 countries with positive trends $(95.3 \%$ of cases). For the remaining five countries, while the trend estimates are negative, they are not statistically significant at the $5 \%$ level. Overall, as discussed above, the fact that temperature is trended in almost all countries poses a problem for those studies that include $\mathcal{T}_{i t}$ in their growth regressions as it can bias the estimates, not to mention that it imposes a trend in per capita GDP growth which is something we do not observe.

We test the predictions of our theoretical model using cross-country data on per-capita output growth and the deviations of temperature and precipitation from their historical norms over the past fifty-five years (1960-2014). Our results suggest that a persistent change in climate conditions has a long-term negative effect on per capita GDP growth. Specifically, we show that if temperature rises (falls) above (below) its historical norm by $0.01^{\circ} \mathrm{C}$ annually, income growth will be lower by 0.0543 percentage points per year. We could not detect any significant evidence of an asymmetric long-term growth impact from positive and negative deviations of temperature from its norms. Furthermore, we show that our empirical findings pertain to poor or rich, and hot or cold countries alike as economic growth is affected not only by higher temperatures but also by the degree of climate variability. ${ }^{5}$ This is contrary to most of the literature which finds that temperature increases have uneven macroeconomic effects, with adverse consequences in countries with hot climates, such as low-income countries; see, for instance, Sachs and Warner (1997), Jones and Olken (2010), Dell et al. (2012), International Monetary Fund (2017), and Mejia et al. (2018).

To contribute to climate policy discussions, we perform a number of counterfactual exercises where we investigate the cumulative income effects of annual increases in temperatures over the period 2015-2100 (when compared to a baseline scenario under which temperature in each country increases according to its historical trend of 1960-2014). We show that an increase in average global temperature of $0.04^{\circ} \mathrm{C}$ per year-corresponding to the Representative Concentration Pathway (RCP) 8.5 scenario (see Figure 1), which assumes higher greenhouse gas emissions in the absence of mitigation policies - reduces world's real GDP per capita by 7.22 percent by 2100 . Limiting the increase to $0.01^{\circ} \mathrm{C}$ per annum, which corresponds to the December 2015 Paris Agreement, reduces the output loss substantially to 1.07 percent, only. Thus our analysis finds strong support for keeping with the Paris Agreement

\footnotetext{
${ }^{5}$ It is not only the level of temperature that affects economic activity, but also its deviations from historical norms. For example, while the level of temperature in Canada is low, the country is warming up twice as fast as rest of the world and therefore is being affected by climate change (including from damages to its physical infrastructure, coastal and northern communities, human health and wellness, ecosystems and fisheries).
} 
pledges or even better increasing their ambition to avoid substantial output losses. ${ }^{6}$

Figure 1: Global Temperature Projections (Deviations from 1984-2014)

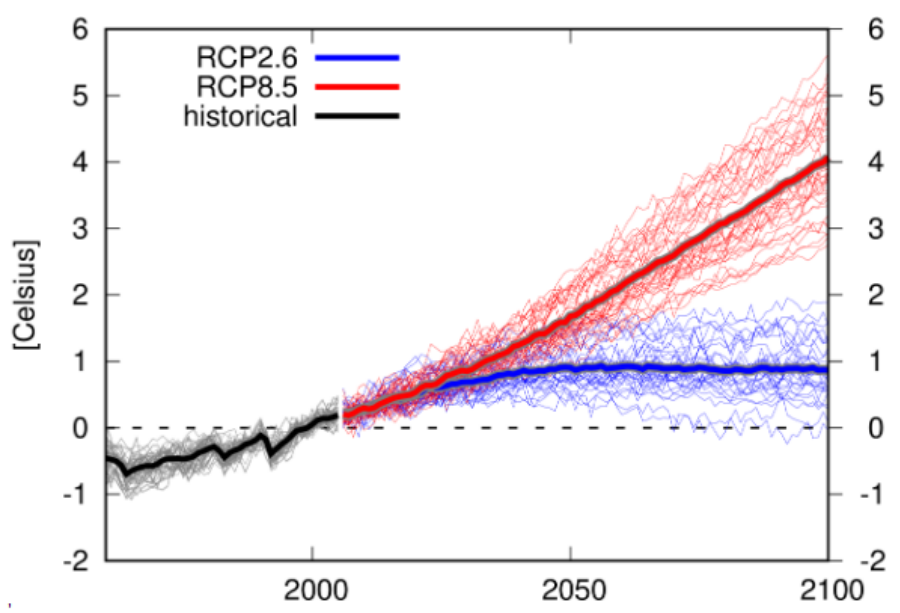

Source: Intergovernmental Panel on Climate Change (IPCC) Coupled Model Intercomparison Project Phase Five AR5 Atlas Subset.

Notes: The thin lines represent each of the 40 models in the IPCC WG1 AR5 Annex I Atlas. The thick lines represent the multimodel mean. Representative Concentration Pathways (RCP) are scenarios of greenhouse gas concentrations, constructed by the IPCC. RCP 2.6 corresponds to the Paris Agreement which aims to hold the increase in the global average temperature to below 2 degrees Celsius above pre-industrial levels. RCP 8.5 is an unmitigated scenario in which emissions continue to rise throughout the 21st century.

To put our results into perspective, the conclusions one might draw from most of the existing climate change-macroeconomy literature are the following: (i) when a poor (hot) country is $1^{\circ} \mathrm{C}$ warmer than usual, its income growth falls by $1-2$ percentage points in the short- to medium-term; (ii) when a rich (temperate) country is $1^{\circ} \mathrm{C}$ warmer than usual, there is little impact on its economic activity; and (iii) the GDP effect of increases in average temperatures (with or without adaptation and/or mitigation policies) is relatively small - a few percent decline in the level of GDP per capita over the next century (see, Figure 2). In contrast, our counterfactual estimates suggest that all regions (cold or hot, and rich or poor) would experience a relatively large fall in GDP per capita by 2100 in the absence of climate change policies (i.e., under a high-emission scenario or RCP 8.5). However, the size of these income effects varies across countries depending on the pace with which temperatures increase and historical variability of climate conditions in each country (see Figures 3, 7 and 8); for instance, for the U.S. the losses are relatively large at 10.52 percent under the RCP 8.5 scenario in year 2100 (reflecting a sharp increase in its average temperatures), but would be limited to 1.88 percent under the Paris Agreement. The estimated losses under the

\footnotetext{
${ }^{6}$ The Paris Agreement, reached within the United Nations Framework Convention on Climate Change (UNFCCC), aims to keep the increase in the global average temperature to below 2 degrees Celsius above pre-industrial levels over the 21st century. The average global temperature is already $1{ }^{\circ} \mathrm{C}$ above the preindustrial levels.
} 
RCP 8.5 scenario would be significantly higher if the country-specific variability of climate conditions were to rise commensurate to temperature increases (see Table 8). Moreover, the speed with which the historical norms change (20-, 30-, or 40-year moving averages), that is how fast countries adapt to global warming or new climate conditions, affects the size of income losses. ${ }^{7}$ Overall, while climate change adaptation could reduce these negative long-run growth effects, it is highly unlikely to offset them entirely.

Finally, having established a long-run negative relationship between economic growth and climate change across countries (regardless of their level of development), we examine the climate change-growth relationship in a within-country context (which is scant in the literature) and also focus on the channels of impact (labour productivity, employment, and output growth in various sectors of the economy). While cross-country studies are informative, they also have drawbacks. Averaging temperature and precipitation data at the country level leads to a loss of information, especially in geographically diverse countries such as Brazil, China, India, Russia and the United States. In particular, while the national average of climate variables may be close to their historical norms, there is significant heterogeneity within countries. The within-country geographic heterogeneity of the United States enables us to compare whether economic activity in 'hot' or 'wet' states responds to a temperature increase in the same way as economic activity does in 'cold' or 'dry' states. The richness of the United States data also allows for a more disaggregated study of the climate change-growth relationship and enables us to test whether the country at the aggregate level, parts of the country, or particular sectors of the economy have been affected more by climate change. To do so, we conduct a case study of the United States using data on 48 states over the period 1963 to 2016, the HPJ-FE estimator, and various state-specific economic performance indicators at the aggregate and sectoral levels.

Our within-country results provide evidence for the damage that climate change causes in the U.S. using various economic indicators at the state level: growth rates of Gross State Product (GSP), GSP per capita, labour productivity, and employment as well as output in different sectors (e.g., agriculture, manufacturing, services, retail and wholesale trade). We show that if temperature increases by $0.01^{\circ} \mathrm{C}$ annually above its historical norm across U.S. states, average per-capita real GSP growth will be lower by 0.0273 percentage points per year - a number that is smaller than those obtained in our cross-country regressions. We also show that the impact of climate change on sectoral output growth is broad based - each of the 10 sectors considered is affected by at least one of the four climate variables. Moreover, in contrast to our cross-country results, the within U.S. estimates tend to be asymmetrical with respect to deviations of climate variables from their historical norms (in the positive and negative directions). Finally, our results highlight the importance of climate change

\footnotetext{
${ }^{7}$ Another way to assess adaptation is to test how the elasticity of per capita GDP to climate variables evolve over time. See Section 5 for details.
} 


\section{Figure 2: GDP Impact of Increases in Temperature}

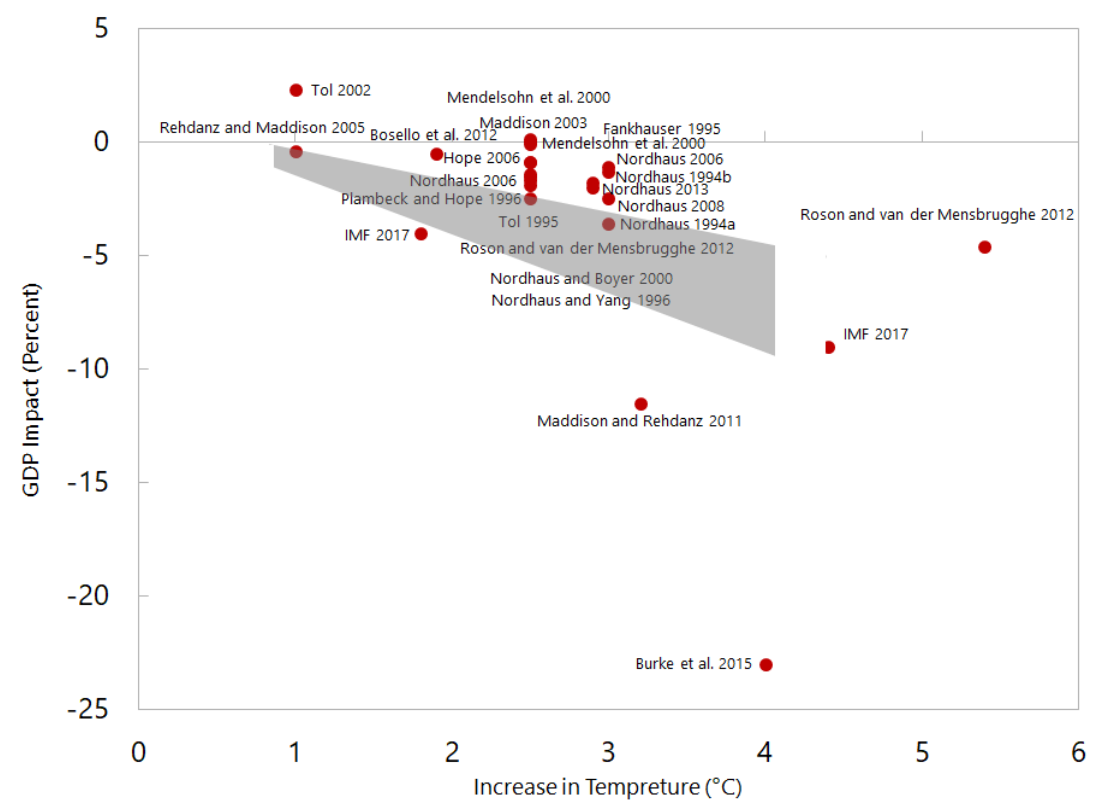

Sources: Tol (2009), Tol (2014), Burke et al. (2015), International Monetary Fund (2017) and authors' estimates (shown as the grey area in the chart).

Notes: Projected GDP impact is for some future year, typically 2100. The shaded area represents the GDP per capita losses from our counterfactual exercise in Section 4 with the upper bound based on $m=20$ and the lower bound based on $m=40$.

Figure 3: GDP Per Capita Losses from Increases in Temperature: Cold vs. Hot

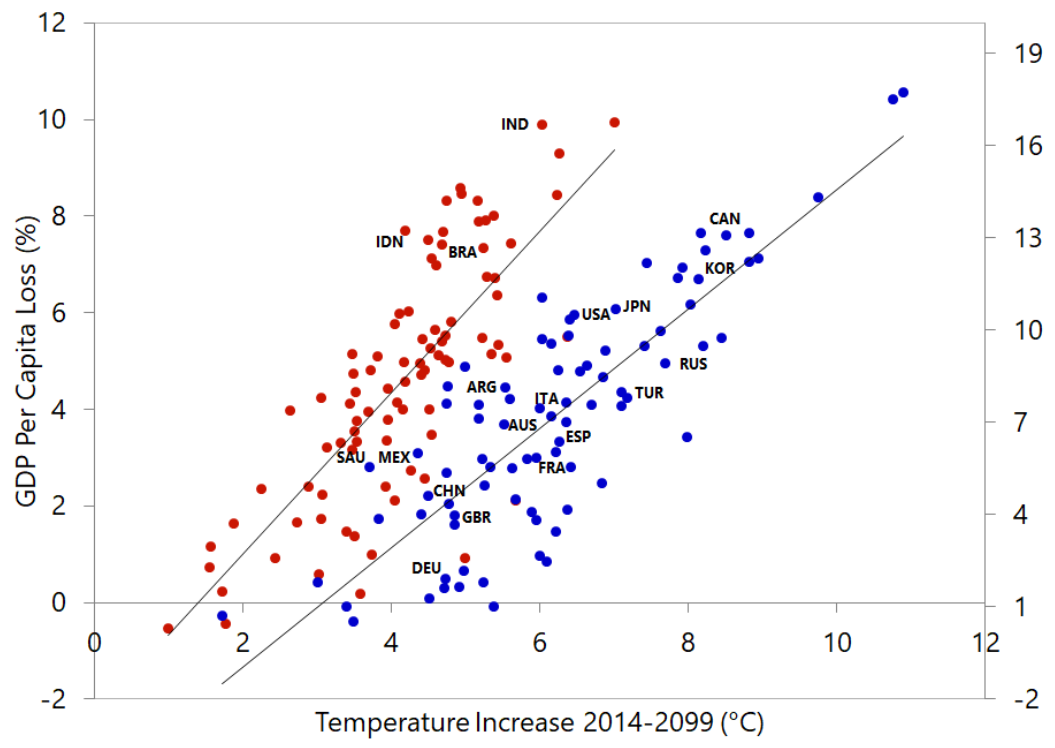

Notes: GDP per capita losses by 2100 from our baseline counterfactual exercise in Section 4 for hot (on left axis and in red) and cold (on right axis and in blue) countries 
policies. While we acknowledge some resilience-building efforts in advanced economies, the evidence from the U.S. study (as well as the cross-country analysis) seems to suggest that it has not entirely offset the negative effects of climate change at the macro level.

The remainder of this paper is organized as follows. Section 2 develops a multi-country stochastic growth model with climate effects. Section 3 considers the extent to which temperature has been rising across countries and globally, and discusses the long-run effects of climate change on output growth across countries. Section 4 conducts counterfactual exercises to investigate the cumulative income effects of annual increases in temperatures under an unmitigated path as well as the Paris Agreement up to the year 2100. Section 5 uses a range of economic performance indicators across U.S. states and production sectors to examine the consequences of climate change for a typical advanced economy and the role of adaptation. Finally, Section 6 offers some concluding remarks.

\section{A Multi-Country Stochastic Growth Model with Cli- mate Effects}

Theoretical growth models generally focus on technological progress and permanent improvements in the efficiency with which factors of production are combined as the main drivers of long-term economic growth, and ignore the possible effects of climate change. Examples include Merton (1975), Brock and Mirman (1972), Donaldson and Mehra (1983), Marimon (1989), and Binder and Pesaran (1999), who have developed stochastic growth models for single economies. We extend this literature and consider the growth process across $N$ countries sharing a common technology but subject to different climate conditions.

Consider a set of economies in which aggregate production possibilities are described by the following production function:

$$
Y_{i t}=\mathcal{F}\left(\Lambda_{i t} L_{i t}, K_{i t}\right)
$$

where $L_{i t}$, and $K_{i t}$, are labour and capital inputs, and $\Lambda_{i t}$ is a scale variable that determines labour productivity in economy $i$. We suppose that labour productivity is governed by a common technological factor, $\theta_{t}>0$, as well as country-specific climate variables. We consider average temperature $\left(\mathcal{T}_{i t}\right)$ and precipitation $\left(\mathcal{P}_{i t}\right)$ as the main climate variables, but assume labour productivity is affected by climate variables only when they deviate from their historical norms, which we denote by $\mathcal{T}_{i, t-1}^{*}$ and $\mathcal{P}_{i, t-1}^{*}$, respectively.

The historical norms are regarded as technologically neutral, in the sense that if climate variables remain close to their historical norms, they are not expected to have any effects on labour productivity. Recent research demonstrates that different regions of the U.S. have 
acclimated themselves to their own temperature niche. Heutel et al. (2016) document that heat waves cause more deaths in U.S. regions that are accustomed to colder norms than it does in hotter places. Moreover, if climate variables deviate from their historical norms, the effects on labour productivity could be positive or negative, depending on the region under consideration. For example, in a historically cold region, a rise in temperature above its historical norm might result in higher labour productivity, whilst for a dry region, a fall in precipitation below its historical norms is likely to have adverse effects on labour productivity. Accordingly, in what follows we also allow for an asymmetry in the effects of deviations from the historical norms on labour productivity, and introduce the following climate threshold variables:

$$
\begin{aligned}
& \left(\mathcal{T}_{i t}-\mathcal{T}_{i, t-1}^{*}\right)^{+}=\left(\mathcal{T}_{i t}-\mathcal{T}_{i, t-1}^{*}\right) I\left(\mathcal{T}_{i t}-\mathcal{T}_{i, t-1}^{*} \geq 0\right) \\
& \left(\mathcal{T}_{i t}-\mathcal{T}_{i, t-1}^{*}\right)^{-}=-\left(\mathcal{T}_{i t}-\mathcal{T}_{i, t-1}^{*}\right) I\left(\mathcal{T}_{i t}-\mathcal{T}_{i, t-1}^{*}<0\right)
\end{aligned}
$$

and

$$
\begin{aligned}
& \left(\mathcal{P}_{i t}-\mathcal{P}_{i, t-1}^{*}\right)^{+}=\left(\mathcal{P}_{i t}-\mathcal{P}_{i, t-1}^{*}\right) I\left(\mathcal{P}_{i t}-\mathcal{P}_{i, t-1}^{*} \geq 0\right) \\
& \left(\mathcal{P}_{i t}-\mathcal{P}_{i, t-1}^{*}\right)^{-}=-\left(\mathcal{P}_{i t}-\mathcal{P}_{i, t-1}^{*}\right) I\left(\mathcal{P}_{i t}-\mathcal{P}_{i, t-1}^{*}<0\right)
\end{aligned}
$$

By distinguishing between positive and negative deviations of the climate variables from their historical norms we also take account of potential nonlinear effects of climate change on economic growth.

Specifically, we consider the following specification for changes in labour productivity in terms of the climate variables: ${ }^{8}$

$$
\Lambda_{i t}=A_{i} \theta_{t}^{\lambda_{i}} \exp \left[-\gamma_{i}^{+\prime}\left(\mathcal{C}_{i t}-\mathcal{C}_{i, t-1}^{*}\right)^{+}-\gamma_{i}^{-\prime}\left(\mathcal{C}_{i t}-\mathcal{C}_{i, t-1}^{*}\right)^{-}\right]
$$

where $A_{i}$ and $\lambda_{i}$ are positive constants, $\mathcal{C}_{i t}=\left(\mathcal{T}_{i t}, \mathcal{P}_{i t}\right)^{\prime}, \mathcal{C}_{i, t-1}^{*}=\left(\mathcal{T}_{i, t-1}^{*}, \mathcal{P}_{i, t-1}^{*}\right)^{\prime}, \gamma_{i}^{+}=$ $\left(\gamma_{i \mathcal{T}}^{+}, \gamma_{i \mathcal{P}}^{+}\right)^{\prime}$, and $\gamma_{i}^{-}=\left(\gamma_{i \mathcal{T}}^{-}, \gamma_{i \mathcal{P}}^{-}\right)^{\prime}$.

The historical norms can vary over time, but such variations are likely to be small in the short- to medium-term. One could also consider modelling the adverse effects of deviating from climatic norms, by using the quadratic formulation, for example, $\left(\mathcal{T}_{i t}-\mathcal{T}_{i, t-1}^{*}\right)^{2}$ instead of the threshold effects $\left(\mathcal{T}_{i t}-\mathcal{T}_{i, t-1}^{*}\right)^{+}$and $\left(\mathcal{T}_{i t}-\mathcal{T}_{i, t-1}^{*}\right)^{-}$. But in cases where $\mathcal{T}_{i t}$ is trended, which is the situation in almost all the 174 countries in our sample (see Table 1 and the discussion in Section 3.1), the inclusion of $\gamma_{i}\left(\mathcal{T}_{i t}-\mathcal{T}_{i, t-1}^{*}\right)^{2}$ will induce a quadratic trend in equilibrium log per capita output (or equivalently a linear trend in per capita output growth)

\footnotetext{
${ }^{8}$ Additional country-specific technology shocks can also be included, but to simplify the theoretical exposition we abstract from such shocks and note that part of the shock to $L_{i t}$ defined below by $u_{i t}$ (see equation (7)) could be viewed as technological in nature.
} 
which is not desirable and can bias the estimates of the growth-climate change equation. Our focus on the deviations of temperature and precipitation from their historical norms marks a departure from the existing literature by implicitly modelling climate variability around long-term trends. To simplify the notation in what follows, we write $\Lambda_{i t}$ in (3) as

$$
\Lambda_{i t}=A_{i} \theta_{t}^{\lambda_{i}} \exp \left(-\gamma_{i}^{\prime} \mathbf{x}_{i t}\right)
$$

where

$$
\mathbf{x}_{i t}=\left[\begin{array}{c}
\left(\mathcal{C}_{i t}-\mathcal{C}_{i, t-1}^{*}\right)^{+} \\
\left(\mathcal{C}_{i t}-\mathcal{C}_{i, t-1}^{*}\right)^{-}
\end{array}\right], \quad \text { and } \quad \gamma_{i}=\left(\begin{array}{c}
\gamma_{i}^{+} \\
\gamma_{i}^{-}
\end{array}\right)
$$

Assuming constant returns to scale, we have

$$
Y_{i t}=\Lambda_{i t} L_{i t} f\left(\kappa_{i t}\right)
$$

where $\kappa_{i t}$ denotes the ratio of physical capital to effective units of labour input, that is

$$
\kappa_{i t}=\frac{K_{i t}}{\Lambda_{i t} L_{i t}}
$$

Further, we assume that labour input, $L_{i t}$, evolves according to the following process

$$
\log \left(L_{i t}\right)=l_{i 0}+n_{i} t+u_{i t}
$$

where $l_{i 0}$ is an economy-specific initial endowment of labour input, $n_{i}$ is the exogenouslydetermined rate of growth of labour input, and $u_{i t}$ is the stochastic component which could be driven by a combination of demand and supply shocks. Given our emphasis on the longrun effects of climate change on income growth, we do not attempt to identify such shocks, and assume that $u_{i t}$ follows an $\operatorname{AR}(1)$ process

$$
\triangle u_{i t}=-\left(1-\rho_{i}\right) u_{i, t-1}+\varepsilon_{i t}, \quad\left|\rho_{i}\right| \leq 1, \varepsilon_{i t} \sim i i d\left(0, \sigma_{i}^{2}\right)
$$

Shocks to labour input could be correlated with the predictable part of weather conditions. For example, during heat waves, labour supply could fall before recovering in normal times, something that is reflected in work patterns of "Siesta economies". In such a setting, seasonal or cyclical changes in weather conditions might not have long-run growth effects, but can nevertheless lead to negative short-run correlations between labour input and weather shocks (as workers adapt their schedules to the changing weather conditions). It is, therefore, important to distinguish between short-run effects and the long-term impact of climate change on income growth. The short-run correlation between weather and labour input shocks also renders the weather variable weakly exogenous, with important econometric implications for 
estimation of long-run growth effects of permanent shifts in climate conditions.

The physical capital stock depreciates in each period at a constant rate $\delta_{i}$, and obeys the linear law of motion

$$
K_{i, t+1}=\left(1-\delta_{i}\right) K_{i t}+I_{i t}, \quad \delta_{i} \in(0,1)
$$

The assumption of a constant rate of capital depreciation is made for analytical convenience, and can be relaxed. In practice, the rate of capital depreciation is likely to vary over timerising significantly at times of armed conflicts and natural disasters such as earthquakes, tsunamis and hurricanes, and gradual reversals afterwards with reconstruction activities and new capital investments. Once again, this highlights the importance of distinguishing between short-term and long-term effects. One would expect the contemporaneous negative effects of natural disasters to be somewhat reversed in subsequent periods.

The model specification is completed by assuming that households' aggregate saving is given by

$$
S_{i t}=s\left(\kappa_{i t}\right) Y_{i t}
$$

where the saving function, $s(\cdot)$, is assumed to be continuously differentiable and $s_{i t} \in(0,1)$. In equilibrium, we have

$$
S_{i t}=I_{i t}=s\left(\kappa_{i t}\right) Y_{i t}
$$

hence

$$
K_{i, t+1}=\left(1-\delta_{i}\right) K_{i t}+s\left(\kappa_{i t}\right) Y_{i t}
$$

Following the literature, we assume that that $f(\cdot)$ is twice continuously differentiable, is strictly increasing and concave, and satisfies $f(0)=0$, as well as the Inada conditions $\lim _{\kappa \rightarrow 0} f^{\prime}(\kappa)=+\infty$, and $\lim _{\kappa \rightarrow \infty} f^{\prime}(\kappa)=0$, for any given value of $\kappa_{i t}=\kappa$.

The capital accumulation process, (12), can then be written as

$$
\frac{K_{i, t+1}}{\Lambda_{i, t+1} L_{i, t+1}} \frac{\Lambda_{i, t+1} L_{i, t+1}}{\Lambda_{i t} L_{i t}}=\left(1-\delta_{i}\right) \frac{K_{i t}}{\Lambda_{i t} L_{i t}}+s\left(\kappa_{i t}\right) \frac{Y_{i t}}{\Lambda_{i t} L_{i t}},
$$

which upon using (5) and (6) yields

$$
\kappa_{i, t+1} \exp \left[\Delta \ln \left(\Lambda_{i, t+1} L_{i, t+1}\right)\right]=\left(1-\delta_{i}\right) \kappa_{i t}+s\left(\kappa_{i t}\right) f\left(\kappa_{i t}\right)
$$

Also,

$$
\Delta \ln \left(\Lambda_{i, t+1} L_{i, t+1}\right)=n_{i}+\lambda_{i} \Delta \theta_{t+1}-\gamma_{i}^{\prime} \Delta \mathbf{x}_{i, t+1}+\triangle u_{i, t+1} .
$$

In what follows, we assume that

$$
\mathbf{x}_{i, t+1}=\boldsymbol{\mu}_{w i}+\boldsymbol{\beta}_{i} t+\mathbf{v}_{i, t+1}
$$




$$
\Delta \theta_{t+1}=\mu_{\theta}-(1-\rho) \theta_{t}+v_{\theta, t+1},
$$

where $\mathbf{v}_{i, t+1}$ and $v_{\theta, t+1}$ are climate and technology "shocks" that are assumed to be serially uncorrelated. The above processes allow for linear trends in the climate variables and unit roots in the technology. The steady state value of $\kappa_{i t}$ depends on the distribution of the combined shock ${ }^{9}$

$$
\xi_{i, t+1}=\lambda_{i} v_{\theta, t+1}+\gamma_{i}^{\prime} \mathbf{v}_{i, t+1}+\triangle u_{i, t+1}
$$

If we assume that all moments of $\xi_{i, t+1}$ exist, and extend the analysis of Binder and Pesaran (1999) to $N$ countries by allowing for a common technology factor and climate effects, it is possible to show that $\left\{\ln \kappa_{t}\right\}$ and $\left\{\kappa_{t}\right\}$ are bounded by first-order stationary processes with finite moments, and hence they converge to random variables that have moments.

Suppose the production technology is Cobb-Douglas, then using (4), (5) and (13), we have

$$
y_{i t}=\ln \left(Y_{i t} / L_{i t}\right)=\ln \left(A_{i}\right)+\lambda_{i} \theta_{t}+\gamma_{i}^{\prime} \mathbf{x}_{i t}+\alpha_{i} \ln \left(\kappa_{i t}\right) \text {, }
$$

where $\alpha_{i}$ is the exponent of the capital input in economy $i$ 's production function. Using the result that $\ln \left(\kappa_{i t}\right)$ is bounded by a stationary $\mathrm{AR}(1)$ process, and noting that $\mathbf{x}_{i t}$ and $\theta_{t}$ are exogenously determined, then variations in the steady state values of $y_{i t}$ are determined by changes in technology and climate variables. The model can generate a unit root in $y_{i t}$ by setting $\rho=1$ in (13). In this case the growth rate of per capita output can be written as

$$
\triangle y_{i t}=\lambda_{i} \mu_{\theta}-\gamma_{i}^{\prime} \triangle \mathbf{x}_{i t}+\alpha_{i} \triangle \ln \left(\kappa_{i t}\right)+v_{\theta t},
$$

where owing to the mean stationarity of $\ln \left(\kappa_{i t}\right)$, we have $E\left[\triangle \ln \left(\kappa_{i t}\right)\right]=0$, and hence

$$
E\left(\triangle y_{i t}\right)=\lambda_{i} \mu_{\theta}-\gamma_{i}^{\prime} E\left(\triangle \mathbf{x}_{i t}\right)
$$

Therefore, in equilibrium the mean per capita output growth is positively affected by technological progress, $\lambda_{i} \mu_{\theta}>0$, and negatively impacted by deviation of the climate variables from their historical norms when $\gamma_{i}>0$. This specification has the added advantage that $E\left(\triangle y_{i t}\right)$ does not inherit the strong trend in $\mathcal{T}_{i t}$, which the country/global temperatures have been subject to over the past 55 years (see Section 3.1 and Table 1).

In a panel data context, $\ln \left(\kappa_{i t}\right)$ can be approximated by a linear stationary process with possibly common factors, which yields the following Auto-Regressive Distributed Lag (ARDL) specification for $y_{i t}$

$$
\varphi_{i}(L) \Delta y_{i t}=a_{i}+b_{i}(L) \boldsymbol{\gamma}_{i}^{\prime} \triangle \mathbf{x}_{i t}+\varepsilon_{i t},
$$

\footnotetext{
${ }^{9}$ We follow Binder and Pesaran (1999) in ruling out large negative shocks (e.g., global climate catastrophes).
} 
where $i=1,2, \ldots, N ; t=1,2, \ldots, T, \varphi_{i}(L)$ and $b_{i}(L)$ are finite order distributed lag functions, $a_{i}\left(\right.$ related to $\left.\lambda_{i} \mu_{\theta}\right)$ is the fixed effect, and $\varepsilon_{i t}$ is a serially uncorrelated shock.

\section{Empirical Results}

In the empirical application, we use annual population-weighted climate data and real GDP per capita. For the climate variables we consider temperature (measured in degrees Celsius, ${ }^{\circ} \mathrm{C}$ ) and precipitation (measured in meters). We construct population-weighted climate data for each country and year between 1900 and 2014 using the terrestrial air temperature and precipitation observations from Matsuura and Willmott (2015) (containing 0.5 degree gridded monthly time series), and the gridded population of the world collection from CIESIN (2016), for which we use the population density in 2010. We obtain the real GDP per capita data between 1960 and 2014 from the World Development Indicators database of the World Bank. Combining the GDP per capita and the climate data, we end up with an unbalanced panel, which is very rich both in terms of the time dimension $(T)$, with maximum $T=55$ and average $T \approx 39$, and the cross-sectional dimension $(N)$, containing 174 countries. Before investigating the long-run effects of climate change on economic growth, we begin by providing some evidence on how the climate is changing.

\subsection{Climate Change: Historical Patterns}

This section examines how global temperature has evolved over the past half century (19602014). Allowing for the significant heterogeneity that exists across countries with respect to changes in temperature over time, we estimate country-specific regressions

$$
\mathcal{T}_{i t}=a_{\mathcal{T} i}+b_{\mathcal{T} i} t+v_{\mathcal{T} i, t}, \text { for } i=1,2, \ldots, N=174
$$

where $\mathcal{T}_{i t}$ denotes the population-weighted average temperature of country $i$ at year $t$. The per annum average increase in land temperature for country $i$ is given by $b_{\mathcal{T} i}$, with the corresponding global measure defined by $b_{\mathcal{T}}=N^{-1} \Sigma_{i=1}^{N} b_{\mathcal{T} i}$. Individual country estimates of $b_{\mathcal{T} i}$ together with their standard errors are summarised in Table 1 . As can be seen, the estimates range from -0.0044 (Samoa) to 0.0390 (Afghanistan). For 169 countries (97.1\% of cases), these estimates are positive; out of which, the estimates in 161 countries (95.3\% of cases) are statistically significant at the $5 \%$ level. There are only five countries for which the

estimate, $\widehat{b}_{\mathcal{T} i}$, is not positive: Bangladesh, Bolivia, Cuba, Ecuador and Samoa, but none of these estimates are statistically significant at the $5 \%$ level. See also Figure 5 which illustrates the increase in temperature per year for the 174 countries over 1960-2014.

Appendix A presents estimates of $b_{\mathcal{T} i}$ over a longer time horizon (1900-2014). The 
Table 1: Individual Country Estimates of the Average Yearly Rise in Temperature Over the Period 1960-2014

\begin{tabular}{|c|c|c|c|c|c|}
\hline Country & $\widehat{b}_{\mathcal{T} i}$ & Country & $\widehat{b}_{\mathcal{T} i}$ & Country & $\widehat{b}_{\mathcal{T} i}$ \\
\hline Afghanistan & $0.0390^{* * *}$ & Georgia & $0.0159^{* * *}$ & Oman & $0.0082^{* * *}$ \\
\hline Albania & $0.0240 * * *$ & Germany & $0.0229 * * *$ & Pakistan & $0.0096 * * *$ \\
\hline Algeria & $0.0288 * * *$ & Ghana & $0.0184^{* * *}$ & Panama & $0.0169 * * *$ \\
\hline Angola & $0.0193 * * *$ & Greece & $0.0112^{* * *}$ & Papua New Guinea & $0.0074^{* * *}$ \\
\hline Argentina & $0.0070^{* * *}$ & Greenland & $0.0381^{* * *}$ & Paraguay & 0.0047 \\
\hline Armenia & $0.0140 * *$ & Guatemala & $0.0276 * * *$ & Peru & $0.0065^{* *}$ \\
\hline Australia & $0.0094^{* * *}$ & Guinea & $0.0166^{* * *}$ & Philippines & $0.0068 * * *$ \\
\hline Austria & $0.0170 * * *$ & Guinea-Bissau & $0.0237 * * *$ & Poland & $0.0255^{* * *}$ \\
\hline Azerbaijan & $0.0188 * * *$ & Guyana & 0.0029 & Portugal & $0.0104 * * *$ \\
\hline Bahamas & $0.0195 * * *$ & Haiti & $0.0163^{* * *}$ & Puerto Rico & $0.0059^{* *}$ \\
\hline Bangladesh & -0.0007 & Honduras & $0.0207 * * *$ & Qatar & $0.0271 * * *$ \\
\hline Belarus & $0.0316^{* * *}$ & Hungary & $0.0163^{* * *}$ & Romania & $0.0186^{* * *}$ \\
\hline Belgium & $0.0261 * * *$ & Iceland & $0.0206^{* * *}$ & Russian Federation & $0.0348 * * *$ \\
\hline Belize & $0.0114^{* * *}$ & India & $0.0095^{* * *}$ & Rwanda & $0.0158 * * *$ \\
\hline Benin & $0.0180 * * *$ & Indonesia & $0.0053^{* * *}$ & Saint Vincent and the Grenadines & $0.0124 * * *$ \\
\hline Bhutan & $0.0143^{* * *}$ & Iran & $0.0229 * * *$ & Samoa & $-0.0044^{*}$ \\
\hline Bolivia & -0.0000 & Iraq & $0.0244^{* * *}$ & Sao Tome and Principe & $0.0240 * * *$ \\
\hline Bosnia and Herzegovina & $0.0373^{* * *}$ & Ireland & $0.0151^{* * *}$ & Saudi Arabia & $0.0207 * * *$ \\
\hline Botswana & $0.0260 * * *$ & Israel & $0.0168 * * *$ & Senegal & $0.0255^{* * *}$ \\
\hline Brazil & $0.0162 * * *$ & Italy & $0.0283^{* * *}$ & Serbia & $0.0155^{* * *}$ \\
\hline Brunei Darussalam & $0.0096^{* * *}$ & Jamaica & $0.0204^{* * *}$ & Sierra Leone & $0.0161^{* * *}$ \\
\hline Bulgaria & $0.0124^{* * *}$ & Japan & $0.0133 * * *$ & Slovakia & $0.0197^{* * *}$ \\
\hline Burkina Faso & $0.0191^{* * *}$ & Jordan & $0.0146^{* * *}$ & Slovenia & $0.0298 * * *$ \\
\hline Burundi & $0.0186^{* * *}$ & Kazakhstan & $0.0240^{* * *}$ & Solomon Islands & $0.0096^{* * *}$ \\
\hline Cabo Verde & $0.0181^{* * *}$ & Kenya & $0.0176^{* * *}$ & Somalia & $0.0213 * * *$ \\
\hline Cambodia & $0.0167^{* * *}$ & Kuwait & $0.0254^{* * *}$ & South Africa & $0.0073^{* * *}$ \\
\hline Cameroon & $0.0117^{* * *}$ & Kyrgyzstan & $0.0280 * * *$ & South Korea & $0.0081^{*}$ \\
\hline Canada & $0.0300 * * *$ & Laos & $0.0091^{* * *}$ & South Sudan & $0.0308 * * *$ \\
\hline Central African Republic & $0.0099 * * *$ & Latvia & $0.0304^{* * *}$ & Spain & $0.0260 * * *$ \\
\hline Chad & $0.0181^{* * *}$ & Lebanon & $0.0247^{* * *}$ & Sri Lanka & $0.0107 * * *$ \\
\hline Chile & $0.0102^{* * *}$ & Lesotho & $0.0099^{* *}$ & Sudan & $0.0295^{* * *}$ \\
\hline China & $0.0230 * * *$ & Liberia & $0.0094^{* * *}$ & Suriname & 0.0042 \\
\hline Colombia & $0.0061^{* *}$ & Libya & $0.0333^{* * *}$ & Swaziland & $0.0174 * * *$ \\
\hline Comoros & $0.0062^{*}$ & Lithuania & $0.0277^{* * *}$ & Sweden & $0.0210^{* * *}$ \\
\hline Congo & $0.0146^{* * *}$ & Luxembourg & $0.0281^{* * *}$ & Switzerland & $0.0183^{* * *}$ \\
\hline Congo DRC & $0.0150 * * *$ & Macedonia & $0.0129 * * *$ & Syria & $0.0225^{* * *}$ \\
\hline Costa Rica & $0.0173^{* * *}$ & Madagascar & $0.0214^{* * *}$ & Tajikistan & 0.0002 \\
\hline Côte d'Ivoire & $0.0131^{* * *}$ & Malawi & $0.0234^{* * *}$ & Tanzania & $0.0104^{* * *}$ \\
\hline Croatia & $0.0247^{* * *}$ & Malaysia & $0.0133^{* * *}$ & Thailand & $0.0055^{* *}$ \\
\hline Cuba & -0.0006 & Mali & $0.0214^{* * *}$ & Togo & $0.0185^{* * *}$ \\
\hline Cyprus & $0.0151^{* * *}$ & Mauritania & $0.0243^{* * *}$ & Trinidad and Tobago & $0.0243^{* * *}$ \\
\hline Czech Republic & $0.0192^{* * *}$ & Mauritius & $0.0216^{* * *}$ & Tunisia & $0.0368 * * *$ \\
\hline Denmark & $0.0195^{* * *}$ & Mexico & $0.0117^{* * *}$ & Turkey & $0.0141^{* *}$ \\
\hline Djibouti & $0.0135 * * *$ & Moldova & $0.0202^{* * *}$ & Turkmenistan & $0.0255^{* * *}$ \\
\hline Dominican Republic & $0.0152^{* * *}$ & Mongolia & $0.0276^{* * *}$ & Uganda & $0.0198 * * *$ \\
\hline Ecuador & -0.0031 & Montenegro & $0.0196 * * *$ & Ukraine & $0.0263^{* * *}$ \\
\hline Egypt & $0.0272 * * *$ & Morocco & $0.0211^{* * *}$ & United Arab Emirates & $0.0158 * * *$ \\
\hline El Salvador & $0.0319 * * *$ & Mozambique & $0.0148 * * *$ & United Kingdom & $0.0129 * * *$ \\
\hline Equatorial Guinea & $0.0275 * * *$ & Myanmar & $0.0200 * * *$ & United States & $0.0147^{* * *}$ \\
\hline Eritrea & $0.0178 * * *$ & Namibia & $0.0262^{* * *}$ & Uruguay & $0.0151^{* * *}$ \\
\hline Estonia & $0.0330 * * *$ & Nepal & $0.0176^{* * *}$ & US Virgin Islands & $0.0226 * * *$ \\
\hline Ethiopia & $0.0219 * * *$ & Netherlands & $0.0240 * * *$ & Uzbekistan & $0.0214^{* * *}$ \\
\hline Fiji & $0.0115^{* * *}$ & New Caledonia & $0.0118 * * *$ & Vanuatu & $0.0279 * * *$ \\
\hline Finland & $0.0304^{* * *}$ & New Zealand & 0.0018 & Venezuela & $0.0160 * * *$ \\
\hline France & $0.0215^{* * *}$ & Nicaragua & $0.0286 * * *$ & Vietnam & $0.0054^{* *}$ \\
\hline French Polynesia & $0.0236^{* * *}$ & Niger & 0.0075 & Yemen & $0.0345^{* * *}$ \\
\hline Gabon & $0.0177^{* * *}$ & Nigeria & $0.0163^{* * *}$ & Zambia & $0.0190^{* * *}$ \\
\hline Gambia & $0.0234^{* * *}$ & Norway & $0.0232^{* * *}$ & Zimbabwe & $0.0139 * * *$ \\
\hline
\end{tabular}

Notes: $\widehat{b}_{\mathcal{T} i}$ is the OLS estimate of $b_{\mathcal{T} i}$ in the country-specific regressions $\mathcal{T}_{i t}=a_{\mathcal{T} i}+b_{\mathcal{T} i} t+v_{\mathcal{T}, i t}$, where $\mathcal{T}_{i t}$ denotes the population-weighted average temperature $\left({ }^{\circ} \mathrm{C}\right)$. Asterisks indicate statistical significance at the $1 \%(* * *), 5 \%(* *)$ and $10 \%(*)$ levels. 
country-specific estimates of $b_{\mathcal{T} i}$ for the 174 countries over this longer sample period range from -0.0008 (Greece) to 0.0190 (Haiti). In 172 countries (98.9\% of the cases) these estimates are positive and in 156 countries (90.7\% of cases) they are statistically significant at the $5 \%$ level. There are only two countries for which the estimate of $b_{\mathcal{T} i}$ is not positive: Greece and Macedonia but these are not statistically significant. The estimated results over 1900-2014 echo those obtained over the 1960-2014 period. Temperature has been rising for pretty much all of the countries in our sample, indicating that $\mathcal{T}_{i t}$ is trended. As discussed earlier, the econometric specifications in the literature involve real GDP growth rates and the level of temperature, $\mathcal{T}_{i t}$, and in some cases also $\mathcal{T}_{i t}^{2}$; see, for instance, Dell et al. (2012) and Burke et al. (2015). But in cases where $\mathcal{T}_{i t}$ is trended, which is the situation in almost all the countries in the world (based on both the 1900-2014 and the 1960-2014 samples), inclusion of $\mathcal{T}_{i t}$ in the regressions will induce a quadratic trend in equilibrium log per capita output (or equivalently a linear trend in per capita output growth) which is not desirable and can bias the estimates of the growth-climate change equation.

The above country-specific estimates are also in line with the average increases in global temperature published by the Goddard Institute for Space Studies (GISS) at National Aeronautics and Space Administration (NASA), and close to the estimates by the National Centers for Environmental Information (NCEI) at the National Oceanic and Atmospheric Administration (NOAA). The right panel in Figure 4 plots the global land temperatures between 1960 and 2014 recorded by NOAA and NASA; clearly showing that $\mathcal{T}_{t}$ is trended. IPCC (2013) also estimates similar trends using various datasets and over different sub-periods. For instance, the trend estimates of global land-surface air temperature (in ${ }^{\circ} \mathrm{C}$ per decade) over the 1951-2012 period, based on data from the Climatic Research Unit's CRUTEM4.1.1.0, NOAA's Global Historical Climatology Network Version 3 (GHCNv3), and Berkeley Earth, are reported as $0.175( \pm 0.037), 0.197( \pm 0.031)$, and $0.175( \pm 0.029)$, respectively with $90 \%$ confidence intervals in brackets; see Chapter 2 of IPCC (2013) for details.

Using the individual country estimates in Table 1, the average rise in global temperature over the 1960-2014 period is given by $\hat{b}_{\mathcal{T}}=0.0181(0.0007)$ degrees Celsius per annum, which is statistically highly significant. ${ }^{10}$ In comparison, according to NASA observations global land temperature has risen by $0.89^{\circ} \mathrm{C}$ between 1960 and 2014 , or around $0.0165^{\circ} \mathrm{C}$ per year, and based on NCEI data the global land-surface air temperature has risen by $1.07^{\circ} \mathrm{C}$ over the same period, or around $0.0198^{\circ} \mathrm{C}$ per year. Thus our global estimate of $0.0181^{\circ} \mathrm{C}$ lies in the middle of these two estimates, but has the added advantage of having a small standard error, noting that it is a pooled estimate across a large number of countries.

We also plot the global land-surface air and sea-surface water temperatures in the left panel of Figure 4. We observe an upward trend using data from NOAA (a rise of $0.72^{\circ} \mathrm{C}$ )

\footnotetext{
${ }^{10}$ The standard error of $\hat{b}_{\mathcal{T}}=N^{-1} \sum_{i=1}^{N} \hat{b}_{\mathcal{T}}$, given in round brackets, is computed using the mean group approach of Pesaran and Smith (1995).
} 
Figure 4: Global Land-Surface Air and Sea-Surface Water Temperatures (Degrees Celsius, $1960=0$ )
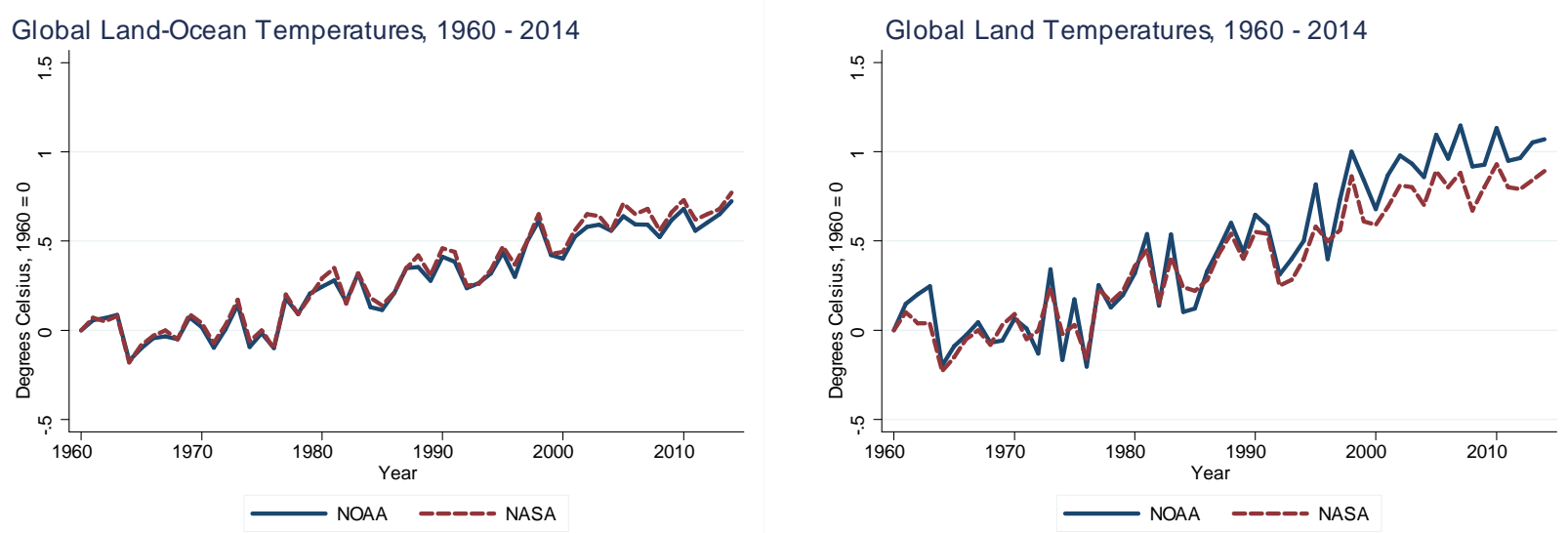

Note: The left panel shows the global land-surface air and sea-surface water temperatures, and the right panel shows the global land-surface air temperatures, both over the 1960-2014 period. The blue lines show the temperatures observed by the National Centers for Environmental Information (NCEI) at the National Oceanic and Atmospheric Administration (NOAA); and the broken red lines show the temperatures observed by the Goddard Institute for Space Studies (GISS) at National Aeronautics and Space Administration (NASA). The temperatures in 1960 are standardised to zero.

Figure 5: Temperature Increase per year for the 174 Countries, 1960-2014
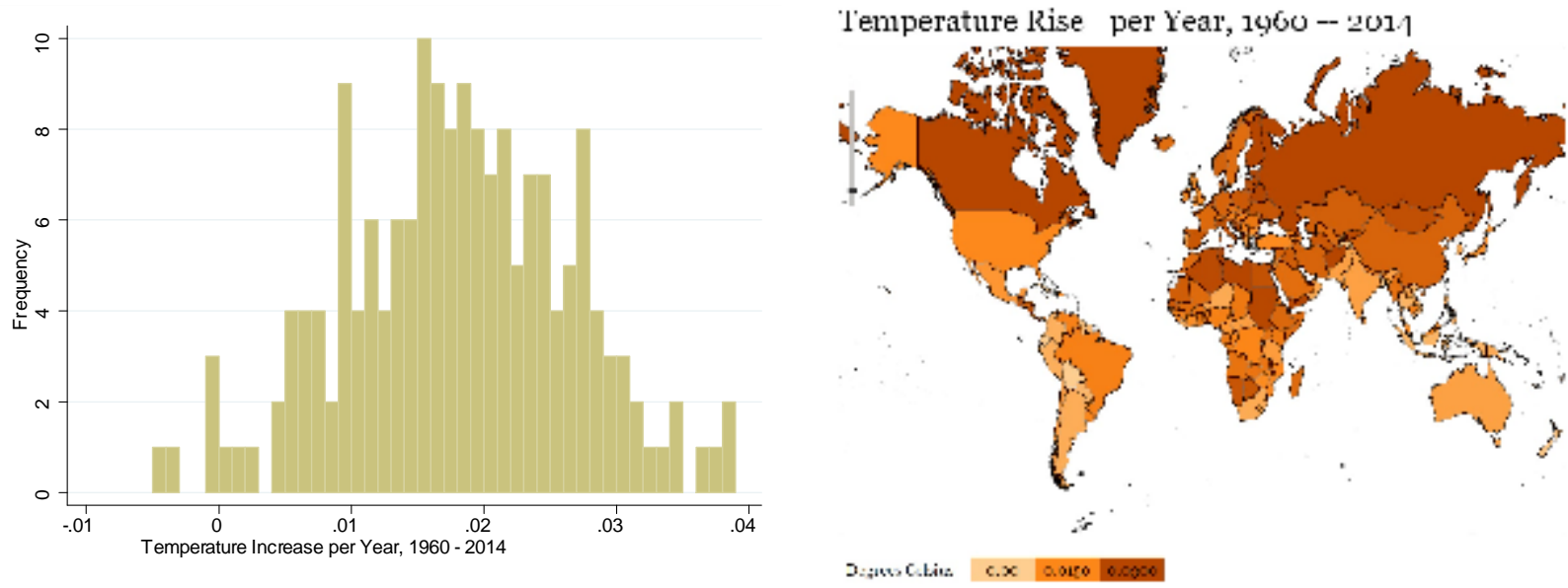
or data from NASA (a rise of $0.77^{\circ} \mathrm{C}$ ) between 1960 and 2014 ; equivalent to $0.0134^{\circ} \mathrm{C}$ and $0.0143^{\circ} \mathrm{C}$ per year, respectively. Note that the land-surface air temperature has risen by more than the sea-surface water temperature over this period, because oceans have a larger effective heat capacity and lose more heat through evaporation.

\subsection{Long-Term Impact of Climate Change on Economic Growth}

Guided by the theoretical growth model with climate variables set out above in Section 2, we examine the long-term impact of climate change on per capita output growth across countries. To this end, we estimate the following panel ARDL model:

$$
\Delta y_{i t}=a_{i}+\sum_{\ell=1}^{p} \varphi_{\ell} \Delta y_{i, t-\ell}+\sum_{\ell=0}^{p} \boldsymbol{\beta}_{\ell}^{\prime} \Delta \mathbf{x}_{i, t-\ell}+\varepsilon_{i t},
$$

where $y_{i t}$ is the log of real GDP per capita of country $i$ in year $t, a_{i}$ is the country-specific fixed effect, $\mathbf{x}_{i t}=\left[\left(\mathcal{C}_{i t}-\mathcal{C}_{i, t-1}^{*}\right)^{+},\left(\mathcal{C}_{i t}-\mathcal{C}_{i, t-1}^{*}\right)^{-}\right]^{\prime}, \mathcal{C}_{i t}=\left(\mathcal{T}_{i t}, \mathcal{P}_{i t}\right)^{\prime}, \mathcal{C}_{i, t-1}^{*}=\left(\mathcal{T}_{i, t-1}^{*}, \mathcal{P}_{i, t-1}^{*}\right)^{\prime}$, $\mathcal{T}_{i t}$ and $\mathcal{P}_{i t}$ are the population-weighted average temperature and precipitation of country $i$ in year $t$, respectively, and $\mathcal{T}_{i, t-1}^{*}$ and $\mathcal{P}_{i, t-1}^{*}$ are the historical norms of climate variables. With $\mathcal{C}_{i t}-\mathcal{C}_{i, t-1}^{*}$ separated into positive and negative values, we account for the potential asymmetrical effects of climate change on economic growth. The (average) long-run effects, $\theta$, are calculated from the OLS estimates of the short-run coefficients in equation (17): $\boldsymbol{\theta}=\phi^{-1} \sum_{\ell=0}^{p} \boldsymbol{\beta}_{\ell}$, where $\phi=1-\sum_{\ell=1}^{p} \varphi_{\ell}$.

For the historical norms, we consider the moving averages of temperature and precipitation of country $i$ based on the past $m$ years: $\mathcal{T}_{i, t-1}^{*}=m^{-1} \sum_{s=1}^{m} \mathcal{T}_{i, t-s}$ and $\mathcal{P}_{i, t-1}^{*}=$ $m^{-1} \sum_{l=1}^{m} \mathcal{P}_{i, t-l}$, with $m$ being a large enough number to make the variations of the historical norm in each year small. We select $m=30$, given that climate norms are typically computed using 30-year moving averages (see, for instance, Arguez et al. 2012 and Vose et al. 2014), but to check the robustness of our results, we also consider historical norms computed using moving averages with $m=20$ and 40 in Section 3.3.

Pesaran and Smith (1995), Pesaran (1997), and Pesaran and Shin (1999) show that: the traditional ARDL approach can be used for long-run analysis; it is valid regardless of whether the underlying variables are $I(0)$ or $I(1)$; and it is robust to omitted variables bias and bi-directional feedback effects between economic growth and its determinants. These features of the panel ARDL approach are clearly appealing in our empirical application. For validity of this technique, however, the dynamic specification of the model needs to be augmented with a sufficient number of lagged effects so that the regressors become weakly exogenous. Specifically, Chudik et al. (2016), show that sufficiently long lags are necessary for the consistency of the panel ARDL approach. ${ }^{11}$ Since the impact of climate change on

\footnotetext{
${ }^{11}$ See also Chudik et al. (2013) and Chudik et al. (2017).
} 
output growth could be long lasting, the lag order should be long enough, and as such we set $p=4$ for all the variables/countries. Using the same lag order across all the variables and countries help reduce the possible adverse effects of data mining that could accompany the use of country and variable specific lag order selection procedures such as Akaike or Schwarz criteria. Note also that our primary focus here is on the long-run estimates rather than the specific dynamics that might be relevant for a particular country.

Table 2 presents the estimates for the four different specifications of panel ARDL regressions in (17). We report the fixed effects (FE) estimates of the long-run impact of changes in the climate variables on GDP per capita growth $(\widehat{\theta})$, and the estimated coefficients of the error correction term $(\widehat{\phi})$ in columns (a). When the cross-sectional dimension of the panel is larger than the time dimension (in our panel, $N=174$ and the average $T \approx 38$, see Table 2 ), the standard FE estimator suffers from small- $T$ bias regardless of whether the lags of the dependent variable are included or not, so long as one or more of the regressors are not strictly exogenous (see Chudik et al. 2018). Since the lagged values of growth and the climate variables can be correlated with the lagged values of the error term $\varepsilon_{i t}$, the regressors (climate variables) are weakly exogenous, and hence, inference based on the standard FE estimator is invalid and can result in large size distortions. To deal with these issues, we use the half-panel Jackknife FE (HPJ-FE) estimator of Chudik et al. (2018) and report the results in columns (b) of Table 2. The jackknife bias correction requires $N, T \rightarrow \infty$, but it allows $T$ to rise at a much slower rate than $N$, making it attractive in our application.

Specification 1 of Table 2 reports the baseline results. The FE and HPJ-FE estimated coefficients of the precipitation variables, $\left.\widehat{\theta}_{\Delta\left(\mathcal{P}_{i t}-\mathcal{P}_{i, t-1}^{*}\right)}\right)^{+}$and $\widehat{\theta}_{\Delta\left(\mathcal{P}_{i t}-\mathcal{P}_{i, t-1}^{*}\right)^{-}}$, are not statistically significant. However, long-run economic growth is adversely affected when temperature deviates from its historical norm persistently, as $\widehat{\theta}_{\Delta\left(\mathcal{T}_{i t}-\mathcal{T}_{i, t-1}^{*}\right)^{+}}$and $\widehat{\theta}_{\Delta\left(\mathcal{I}_{i t}-\mathcal{T}_{i, t-1}^{*}\right)^{-}}$are both statistically significant. The HPJ-FE estimates suggest that a $0.01^{\circ} \mathrm{C}$ annual increase in the temperature above its historical norm reduces real GDP per capita growth by 0.0577 percentage points per year and a $0.01^{\circ} \mathrm{C}$ annual decrease in the temperature below its historical norm reduces real GDP per capita growth by 0.0505 percentage points per year. Note that the FE estimates (which are widely used in the literature) are smaller than their HPJ-FE counterparts in absolute values. ${ }^{12}$

Since the estimates of deviations of precipitation variables from their historical norms (both above and below) are not statistically significant in the baseline, we re-estimate equation (17) without them; setting $\mathbf{x}_{i t}=\left[\left(\mathcal{T}_{i t}-\mathcal{T}_{i, t-1}^{*}\right)^{+},\left(\mathcal{T}_{i t}-\mathcal{T}_{i, t-1}^{*}\right)^{-}\right]^{\prime}$ in specification 2 . The results show that persistent deviations of temperature above or below its historical norm, $\left(\mathcal{T}_{i t}-\mathcal{T}_{i, t-1}^{*}\right)^{+}$or $\left(\mathcal{T}_{i t}-\mathcal{T}_{i, t-1}^{*}\right)^{-}$, have negative effects on long-run economic growth. Specif-

\footnotetext{
${ }^{12}$ Since the half-panel jackknife procedure splits the data set into two halves, for countries with an odd number of time observations, we drop the first observation. Thus, the number of observations in Columns (a) and (b) are somewhat different.
} 


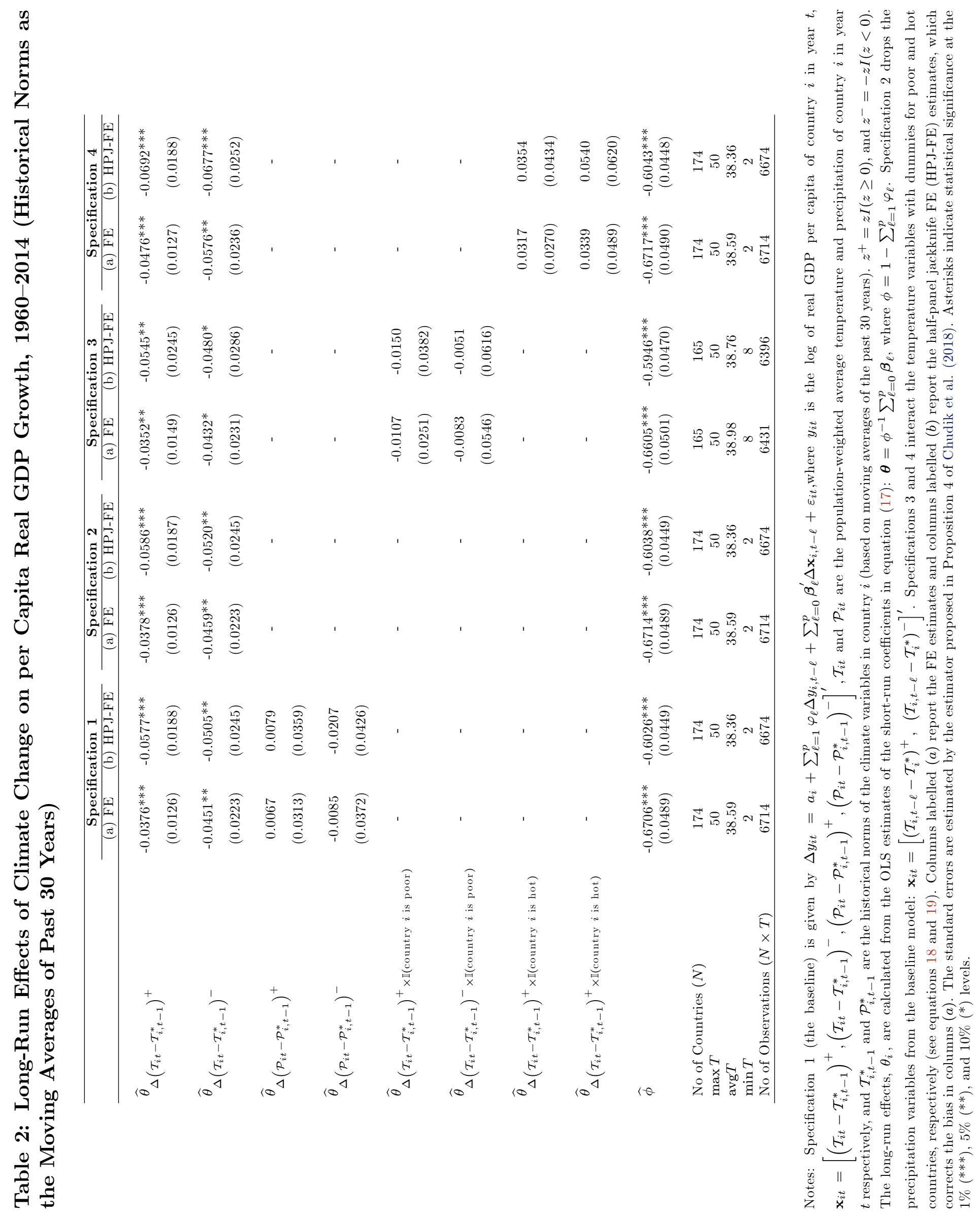


ically, the HPJ-FE estimates suggest that a persistent $0.01^{\circ} \mathrm{C}$ increase in the temperature above its historical norm reduces real GDP per capita growth by 0.0586 percentage points per annum in the long run (being statistically significant at the $1 \%$ level), and a $0.01^{\circ} \mathrm{C}$ annual decrease in the temperature below its historical norm reduces real GDP per capita growth by 0.0520 percentage points per year (being statistically significant at the $5 \%$ level). Given that the estimates of the coefficients of $\left(\mathcal{T}_{i t}-\mathcal{T}_{i, t-1}^{*}\right)^{+}$and $\left(\mathcal{T}_{i t}-\mathcal{T}_{i, t-1}^{*}\right)^{-}$are very similar in magnitude suggests that positive and negative deviations of temperature from its historical norm have similar effects on long-term growth.

Most studies in the literature provide evidence for the uneven macroeconomic effects of climate change, with adverse short-term consequences in countries with hot climates, such as low-income countries; see, for instance, Sachs and Warner (1997), Jones and Olken (2010), and Dell et al. (2012). In other words, when a rich (temperate) country is warmer, there is little impact on its economic activity. There are intuitive reasons and anecdotal evidence for this, including adaptation that has taken place particularly in advanced economies; they are more urbanised and much of the economic activity takes place indoors. For instance, Singapore has attempted to insulate its economy from the heat by extensively engaging in economic activity in places with air conditioning. Therefore, if individuals are aware of how extreme heat affects their economic performance, they can invest in self protection to reduce their exposure to such risks. ${ }^{13}$ More recently Burke et al. (2015) and Mejia et al. (2018) also show that the negative short- and medium-term macroeconomic effects of climate change are more concentrated in hot countries (i.e. mostly low-income countries).

Given our heterogenous sample of 174 countries and motivated by above studies, a followup question is whether the estimated adverse long-run growth effects we found in Specifications 1 and 2 of Table 2 are driven by poor countries. We, therefore, follow Dell et al. (2012) and Burke et al. (2015) and augment Specification 2 with an interactive term, $\Delta \mathbf{x}_{i, t-\ell} \times \mathbb{I}$ (country $i$ is poor), to capture any possible differential effects of temperature increases (decreases) above (below) the norm for the rich and poor countries:

$$
\Delta y_{i t}=a_{i}+\sum_{\ell=1}^{p} \varphi_{\ell} \Delta y_{i, t-\ell}+\sum_{\ell=0}^{p} \boldsymbol{\beta}_{\ell}^{\prime} \Delta \mathbf{x}_{i, t-\ell}+\sum_{\ell=0}^{p} \boldsymbol{\zeta}_{\ell}^{\prime} \Delta \mathbf{x}_{i, t-\ell} \times \mathbb{I}(\text { country } i \text { is poor })+\varepsilon_{i t}
$$

where, as in Burke et al. (2015), we define country $i$ as poor (rich) if its purchasingpower-parity-adjusted (PPP) GDP per capita was below (above) the global median in 1980. Moreover, to investigate whether temperature increases affect hotter countries more than colder ones, we estimated the following panel data model

$$
\Delta y_{i t}=a_{i}+\sum_{\ell=1}^{p} \varphi_{\ell} \Delta y_{i, t-\ell}+\sum_{\ell=0}^{p} \boldsymbol{\beta}_{\ell}^{\prime} \Delta \mathbf{x}_{i, t-\ell}+\sum_{\ell=0}^{p} \boldsymbol{\xi}_{\ell}^{\prime} \Delta \mathbf{x}_{i, t-\ell} \times \mathbb{I}(\text { country } i \text { is hot })+\varepsilon_{i t},
$$

\footnotetext{
${ }^{13}$ For a survey of the literature on heat and productivity, see Heal and Park (2016).
} 
where a country is defined as cold (hot) if its historical average temperature is below (above) the global median. The results from estimating specifications (18) and (19) are also reported in Table 2. The estimated coefficients of the interactive terms are not statistically significant - we cannot reject the hypothesis that there are no differential effects of climate change on poor versus rich nations or hot versus cold countries. Therefore, specification 2 is our preferred model and will be used in the counterfactual analysis in Section 4.

The results across all four specifications suggest that climate change, defined as persistent deviations of temperature from its historical norm, affects long-run income growth negatively. Specifically, $\widehat{\theta}_{\left(\mathcal{T}_{i t}-\mathcal{T}_{i}^{*}\right)^{+}}$is always negative, with the estimates ranging from -0.0352 to -0.0692 across the two estimation techniques. Moreover, it is clear that the jackknife bias correction makes a difference as the HPJ-FE estimates (ranging from -0.0545 to -0.0692) are always larger in absolute value than the FE estimates ( -0.0352 to -0.0476$)$. Similarly, the estimates for the coefficients of $\left(\mathcal{T}_{i t}-\mathcal{T}_{i, t-1}^{*}\right)^{-}$, namely $\widehat{\theta}_{\Delta\left(\mathcal{T}_{i t}-\mathcal{T}_{i}^{*}\right)^{-}}$, are also always negative, with the estimates ranging from -0.0432 to -0.0677 across the two estimation techniques, but the HPJ-FE estimates (ranging from -0.0480 to -0.0677 ) are always larger in absolute value than the FE estimates $(-0.0432$ to -0.0576$)$. Therefore, bias correction is essential when it comes to the counterfactual exercises in Section 4, otherwise the cumulative effects of climate change could be significantly underestimated. In all cases, the speed of adjustment to long-run equilibrium $(\widehat{\phi})$ is quick. However, this does not mean that the effects of changes in $\left(\mathcal{T}_{i t}-\mathcal{T}_{i, t-1}^{*}\right)^{+}$and $\left(\mathcal{T}_{i t}-\mathcal{T}_{i, t-1}^{*}\right)^{-}$are short lived.

The results across all specifications suggest that the adverse growth effects of rises in temperature above the historical norm or falls in temperature below the historical norm are similar. There is little evidence of asymmetry in the long-run relationship between output growth and positive or negative deviations of temperature from its historical norm. This lack of asymmetry suggests that a simpler specification might be preferred and we therefore reestimate equation (17) by replacing $\mathbf{x}_{i t}=\left[\left(\mathbf{C}_{i t}^{\prime}-\mathbf{C}_{i, t-1}^{* *}\right)^{+},\left(\mathbf{C}_{i t}^{\prime}-\mathbf{C}_{i, t-1}^{* *}\right)^{-}\right]^{\prime}, \mathbf{C}_{i t}=\left(\mathcal{T}_{i t}, \mathcal{P}_{i t}\right)^{\prime}$, $\mathbf{C}_{i, t-1}^{*}=\left(\mathcal{T}_{i, t-1}^{*}, \mathcal{P}_{i, t-1}^{*}\right)^{\prime}$ with $\mathbf{x}_{i t}=\left(\left|\mathcal{T}_{i t}-\mathcal{T}_{i, t-1}^{*}\right|,\left|\mathcal{P}_{i t}-\mathcal{P}_{i, t-1}^{*}\right|\right)^{\prime}$. The HPJ-FE results are reported in Table 3. Like our earlier results, permanent deviations of precipitation from their historical norms do not affect long-term growth, but permanent deviations of temperature from their historical norms have a negative effect on long-run growth (regardless of whether a country is poor or rich), with the magnitudes of the coefficient of $\left|\mathcal{T}_{i t}-\mathcal{T}_{i, t-1}^{*}\right|$ being similar to those reported for $\left(\mathcal{T}_{i t}-\mathcal{T}_{i, t-1}^{*}\right)^{+}$and $\left(\mathcal{T}_{i t}-\mathcal{T}_{i, t-1}^{*}\right)^{-}$in Table 2.

To put our results into perspective, note that the integrated assessment models (IAMs) largely postulate that climate change has only level effects (or short-term growth effects). The IAMs have been extensively used in the past few decades to investigate the welfare effects of temperature increases, see Tol (2014); they have also been used as tools for policy analyses (including by the Obama administration, see Obama (2017), and at international forums). Even more recent studies, that use panel data models, show that temperature in- 


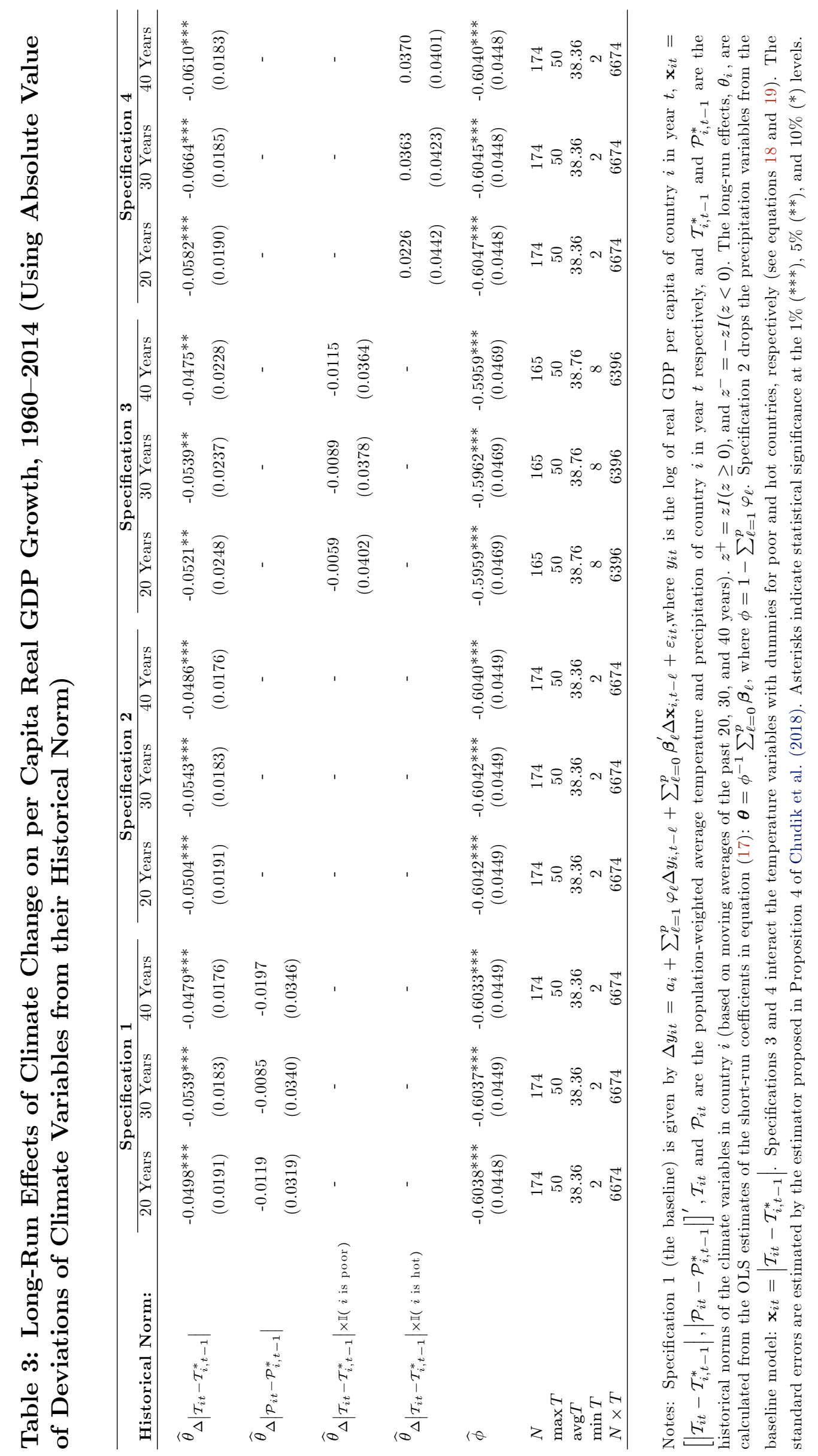




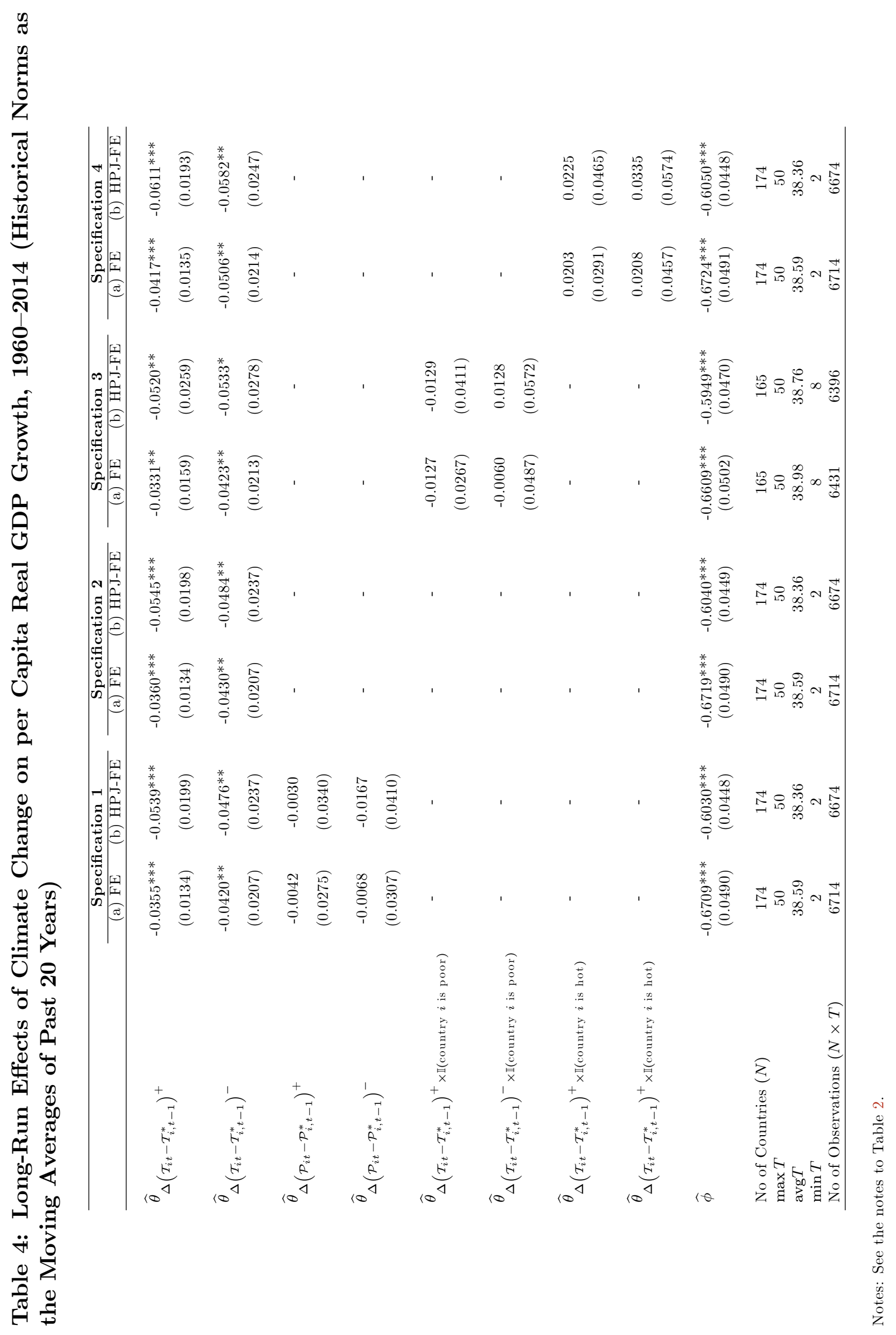




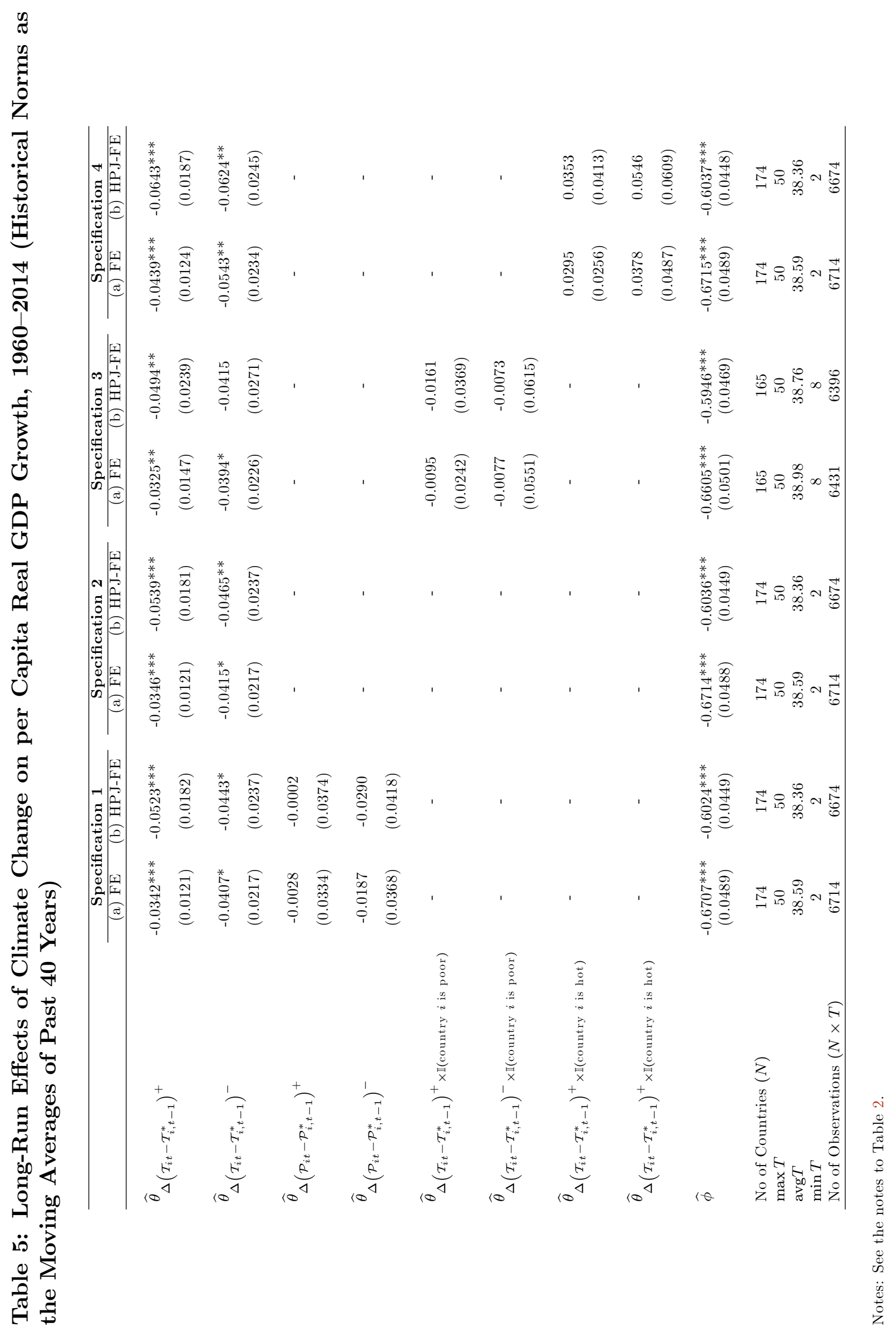


creases reduce per capita output growth in the short- to medium-term (i.e., they have only level effects) - see Dell et al. (2014) and the references therein. Burke et al. (2015) consider an alternative panel specification that adds quadratic climate variables to the equation and detect: (i) non-linearity in the relationship; (ii) differential impact on rich versus poor countries; and (iii) noisy medium-term growth effects - their higher lag order (between 1 and 5) estimates reported in Supplementary Table S2, show that only 3 out of 18 estimates are statistically significant. Overall, apart from the econometric shortcomings of existing studies, robust evidence for the long-run growth effects of climate change are nonexistent in the literature. However, our results show that an increase in temperature above its historical norm is associated with lower economic growth in the long run - suggesting that the welfare effects of climate change are significantly underestimated in the literature. Therefore, our findings call for a more forceful policy response to climate change.

\subsection{Robustness to the Choice of Historical Norms}

To make sure that our results are robust to the choice of historical norms, we consider different ways of constructing $\mathcal{T}_{i, t-1}^{*}$ and $\mathcal{P}_{i, t-1}^{*}$. Tables $3-5$ report the results with climate norms constructed as moving averages of the past $20(m=20)$ and $40(m=40)$ years, respectively. As in the case with $m=30$, we note that the estimated coefficients of the precipitation variables, $\widehat{\theta}_{\Delta\left(\mathcal{P}_{i t}-\mathcal{P}_{i, t-1}^{*}\right)^{+}}, \widehat{\theta}_{\Delta\left(\mathcal{P}_{i t}-\mathcal{P}_{i, t-1}^{*}\right)^{-}}$, and $\widehat{\theta}_{\Delta\left|\mathcal{P}_{i t}-\mathcal{P}_{i, t-1}^{*}\right|}$ are not statistically significant (Specification 1). Moreover, there is no statistically significant difference between "rich" and "poor" or "hot" and "cold" countries given the estimates of the interactive terms (Specifications 3 and 4). However, the estimated coefficients of the deviations of temperature from its historical norm are statistically significant in all four specifications. Focusing on Specification 2 with $\mathbf{x}_{i t}=\left|\mathcal{T}_{i t}-\mathcal{T}_{i, t-1}^{*}\right|$ and the HPJ-FE estimates (our preferred model and estimator), we observe that $\widehat{\theta}_{\Delta\left|\mathcal{T}_{i t}-\mathcal{T}_{i, t-1}^{*}\right|}$ is robust to alternative ways of measuring $\mathcal{T}_{i, t-1}^{*}$, being $-0.0504(0.0191),-0.0543(0.0183)$, and $-0.0486(0.0176)$ for $m=20,30$, and 40, respectively. Standard errors are reported in brackets next to these estimates.

\section{Counterfactual Analysis}

We perform a number of counterfactual exercises to measure the cumulative output per capita effects of persistent increases in annual temperatures above their norms over the period 2015-2100. We carry out this analysis using the HPJ-FE estimates based on the ARDL specification given by (17), which we write equivalently as

$$
\varphi(L) \Delta y_{i t}=a_{i}+\boldsymbol{\beta}^{\prime}(L) \Delta \mathbf{x}_{i t}+\varepsilon_{i t},
$$


where $\mathbf{x}_{i t}=\left[\left(\mathcal{T}_{i t}-\mathcal{T}_{i, t-1}^{*}\right)^{+},\left(\mathcal{T}_{i t}-\mathcal{T}_{i, t-1}^{*}\right)^{-}\right], \varphi(L)=1-\sum_{\ell=1}^{4} \varphi_{\ell} L^{l}, \boldsymbol{\beta}(L)=\sum_{\ell=0}^{4} \boldsymbol{\beta}_{\ell} L^{l}$, and $L$ is the lag operator. Pre-multiplying both sides of the above equation by the inverse of $\varphi(L)$ yields

$$
\Delta y_{i t}=\tilde{a}_{i}+\boldsymbol{\psi}(L) \Delta \mathbf{x}_{i t}+\vartheta(L) \varepsilon_{i t},
$$

where $\tilde{a}_{i}=\varphi(1)^{-1} a_{i}, \vartheta(L)=\vartheta_{0}+\vartheta_{1} L+\vartheta_{2} L^{2}+\ldots$ and $\boldsymbol{\psi}(L)=\varphi(L)^{-1} \boldsymbol{\beta}(L)=\boldsymbol{\psi}_{0}^{\prime}+\boldsymbol{\psi}_{1}^{\prime} L+$ $\psi_{2}^{\prime} L^{2}+\ldots$, in which $\boldsymbol{\psi}_{j}^{\prime}=\left(\psi_{j}^{(+)}, \psi_{j}^{(-)}\right)$for $j=0,1,2, \ldots \psi_{j}^{(+)}$and $\psi_{j}^{(-)}$are the coefficients of changes in the climate variables, $\Delta\left(\mathcal{T}_{i, t-j}-\mathcal{T}_{i, t-j-1}^{*}\right)^{+}$and $\Delta\left(\mathcal{T}_{i, t-j}-\mathcal{T}_{i, t-j-1}^{*}\right)^{-}$, respectively. To simplify the exposition, suppose that the impact of climate change above and below the historical norm is symmetric, and consider the ARDL model:

$$
\Delta y_{i t}=\tilde{a}_{i}+\psi(L) \Delta x_{i t}+\vartheta(L) \varepsilon_{i t}
$$

where $x_{i t}=\left|\mathcal{T}_{i t}-\mathcal{T}_{i, t-1}^{*}\right|$, and $\psi(L)=\sum_{j=0}^{\infty} \psi_{j} L^{j}$.

The counterfactual effects of climate change can now be derived by comparing the output trajectory of country $i$ over the period $T+1$ to $T+h$ under the no change scenario denoted by $b_{\mathcal{T} i}^{0}$ and $\sigma_{\mathcal{T} i}^{0}$, with an alternative expected trajectory having the counterfactual values of $b_{\mathcal{T} i}^{1}$ and $\sigma_{\mathcal{T} i}^{1}$. Denoting the values of $x_{i t}$ for $t=T+1, T+2, \ldots, T+h$ under these two scenarios by $\mathbf{x}_{i, T+1, T+h}^{0}=\left\{x_{i, T+1}^{0}, x_{i, T+2}^{0}, \ldots, x_{i, T+h}^{0}\right\}$, and $\mathbf{x}_{i, T+1, T+h}^{1}=\left\{x_{i, T+1}^{1}, x_{i, T+2}^{1}, \ldots, x_{i, T+h}^{1}\right\}$, the counterfactual output change can be written as

$$
\xi_{i, T+h}=\mathbb{E}\left(y_{i, T+h} \mid \digamma_{i, T}, \mathbf{x}_{i, T+1, T+h}^{1}\right)-E\left(y_{i, T+h} \mid \digamma_{i, T}, \mathbf{x}_{i, T+1, T+h}^{0}\right)
$$

where $\digamma_{i T}=\left(y_{i T}, y_{i, T-1}, y_{i, T-2}, \ldots ; x_{i T}, x_{i, T-1}, x_{i, T-2}, \ldots\right)$. Cumulating both sides of (21) from $t=T+1$ to $T+h$ and taking conditional expectations under the two scenarios we have

$$
\xi_{i, T+h}=\sum_{j=1}^{h} \psi_{h-j}\left(x_{i, T+j}^{1}-x_{i, T+j}^{0}\right),
$$

The impact of climate change clearly depends on the magnitude of $x_{i, T+j}^{1}-x_{i, T+j}^{0}$.

We consider the output effects of country-specific average annual increases in temperatures over the period 2015-2100 as predicted under RCP 2.6 and RCP 8.5 scenarios, and compare them with a baseline scenario under which temperature in each country increases according to its historical trend of 1960-2014. ${ }^{14}$ However, owing to the non-linear nature of our output-growth specification, changes in trend temperature do not translate on a one-toone basis to absolute changes in temperature. In line with (16), future temperature changes

\footnotetext{
${ }^{14} \mathrm{~A}$ similar analysis can also be carried out in terms of changes in precipitation. For brevity and given the empirical results in Section 3, we focus on the counterfactual effects of changes in temperature only.
} 
over the counterfactual horizon, $T+j, j=1,2, \ldots$ can be represented by

$$
\mathcal{T}_{i, T+j}=a_{\mathcal{T} i}+b_{\mathcal{T} i, j}(T+j)+v_{\mathcal{T} i, T+j}, \text { for } j=1,2, \ldots,
$$

where we allow for the trend change in the temperature to vary over time. The above equation reduces to (16) if we set $b_{\mathcal{T} i, j}=b_{\mathcal{T} i}$ for all $j$. Suppose also that, as before, the historical norm variable associated with $\mathcal{T}_{i, T+j}$, namely $\mathcal{T}_{i, T+j-1}^{*}$, is constructed using the past $m$ years. Then it is easy to show that

$$
\mathcal{T}_{i, T+j}-\mathcal{T}_{i, T+j-1}^{*}=\left(\frac{m+1}{2}\right) b_{\mathcal{T} i, j}+\left(v_{\mathcal{T} i, T+j}-\bar{v}_{\mathcal{T} i, T+j-1, m}\right), j=1,2, \ldots, h,
$$

where $\bar{v}_{\mathcal{T} i, T+j-1, m}=m^{-1} \sum_{s=1}^{m} v_{\mathcal{T} i, T+j-s}$. The realised values of $\left(\mathcal{T}_{i, T+j}-\mathcal{T}_{i, T+j-1}^{*}\right)^{+}$and $\left(\mathcal{T}_{i, T+j}-\mathcal{T}_{i, T+h-1}^{*}\right)^{-}$depend on the probability distribution of weather shocks, $v_{\mathcal{T} i, T+j}$, as well as the trend change in temperature, given by $b_{\mathcal{T} i, j}$. As a first order approximation, and in order to obtain analytic expressions, we assume that temperature shocks, $v_{\mathcal{T} i, T+j}$, over $j=1,2, \ldots$, are serially uncorrelated, Gaussian random variables with zero means and variances, $\sigma_{\mathcal{T} i}^{2}$. Under these assumptions and using the results in Lemma 3.1 of Dhyne et al. (2011), we have

$$
E\left[\left(\mathcal{T}_{i, T+j}-\mathcal{T}_{i, T+j-1}^{*}\right)^{+}\right]=\mu_{\mathcal{T} i, j} \Phi\left(\frac{\mu_{\mathcal{T}_{i, j}}}{\omega_{\mathcal{T} i}}\right)+\omega_{\mathcal{T} i} \phi\left(\frac{\mu_{\mathcal{T} i, j}}{\omega_{\mathcal{T} i}}\right)=g_{\mathcal{T} i}^{+}\left(m, b_{\mathcal{T} i, j}, \sigma_{\mathcal{T} i}\right)
$$

where $\Phi($.$) and \phi($.$) are the cumulative and density distribution functions of a standard$ Normal variate, respectively, and

$$
\mu_{\mathcal{T} i, j}=\left(\frac{m+1}{2}\right) b_{\mathcal{T} i, j}, \text { and } \omega_{\mathcal{T} i}^{2}=\sigma_{\mathcal{T} i}^{2}\left(1+\frac{1}{m}\right) .
$$

Similarly ${ }^{15}$

$$
E\left[\left(\mathcal{T}_{i, T+j}-\mathcal{T}_{i, T+j-1}^{*}\right)^{-}\right]=-\mu_{\mathcal{T} i, j} \Phi\left(\frac{-\mu_{\mathcal{T} i, j}}{\omega_{\mathcal{T} i}}\right)+\omega_{\mathcal{T} i} \phi\left(\frac{\mu_{\mathcal{T} i, j}}{\omega_{\mathcal{T} i}}\right)=g_{\mathcal{T}_{i}}^{-}\left(m, b_{\mathcal{T} i, j}, \sigma_{\mathcal{T} i}\right),
$$

and

$E\left|\mathcal{T}_{i, T+j}-\mathcal{T}_{i, T+j-1}^{*}\right|=\mu_{\mathcal{T} i, j}\left[\Phi\left(\frac{\mu_{\mathcal{T}_{i, j}}}{\omega_{\mathcal{T} i}}\right)-\Phi\left(\frac{-\mu_{\mathcal{T}_{i, j}}}{\omega_{\mathcal{T} i}}\right)\right]+2 \omega_{\mathcal{T} i} \phi\left(\frac{\mu_{\mathcal{T}_{i, j}}}{\omega_{\mathcal{T} i}}\right)=g_{\mathcal{T} i}\left(m, b_{\mathcal{T} i, j}, \sigma_{\mathcal{T} i}\right)$.

It is clear from the above expressions that the responses of our climate variables to a postulated rise in temperature most crucially depend on the volatility of temperature around its

\footnotetext{
${ }^{15}$ These results follow noting that $z=z^{+}-z^{-}$and $|z|=z^{+}+z^{-}$.
} 
trend, $\sigma_{\mathcal{T} i}$, which differs markedly across countries. ${ }^{16}$

For the baseline scenario, we set $m=30$ and consider the following counterfactual country-specific changes in the trend temperature over the period $T+j$, for $j=1,2, \ldots, H$, as compared to the historical trend rise in temperature (namely $b_{\mathcal{T} i}^{0}$ ):

$$
b_{\mathcal{T}_{i, j}}^{1}=\mathcal{T}_{i, T+j}-\mathcal{T}_{i, T+j-1}=b_{\mathcal{T}_{i}}^{0}+j d_{i}, \text { for all } j=1,2 \ldots, H,
$$

where $d_{i}$ is the average incremental change in the trend rise in temperature for country $i$. We set $d_{i}$ to ensure that the average rise in temperature over the counterfactual period in country $i$ is equal to the hypothesised value of $b_{\mathcal{T} i}^{1}$, and note that

$$
b_{\mathcal{T} i}^{1}=H^{-1} \sum_{j=1}^{H} b_{\mathcal{T}_{i, j}}^{1}=H^{-1} \sum_{j=1}^{H}\left(\mathcal{T}_{i, T+j}-\mathcal{T}_{i, T+j-1}\right)=\frac{\mathcal{T}_{i, T+H}-\mathcal{T}_{i, T}}{H}
$$

where $\mathcal{T}_{i, T+H}$ denotes the level of temperature at the end of the counterfactual period. Averaging (28) over $j$ we have

$$
d_{i}=\frac{2\left(b_{\mathcal{T}_{i}}^{1}-b_{\mathcal{T}_{i}}^{0}\right)}{H+1} .
$$

In our empirical application we set $\mathcal{T}_{i, T+H}=\mathcal{T}_{i, 2099}$ and $\mathcal{T}_{i, T+1}=\mathcal{T}_{i, 2015}$, with implied $H=85$. For $\mathcal{T}_{i, 2099}$, for $i=1,2, \ldots, N$, we consider two sets of values based on IPCC's projections under the RCP 2.6 and RCP 8.5 scenarios (see Table A.2). In effect, this specification assumes that over the counterfactual period temperature in country $i$ increases by $j d_{i}$ per annum over the period $T+1$ to $T+j$, relative to its historical trend value of $b_{\mathcal{T} i}^{0}$.

We also assume that the postulated trend rise in temperature, specified in (28), does not affect the volatility of temperature shocks, and set $\sigma_{\mathcal{T} i}^{1}$ to its pre-counterfactual value of $\sigma_{\mathcal{T} i}^{0}$. This is a conservative assumption and most likely will result in an under-estimation of the adverse effects of temperature increases, since one would expect rising temperature to be associated with an increase in volatility. ${ }^{17}$ With these considerations in mind, and using (22), the mean counterfactual impact of the temperature change on output is given by (using $\left.x_{i t}=\left|\mathcal{T}_{i t}-\mathcal{T}_{i, t-1}^{*}\right|\right)$

$$
\begin{aligned}
\Delta_{i h}\left(d_{i}\right) & =\mathbb{E}\left(y_{i, T+h}^{1} \mid \digamma_{i, T}\right)-\mathbb{E}\left(y_{i, T+h}^{0} \mid \digamma_{i, T}\right) \\
& =\sum_{j=1}^{h} \psi_{h-j}\left[g_{\mathcal{T} i}\left(m, b_{\mathcal{T} i}^{0}+j d_{i}, \sigma_{\mathcal{T} i}^{0}\right)-g_{\mathcal{T} i}\left(m, b_{\mathcal{T} i}^{0}, \sigma_{\mathcal{T} i}^{0}\right)\right],
\end{aligned}
$$

where we base the estimates of $b_{\mathcal{T} i}^{0}$ and $\sigma_{\mathcal{T} i}^{0}$ on the pre-counterfactual period 1960-2014 (see

\footnotetext{
${ }^{16}$ For estimates of $\sigma_{\mathcal{T} i}$ across countries see Table A.2.

${ }^{17}$ Moreover, accounting for international spillover effects of climate change, individual countries' long-term growth effects could be larger.
} 
Table A.2), and use

$$
\begin{gathered}
g_{\mathcal{T} i}^{1}\left(m, b_{\mathcal{T} i, j}^{1}, \sigma_{\mathcal{T} i}^{0}\right)=\mu_{\mathcal{T} i, j}^{1}\left[\Phi\left(\frac{\mu_{\mathcal{T} i, j}^{1}}{\omega_{\mathcal{T} i}^{0}}\right)-\Phi\left(\frac{-\mu_{\mathcal{T} i, j}^{1}}{\omega_{\mathcal{T} i}^{0}}\right)\right]+2 \omega_{\mathcal{T} i}^{0} \phi\left(\frac{\mu_{\mathcal{T}_{i, j}}^{1}}{\omega_{\mathcal{T}_{i}}^{0}}\right), \\
g_{\mathcal{T} i}^{0}\left(m, b_{\mathcal{T} i}^{0}, \sigma_{\mathcal{T} i}^{0}\right)=\mu_{\mathcal{T} i}^{0}\left[\Phi\left(\frac{\mu_{\mathcal{T} i}^{0}}{\omega_{\mathcal{T} i}^{0}}\right)-\Phi\left(\frac{-\mu_{\mathcal{T} i}^{0}}{\omega_{\mathcal{T} i}^{0}}\right)\right]+2 \omega_{\mathcal{T} i}^{0} \phi\left(\frac{\mu_{\mathcal{T} i}^{0}}{\omega_{\mathcal{T} i}^{0}}\right), \\
\mu_{\mathcal{T} i, j}^{1}=\left(\frac{m+1}{2}\right)\left(b_{\mathcal{T} i, j}^{1}\right), \mu_{\mathcal{T} i}^{0}=\left(\frac{m+1}{2}\right) b_{\mathcal{T} i}^{0},
\end{gathered}
$$

and $\omega_{\mathcal{T} i}^{0}=\sigma_{\mathcal{T} i}^{0}\left(1+\frac{1}{m}\right)^{1 / 2}$. To obtain $\left\{\hat{\psi}_{j}\right\}$, we use the HPJ-FE estimates of $\left\{\boldsymbol{\beta}_{\ell}\right\}_{l=0}^{4}$ and $\left\{\varphi_{l}\right\}_{l=1}^{4}$ from the ARDL equation with $\left|\mathcal{T}_{i t}-\mathcal{T}_{i, t-1}^{*}\right|$ as the climate variable. These estimates and their standard errors are reported in Table 6. Figure 6 plots the estimates of $\psi_{j}$ for $j=0,1,2, \ldots, 20$, for which the estimated mean lag is $\frac{\sum_{j=1}^{\infty} j \hat{\psi}_{j}}{\sum_{j=0}^{\infty} \hat{\psi}_{j}}=3.1943$ years.

Table 6: Effects of Climate Change on per Capita Real GDP Growth, 1960-2014

\begin{tabular}{cccc|lc}
\hline$\widehat{\beta}_{0}$ & $-0.0038^{*}$ & $\widehat{\varphi}_{1}$ & $0.2643^{* * *}$ & No. of Countries $(N)$ & 174 \\
& $(0.0021)$ & & $(0.0500)$ & $\max T$ & 50 \\
$\widehat{\beta}_{1}$ & $-0.0056^{*}$ & $\widehat{\varphi}_{2}$ & $0.0785^{* * *}$ & $\operatorname{avg} T$ & 38.36 \\
& $(0.0029)$ & & $(0.0266)$ & $\min T$ & 2 \\
$\widehat{\beta}_{2}$ & $-0.0084^{* * *}$ & $\widehat{\varphi}_{3}$ & $0.0547^{* *}$ & No. of Obs. $(N \times T)$ & 6,674 \\
& $(0.0031)$ & & $(0.0216)$ & & \\
$\widehat{\beta}_{3}$ & $-0.0090^{* * *}$ & $\widehat{\varphi}_{4}$ & -0.0016 & & \\
& $(0.0026)$ & & $(0.0327)$ & & \\
$\widehat{\beta}_{4}$ & $-0.0060^{* * *}$ & & & & \\
& $(0.0021)$ & & & & \\
& & & & & \\
\hline
\end{tabular}

Notes: Estimates are based on $\Delta y_{i t}=a_{i}+\sum_{\ell=1}^{4} \varphi_{\ell} \Delta y_{i, t-\ell}+\sum_{\ell=0}^{4} \beta_{\ell}^{\prime} \Delta x_{i, t-\ell}+\varepsilon_{i t}$, where $y_{i t}$ is the log of real GDP per capita of country $i$ in year $t, x_{i t}=\left|\mathcal{T}_{i t}-\mathcal{T}_{i, t-1}^{*}\right|, \mathcal{T}_{i t}$ is the population-weighted average temperature of country $i$ in year $t$, and $\mathcal{T}_{i, t-1}^{*}$ is the historical temperature norm of country $i$ (based on moving averages of the past 30 years). The coefficients are estimated by the half-panel jackknife FE (HPJ-FE) procedure and the standard errors are based on the estimator proposed in Proposition 4 of Chudik et al. (2018). Asterisks indicate statistical significance at $1 \%(* * *), 5 \%(* *)$, and $10 \%(*)$ levels.

We report the real GDP per capita losses from global warming under the RCP 2.6 and RCP 8.5 scenarios, compared to the reference case, in country heat maps and for the year 2100 only, but make all of the 174 country-specific estimates over various horizons (by year 2030, 2050, and 2100) available in Table A.2. Figure 7 shows that in the absence of climate change policies (under the RCP 8.5 Scenario with $m=30$ ), the percent losses in per-capita incomes by 2100 are sizable, regardless of whether a country is rich or poor, and hot or cold. Nonetheless, the losses vary significantly across countries depending on the country-specific projected paths of temperatures. Figure 8 shows that if we managed to limit the increase in average global temperatures to $0.01^{\circ} \mathrm{C}$ per annum (the $\mathrm{RCP} 2.6$ scenario), in line with the 
Figure 6: $\left\{\psi_{j}\right\}$ for $j=0,1,2, \ldots, 20$

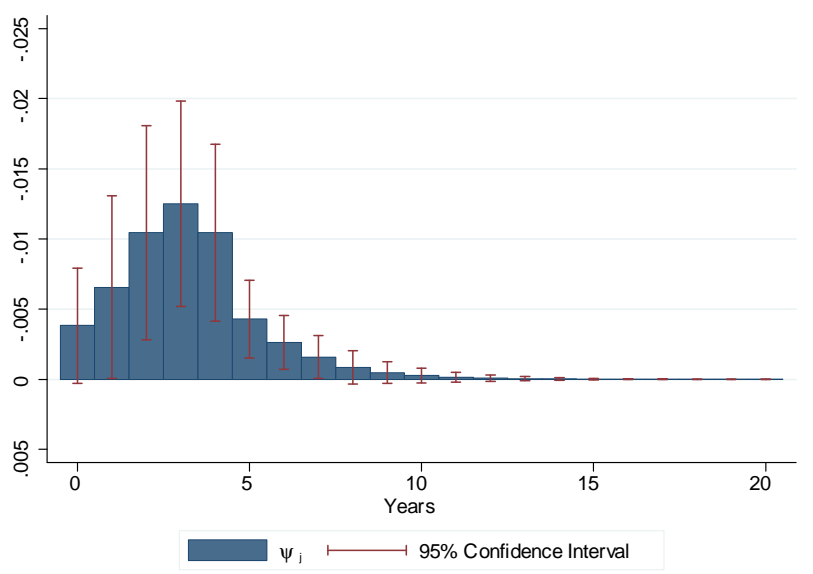

Paris Agreement, we would be able to substantially reduce these losses.

Table 7 reports the real GDP per capita losses for China, the European Union, India, Russia, and the United States, over various time horizons. As in Figure 7, income effects are substantially larger under an unmitigated path (i.e., RCP 8.5). Nonetheless, under both scenarios, the cross-country heterogeneity is significant. Focusing on the RCP 8.5 scenario (with $m=30$ ) we observe that the losses vary between 0.50 and 1.20 percent, 1.53 and 3.77 percent, and 4.35 and 10.52 percent in 2030, 2050 and 2100, respectively; with a relatively large impact estimated for the United States in 2100 (reflecting IPCC's projections of a sharp increase in the country's average temperature in the absence of mitigation efforts).

Averaging the losses across countries, using PPP-GDP weights, we report the global income effects of climate change under the RCP 2.6 and RCP 8.5 scenarios in Table 7. Under the Paris agreement, and assuming $m=30$, our results indicate that the world could actually benefit from mitigation policies in year 2030 (compared to a reference case in which temperatures increase according to their historical trends of 1960-2014), while limiting the economic losses of climate change to 0.11 and 1.07 percent over the next 36 and 86 years, respectively. However, a persistent above-norm increase in average global temperature by $0.04^{\circ} \mathrm{C}$ per year (based on RCP 8.5) leads to substantial output losses, reducing real per capita output by $0.80,2.51$ and 7.22 percent in 2030, 2050 and 2100, respectively. Overall these economic effects are somewhat larger than those obtained in existing studies in the literature and what is generally discussed in policy circles (see Figure 2).

A conclusion one may obtain from the literature is that the economic effects of climate change are highly uneven, with severe negative effects in hot/poor countries and limited impact on cold/rich economies (and in some studies even large gains in Canada, Russia and most of Western Europe) — examples include Annex Figure 3.6.1 in International Mon- 
Figure 7: Percent Loss in GDP per capita by 2100 in the Absence of Climate Change Policies (RCP 8.5 Scenario)

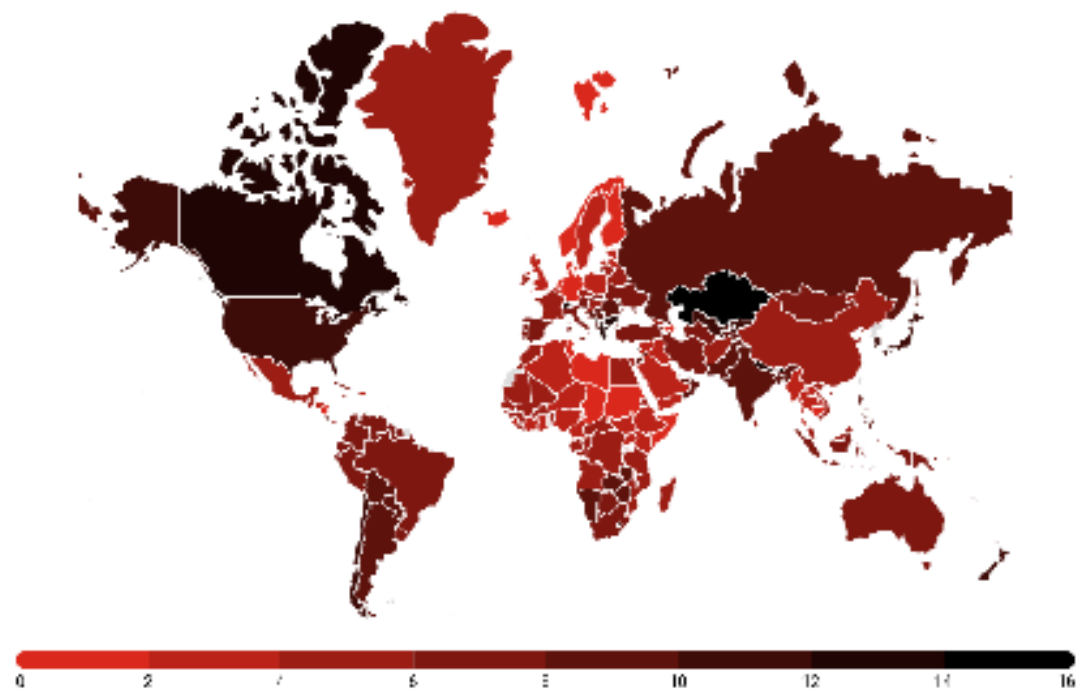

Notes: The heat map shows $\Delta_{i h}\left(d_{i}\right)$, see equation (31), in year 2100 with $m=30$, based on the RCP 8.5 scenario.

Figure 8: Percent Loss in GDP per capita by 2100 Abiding by the Paris Agreement (RCP 2.6 Scenario)

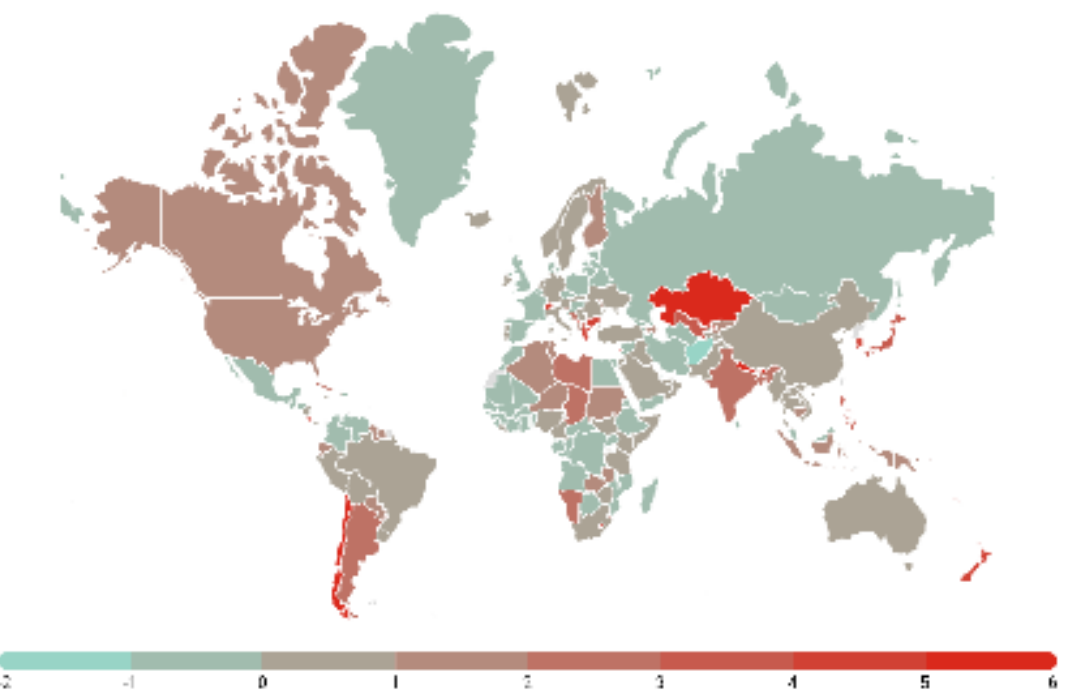

Notes: The heat map shows $\Delta_{i h}\left(d_{i}\right)$, see equation (31), in year 2100 with $m=30$, based on the RCP 2.6 scenario. 
Table 7: Percent Loss in GDP per capita by 2030, 2050, and 2100 under the RCP 2.6 and RCP 8.5 Scenarios

\begin{tabular}{|c|c|c|c|c|c|c|c|c|c|}
\hline \multirow{3}{*}{ World } & \multicolumn{3}{|c|}{ Year $2030(h=16)$} & \multicolumn{3}{|c|}{ Year $2050(h=36)$} & \multicolumn{3}{|c|}{ Year $2100(h=86)$} \\
\hline & \multirow[t]{2}{*}{$m=20$} & \multirow[t]{2}{*}{$m=30$} & \multirow[t]{2}{*}{$m=40$} & \multirow[t]{2}{*}{$m=20$} & \multirow[t]{2}{*}{$m=30$} & \multirow[t]{2}{*}{$m=40$} & \multirow[t]{2}{*}{$m=20$} & \multirow[t]{2}{*}{$m=30$} & \multirow[t]{2}{*}{$m=40$} \\
\hline & & & & & & & & & \\
\hline RCP 2.6 & -0.01 & -0.01 & -0.02 & 0.06 & 0.11 & 0.16 & 0.58 & 1.07 & 1.57 \\
\hline RCP 8.5 & 0.40 & 0.80 & 1.25 & 1.39 & 2.51 & 3.67 & 4.44 & 7.22 & 9.96 \\
\hline \multicolumn{10}{|l|}{ China } \\
\hline RCP 2.6 & -0.22 & -0.45 & -0.71 & -0.38 & -0.80 & -1.31 & 0.24 & 0.45 & 0.67 \\
\hline $\mathrm{RCP} 8.5$ & 0.31 & 0.58 & 0.87 & 0.90 & 1.62 & 2.30 & 2.67 & 4.35 & 5.93 \\
\hline \multicolumn{10}{|c|}{ European Union } \\
\hline RCP 2.6 & -0.04 & -0.08 & -0.13 & -0.06 & -0.13 & -0.22 & 0.05 & 0.09 & 0.13 \\
\hline $\mathrm{RCP} 8.5$ & 0.24 & 0.50 & 0.80 & 0.79 & 1.53 & 2.35 & 2.67 & 4.66 & 6.69 \\
\hline \multicolumn{10}{|l|}{ India } \\
\hline RCP 2.6 & 0.12 & 0.26 & 0.42 & 0.41 & 0.81 & 1.27 & 1.44 & 2.57 & 3.69 \\
\hline $\mathrm{RCP} 8.5$ & 0.60 & 1.16 & 1.78 & 2.13 & 3.62 & 5.08 & 6.37 & 9.90 & 13.39 \\
\hline \multicolumn{10}{|l|}{ Russia } \\
\hline RCP 2.6 & -0.07 & -0.14 & -0.23 & -0.16 & -0.34 & -0.56 & -0.33 & -0.71 & -1.19 \\
\hline $\mathrm{RCP} 8.5$ & 0.51 & 1.03 & 1.63 & 1.62 & 3.08 & 4.61 & 5.28 & 8.93 & 12.46 \\
\hline \multicolumn{10}{|c|}{ United States } \\
\hline RCP 2.6 & 0.10 & 0.20 & 0.33 & 0.29 & 0.60 & 0.96 & 0.98 & 1.88 & 2.84 \\
\hline RCP 8.5 & 0.60 & 1.20 & 1.86 & 2.13 & 3.77 & 5.39 & 6.66 & 10.52 & 14.32 \\
\hline \multicolumn{10}{|c|}{ Rich Countries } \\
\hline RCP 2.6 & 0.02 & 0.05 & 0.09 & 0.12 & 0.23 & 0.37 & 0.58 & 1.09 & 1.62 \\
\hline RCP 8.5 & 0.42 & 0.84 & 1.33 & 1.46 & 2.67 & 3.93 & 4.74 & 7.76 & 10.75 \\
\hline \multicolumn{10}{|c|}{ Poor Countries } \\
\hline RCP 2.6 & -0.08 & -0.16 & -0.25 & -0.08 & -0.18 & -0.32 & 0.55 & 0.99 & 1.43 \\
\hline RCP 8.5 & 0.37 & 0.72 & 1.09 & 1.24 & 2.18 & 3.11 & 3.78 & 6.05 & 8.25 \\
\hline \multicolumn{10}{|c|}{ Hot Countries } \\
\hline RCP 2.6 & 0.00 & 0.00 & 0.01 & 0.08 & 0.15 & 0.23 & 0.62 & 1.11 & 1.60 \\
\hline $\mathrm{RCP} 8.5$ & 0.39 & 0.76 & 1.17 & 1.35 & 2.37 & 3.39 & 4.17 & 6.65 & 9.10 \\
\hline \multicolumn{10}{|c|}{ Cold Countries } \\
\hline RCP 2.6 & -0.01 & -0.02 & -0.03 & 0.05 & 0.09 & 0.14 & 0.56 & 1.05 & 1.57 \\
\hline RCP 8.5 & 0.41 & 0.81 & 1.28 & 1.40 & 2.56 & 3.76 & 4.53 & 7.40 & 10.24 \\
\hline
\end{tabular}

Notes: We consider persistent increases in temperatures based on the RCP 2.6 and RCP 8.5 scenarios. Numbers are PPP GDP weighted averages of $\Delta_{i h}\left(d_{i}\right)$, see equation (31), with $h=16,36$, and 86 (corresponding to the year 2030, 2050, and 2100, respectively) and $m=20,30$, and 40. 
etary Fund (2017) and Figure 4 in Burke et al. (2015). Reporting our counterfactual results for rich, poor, hot and cold economies (averaging the country-specific losses using PPP-GDP weights) in Table 7, we observe that under the RCP 8.5 scenario, rich (cold) countries suffer from larger output per capita losses than poor (hot) economies. Under the RCP 2.6 scenario, the effects are much smaller but the rankings are somewhat similar (apart from hot countries which experience larger income losses). Overall, abiding by the Paris Agreement would go a long way in limiting the adverse macroeconomic effects of the climate change.

Can adaptation help offset these negative income effects? Repeating the counterfactual exercise for different values of $m$ highlights the role of adaptation. The shorter the $m$, the faster agents treat higher temperatures as the new norm. Table 7 shows the effects of global warming over time for various values of $m$. The results indicate that per-capita output losses are lower for $m=20$ but significantly higher if it takes longer to adapt to climate change $(m=40)$. Overall, we argue that while climate change adaptation could reduce these negative economic effects, it is highly unlikely to offset them entirely. More forceful mitigation policies are needed to limit the damage from climate change.

Table 8: Percent Loss in GDP per capita by 2030, 2050, and 2100 under the RCP 8.5 Scenario: the Role of Climate Variability

\begin{tabular}{|c|c|c|c|}
\hline & $\begin{array}{c}\text { Year 2030 } \\
(h=16)\end{array}$ & $\begin{array}{c}\text { Year 2050 } \\
(h=36)\end{array}$ & $\begin{array}{l}\text { Year 2100 } \\
(h=86)\end{array}$ \\
\hline World & 2.02 & 5.18 & 13.11 \\
\hline China & 0.78 & 1.99 & 5.02 \\
\hline European Union & 1.45 & 3.71 & 9.37 \\
\hline India & 2.62 & 6.70 & 16.92 \\
\hline Russia & 2.00 & 5.13 & 12.94 \\
\hline United States & 2.66 & 6.81 & 17.19 \\
\hline Rich Countries & 2.24 & 5.74 & 14.51 \\
\hline Poor Countries & 1.52 & 3.92 & 9.91 \\
\hline Hot Countries & 1.76 & 4.54 & 11.52 \\
\hline Cold Countries & 2.10 & 5.39 & 13.62 \\
\hline
\end{tabular}

Notes: We consider persistent increases in temperatures based on the RCP 8.5 scenario but set $\sigma_{\mathcal{T} i}^{1}=$ $\frac{\mu_{\mathcal{T} i, j}^{T}}{\mu_{\mathcal{T} i}^{0}} \sigma_{\mathcal{T} i}^{0}$. Numbers are PPP GDP weighted averages of $\Delta_{i h}\left(d_{i}\right)$, with $h=16,36$, and 86 (corresponding to the year 2030, 2050, and 2100, respectively) and $m=30$.

We showed that economic growth is affected not only by higher temperatures but also by the degree of climate variability. To study the role of climate volatility in determining GDP per capita losses, instead of setting $\sigma_{\mathcal{T} i}^{1}=\sigma_{\mathcal{T} i}^{0}$, we allow temperature increases to affect the variability of temperature shocks commensurately. That is, we keep the coefficient of variation unchanged, and therefore set $\sigma_{\mathcal{T} i}^{1}=\frac{\mu_{\mathcal{T} i, j}^{1}}{\mu_{\mathcal{T} i}^{0}} \sigma_{\mathcal{T} i}^{0}$. The results are reported in Table 8 for the RCP 8.5 scenario and $m=30$. As expected, the estimated GDP per capita losses become significantly larger, almost doubling at the global level by 2100 to 13.11 percent. 
For the United States, the losses are likely to be 70 percent higher compared to our baseline counterfactual scenario reported in Table 7. In terms of the channels of impact, the increase in the degree of climate variability affects economies by reducing labor productivity, increasing health problems (e.g., heat-related health issues or drought-related water and food shortages), damaging infrastructure (e.g., from flooding in river basins and coasts and landslides), and disruptions in supply chains — see IPCC (2014) for details.

\section{Evidence from an Advanced Economy: The Case of the United States}

While cross-country studies are informative, they also have drawbacks. Averaging temperature and precipitation data at the country level leads to a loss of information, especially in geographically diverse countries with varied temperature and precipitation patterns, such as Brazil, China, India, Russia and the United States. In particular, while the national average climate variables may be close to their historical norms, there is significant heterogeneity within countries. Among the countries mentioned above, the within-country geographic heterogeneity of the United States and its data richness enable us to compare whether economic activity in the 'hot' or 'dry' states responds to a temperature increase in the same way as economic activity does in 'cold' or 'wet' states.

In this section, we use data on climate and macroeconomic variables across the 48 contiguous U.S. states over the period 1963 to 2016 to check the robustness of our cross-country results to within country climate-economy variations. Inspired by recent literature that focuses on channels through which climate change affects the economy, we consider the differential growth effects of our climate variables across the main sectors of the U.S. economy. Details of data sources and their compilation for the purpose of this study are given in Appendix B. In addition to the climate variables, we obtain Gross State Product (GSP), GSP per capita, and GSP per employed as well as output for ten major economic sectors. ${ }^{18}$

We showed in section 3.2 that there exists a universal long-run relationship between climate change and economic growth across countries regardless of whether they are rich or poor and hot or cold. We examine the validity of this finding for the case of U.S.; an advanced economy with a high level of development and some resilience-building activities against climate change across states. This is important as most studies in the literature argue that climate change may only have a limited impact on economic activity of advanced countries as they are located in temperate places. ${ }^{19}$ More generally, these findings may be

\footnotetext{
${ }^{18}$ The ten sectors are: (i) Agriculture, Forestry, and Fisheries, (ii) Mining, (iii) Construction, (iv) Manufacturing, (v) Transport, Communication, and Public Utilities, (vi) Wholesale Trade, (vii) Retail Trade, (viii) Finance, Insurance, and Real Estate, (ix) Services, and (x) Government. See Table B.1.

${ }^{19}$ An exception is a recent paper by Burke and Tanutama (2019).
} 
driven by the fact that advanced economies: (i) have more economic activity taking place indoors where air conditioners can be installed (or other measures taken), ${ }^{20}$ (ii) experience a better diffusion of adaptive technology, (iii) have more flexible labour markets and can optimise their use of physical capital more easily, and (iv) can afford to divert part of their investment to adaptive measures given their level of development.

\subsection{Long-Run Impact of Climate Change on U.S. Economic Growth}

We first examine whether temperature across the 48 U.S. states has been increasing over the period 1963 to 2016 by estimating equation (16). Our results suggest that, on average, temperature in the 48 U.S. states has risen by 0.026 degrees Celsius $\left({ }^{\circ} \mathrm{C}\right)$ per year over 1963-2016 (i.e., $\hat{b}_{\mathcal{T}}=0.0260$ (0.0007); with the standard error in brackets), with this trend estimate being statistically significant at the $1 \%$ level. Compared to our cross-country sample (see Table 1), there is, as to be expected, less heterogeneity across the 48 U.S. states, with all states experiencing statistically significant increases in temperature over time (see Table 9). But, the 48 U.S. states as a whole underwent more warming than the world on average. The U.S. average per annum temperature increase of 0.026 was appreciably higher than the world average rise of 0.018 per annum, which is close to that for Oklahoma, the state which saw the lowest average increase in temperature.

Having shown that temperature is trended across the sample of 48 U.S. states, we examine the long-run impact of climate change on aggregate state-level economic activity as well as states' sectoral outputs. Such a within-country study is scant in the literature as priority is given to studying the impact of climate change on a particular sector of an economy (e.g., agricultural output) or to cross-country analyses. As in the cross-country study in Section 3.2, we estimate the panel ARDL model (17) for the 48 U.S. states, but with $y_{i t}$ denoting an economic indicator (for instance, GSP or sectoral output) of state $i$ in year $t$.

Table 10 reports the long-run estimates of the climate change variables on growth rates of real GSP and real GSP per capita for the 48 U.S. states over the period 1963-2016. We construct the climate variables with historical norms computed using 20, 30, and 40 years moving-averages, and consider the estimates based on the 30-year moving averages as our central estimates. We observe that the estimated long-run coefficients $\widehat{\theta}_{\Delta\left(\mathcal{T}_{i t}-\mathcal{T}_{i, t-1}^{*}\right)^{-}}$, $\widehat{\theta}_{\Delta\left(\mathcal{P}_{i t}-\mathcal{P}_{i, t-1}^{*}\right)^{+}}$, and $\widehat{\theta}_{\Delta\left(\mathcal{P}_{i t}-\mathcal{P}_{i, t-1}^{*}\right)^{-}}$are negative and statistically significant in all cases except for one. Climate change affects the U.S. ecosystem not only through increases in average temperatures, but also through changes in the extremes - more intense droughts; heavier snow and rainfall; as well as extreme cold. However, $\widehat{\theta}_{\Delta\left(\mathcal{T}_{i t}-\mathcal{T}_{i, t-1}^{*}\right)^{+}}$is not statistically significant in three out of six specifications. While this finding might be explained by the improving

\footnotetext{
${ }^{20}$ Barreca et al. (2016) points to the role of air conditioning in insulating the populace from climate change.
} 


\section{Table 9: Individual U.S. State Estimates of the Average Yearly Rise in Temper- ature Over the Period 1963-2016}

\begin{tabular}{llllll}
\hline State & $\hat{b}_{\tau, i}$ & State & $\hat{b}_{\tau, i}$ & State & $\hat{b}_{\tau, i}$ \\
\hline Alabama & $0.0212^{\ddagger}$ & Maine & $0.0288^{\ddagger}$ & Ohio & $0.0263^{\ddagger}$ \\
Arizona & $0.0318^{\ddagger}$ & Maryland & $0.0299^{\ddagger}$ & Oklahoma & $0.0171^{\ddagger}$ \\
Arkansas & $0.0181^{\ddagger}$ & Massachusetts & $0.0311^{\ddagger}$ & Oregon & $0.0198^{\ddagger}$ \\
California & $0.0270^{\ddagger}$ & Michigan & $0.0285^{\ddagger}$ & Pennsylvania & $0.0280^{\ddagger}$ \\
Colorado & $0.0271^{\ddagger}$ & Minnesota & $0.0320^{\ddagger}$ & Rhode Island & $0.0320^{\ddagger}$ \\
Connecticut & $0.0316^{\ddagger}$ & Mississippi & $0.0205^{\ddagger}$ & South Carolina & $0.0250^{\ddagger}$ \\
Delaware & $0.0355^{\ddagger}$ & Missouri & $0.0179^{\ddagger}$ & South Dakota & $0.0234^{\ddagger}$ \\
Florida & $0.0228^{\ddagger}$ & Montana & $0.0292^{\ddagger}$ & Tennessee & $0.0234^{\ddagger}$ \\
Georgia & $0.0228^{\ddagger}$ & Nebraska & $0.0222^{\ddagger}$ & Texas & $0.0245^{\ddagger}$ \\
Idaho & $0.0245^{\ddagger}$ & Nevada & $0.0273^{\ddagger}$ & Utah & $0.0291^{\ddagger}$ \\
Illinois & $0.0223^{\ddagger}$ & New Hampshire & $0.0299^{\ddagger}$ & Vermont & $0.0318^{\ddagger}$ \\
Indiana & $0.0236^{\ddagger}$ & New Jersey & $0.0343^{\ddagger}$ & Virginia & $0.0266^{\ddagger}$ \\
Iowa & $0.0198^{\ddagger}$ & New Mexico & $0.0300^{\ddagger}$ & Washington & $0.0186^{\ddagger}$ \\
Kansas & $0.0186^{\ddagger}$ & New York & $0.0308^{\ddagger}$ & West Virginia & $0.0268^{\ddagger}$ \\
Kentucky & $0.0250^{\ddagger}$ & North Carolina & $0.0257^{\ddagger}$ & Wisconsin & $0.0307^{\ddagger}$ \\
Louisiana & $0.0210^{\ddagger}$ & North Dakota & $0.0263^{\ddagger}$ & Wyoming & $0.0279^{\ddagger}$ \\
\hline
\end{tabular}

Notes: $\widehat{b}_{\mathcal{T} i}$ are the individual state-level estimates based on the regressions $\mathcal{T}_{i t}=a_{\mathcal{T} i}+b_{\mathcal{T} i} t+v_{\mathcal{T}, i t}$, where $\mathcal{T}_{i t}$ denotes the average temperature $\left({ }^{\circ} \mathrm{C}\right)$ in state $i$ in year $t .{ }^{\ddagger}$ indicates statistical significance at the $1 \%$ level.

resilience of the U.S. economy to increasing temperature brought by climate change ${ }^{21}$ the evidence for excessive temperature not affecting the U.S. economy is not conclusive as we will explain below.

While in our cross-country analysis, we did not find any statistically significant impact from deviations of precipitation from its historical norms on output growth (see Tables 2-5), in our within-country study of the United States, we find that deviations of precipitation above and below its historical norm affect various measures of state-level economic activity and these estimates are statistically significant. ${ }^{22}$ This is because averaging precipitation at the country level leads to a loss of information, especially in geographically diverse countries with varied precipitation patterns. While the national average precipitation may be close to its historical norm, there is significant heterogeneity across states with some experiencing plenty of rain and snow and others, like California, suffering from drought for many years. By conducting a within-country study, we account for the variation of precipitation across the states, which is important and does indeed affect economic activity (Table 10).

Considering the richness of our U.S. database, which includes data on state-level employment from 1976, we can also examine the long-run impact of climate change on labour

\footnotetext{
${ }^{21}$ For example, currently about 90 percent of American households have air conditioning.

${ }^{22}$ The importance of focusing on deviations of climate variables from their historical norms is also highlighted by recent research which demonstrate that different regions of the United States have acclimated themselves to their own temperature niche; see, for instance, Heutel et al. (2016).
} 


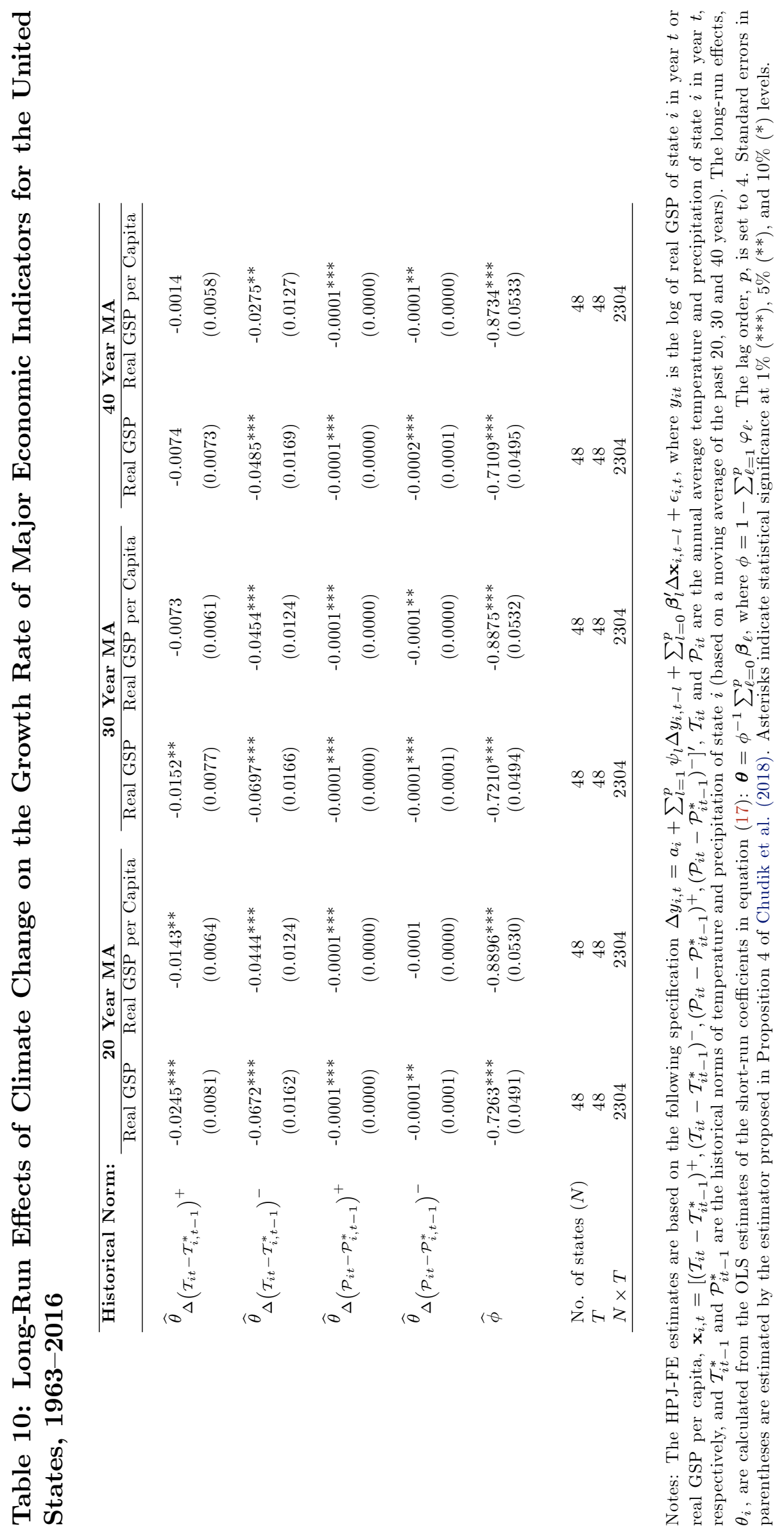


productivity and employment growth directly, in addition to re-estimating the regressions over the period 1976-2016. We, therefore, re-estimate the model for an extended set of outcome variables, with $y_{i t}$ being the natural logarithm of: $(i)$ real GSP, $(i i)$ real GSP per capita, (iii) real GSP per employed (measuring labour productivity), or (iv) employment, but over the period 1976 to 2016. These results are reported in Table 11. Across all specifications, the estimated long-run coefficients $\widehat{\theta}_{\Delta\left(\mathcal{T}_{i t}-\mathcal{T}_{i, t-1}^{*}\right)^{-}}$and $\widehat{\theta}_{\Delta\left(\mathcal{P}_{i t}-\mathcal{P}_{i, t-1}^{*}\right)^{-} \text {are negative }}$ and statistically significant at the $1 \%$ level for almost all outcome variables. Therefore, when temperature and precipitation fall below their historical norms, state-level economic activity suffers, employment declines, and labour productivity growth falls (for $\widehat{\theta}_{\Delta\left(\mathcal{T}_{i t}-\mathcal{T}_{i, t-1}^{*}\right)^{-}}$).

While in Table 10, the climate variable $\left(\mathcal{I}_{i t}-\mathcal{T}_{i t-1}^{*}\right)^{+}$, did not have a statistically significant impact on state-level output growth in three out of six specifications (over the period 1963-2016), the results change substantially when we consider the 1976-2016 sub-sample in Table 11. Consistent with our cross-country estimates, $\widehat{\theta}_{\Delta\left(\mathcal{T}_{i t}-\mathcal{T}_{i, t-1}^{*}\right)^{+}}$is now negative and statistically significant for various specifications and dependent variables: real GSP, real GSP per capita, real GSP per employed, and employment. The size of the estimates for $\widehat{\theta}_{\Delta\left(\mathcal{T}_{i t}-\mathcal{T}_{i, t-1}^{*}\right)^{+}}$is smaller in absolute value than those obtained in our cross-country regressions (Table 2), partly reflecting a higher degree of adaptation in the U.S. to climate change. Nonetheless, contrary to most studies in the literature, our estimates are not negligible. Our results are supported by Deryugina and Hsiang (2014) and Behrer and Park (2017), who exploit county-level variations in climate variables over time in the U.S. and find that hotter temperatures damage economic activity, and also by Colacito et al. (2019) who find that an increase in summer temperatures has adverse effects on GSP growth in the United States.

If the U.S. economy were adapting to climate change, ceteris paribus, should we not expect the impact of deviations of temperature and precipitation from their historical norms to be shrinking over time? To investigate this hypothesis, we re-estimate the model over different time windows using real GSP per capita growth as the dependent variable. We start with the full sample, 1963-2016, and then drop a year at a time (with the last estimation being carried out for the sub-sample 1983-2016). The results are plotted in Figure 9, showing that the estimated coefficients are becoming larger (in absolute value) over time.

Do these results cast doubt on the efficacy of adaptation efforts in the United States over the last five decades? Ceteris paribus, while it is expected that adaptation weakens the relationship between climate change and economic growth over time, we cannot conclude that the U.S. economy has not been adapting to climate change based on Figure 9. First, adaptation efforts might be concentrated in certain sectors. Second, it may be the case that adaptation is not keeping pace with climate change; i.e., global temperatures have increased at an unprecedented pace over the past 40 years. Third, the effects of adaptation might have been offset by structural changes to the U.S. economy (that is a shift of value added to sectors that are more exposed to climate change). Fourth, if firms underestimate the likelihood or 


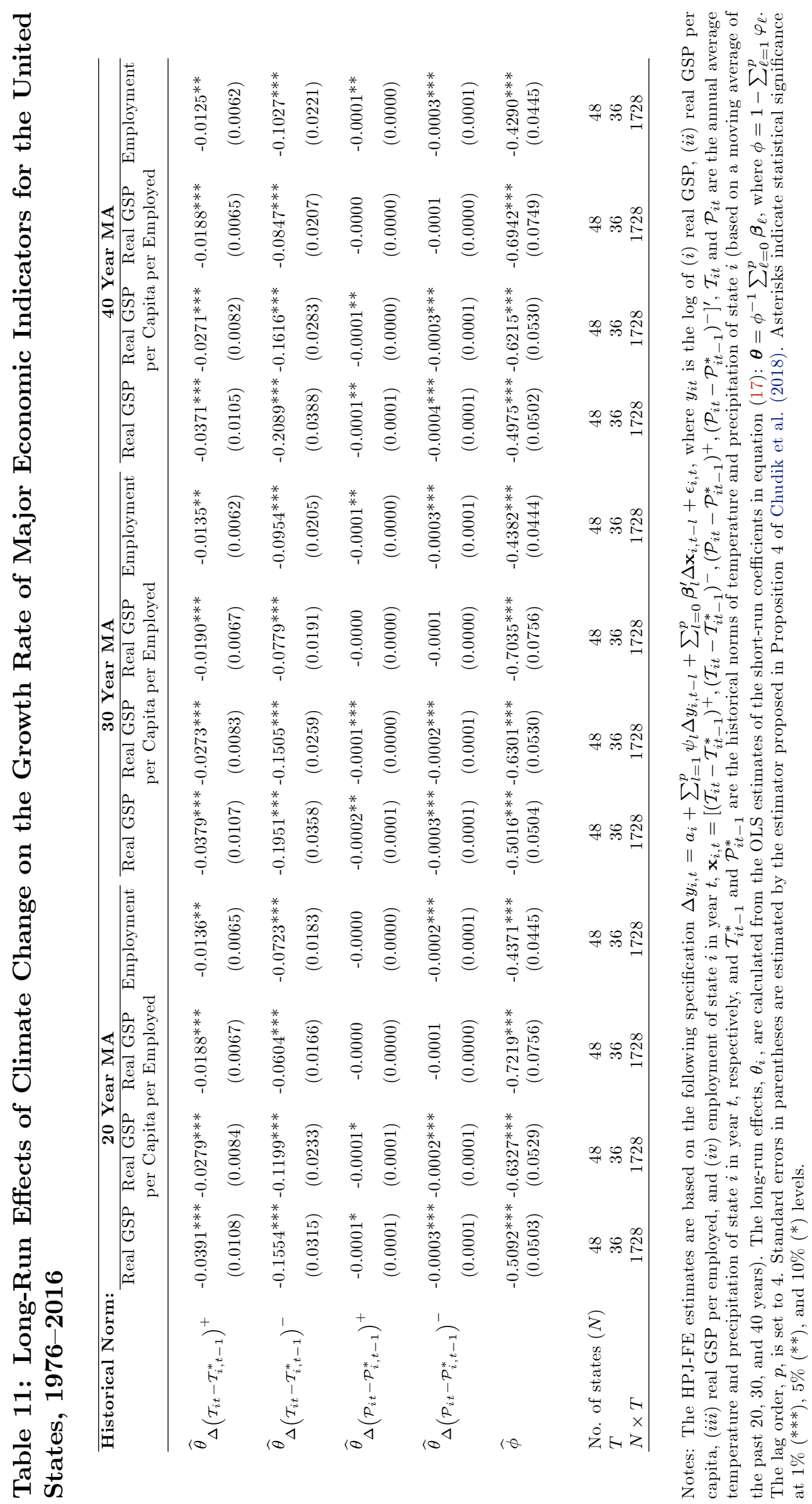


Figure 9: Long-Run Effects of Climate Change on per capita Real GSP Growth in the United States, 1963-2016

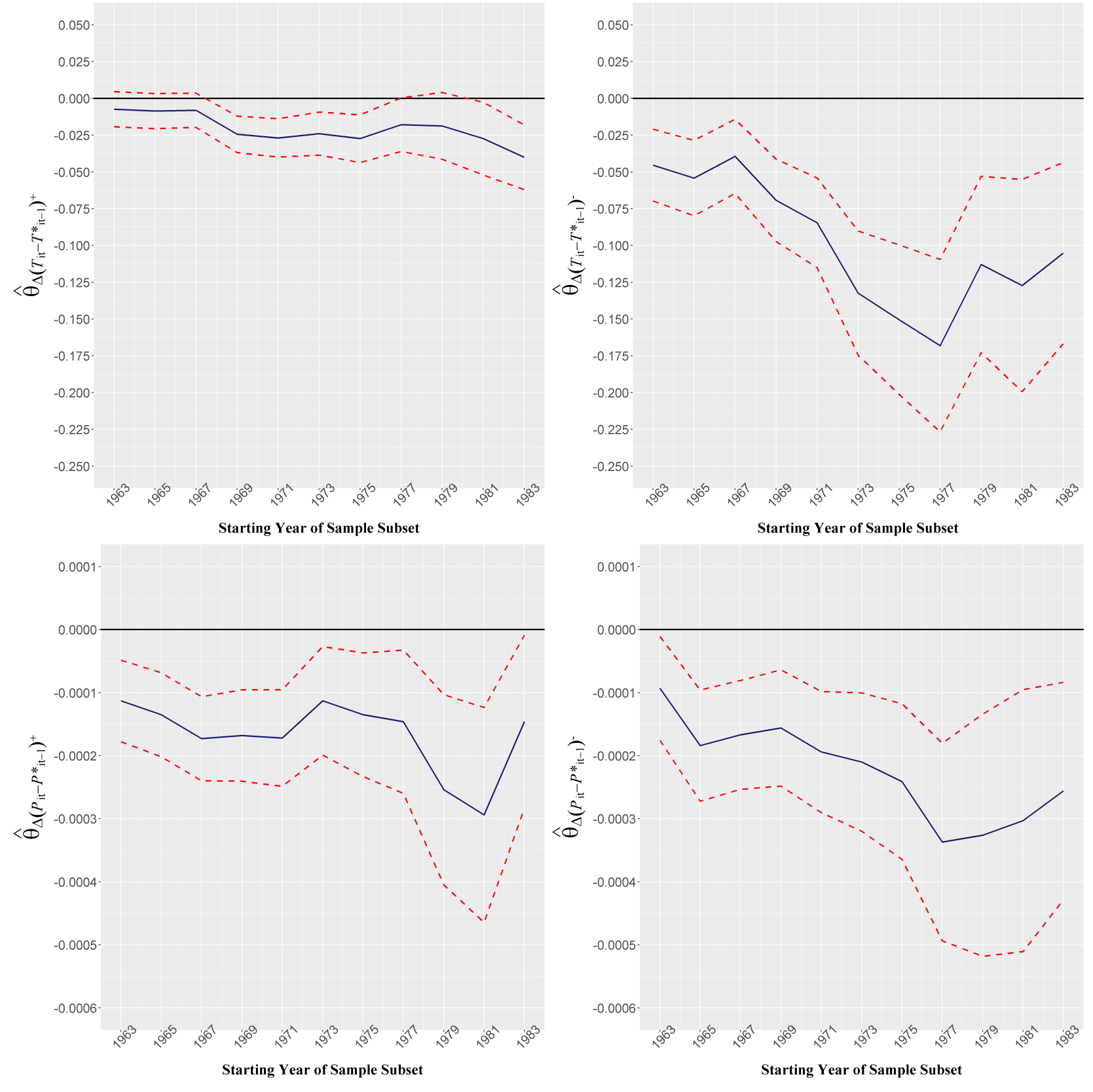

Notes: Figures show the long-run effects (and their 95\% standard error bands) of climate change on statelevel economic growth in the United States over different windows, using the ARDL specification (17). We start the estimation with the full sample (1963-2016) and then drop one year at a time, ending with the final estimates based on the 1983-2016 sub-sample. 
severity of future weather events, they may not adapt sufficiently; i.e. adaptation technologies are readily available but the take-up is limited by firms. In a survey of private sector organizations across multiple industries within the Organization for Economic Cooperation and Development (OECD) countries, Agrawala et al. (2011) find that only few firms have taken sufficient steps to assess and manage the risks from climate change. Fifth, according to Deryugina and Hsiang (2014) firms tend to underinvest in adaptation owing to its high cost. ${ }^{23}$ We argue that there has been some adaptation in the U.S. given that the estimates in Tables 10 and 11 are generally smaller than those obtained in our cross-country study (Table 2). However, overall, the evidence appears to suggest that (at least for now) adaptation has had limited impact in dampening the negative effects of climate change in the United States.

\subsection{Further Evidence from U.S. Sector Level Data}

Adaptation and mitigation can occur in the short-term through a reallocation of resources, and in the long-term through investment in research and development, innovation, or a shift in the economic structure of the country towards an industry mix that is less vulnerable to climate change. Given that adaptation is relatively easier and more effective to implement in some industries than others, we first need to assess which sectors/industries are more likely to be affected by climate change in the U.S. economy. Focusing on different sectors/industries also helps shed light on the channels through which climate change affects the United States economy. We consider ten sectors, and due to lack of worker per sector data at the state level, we only report the results for state-level output growth. ${ }^{24}$

The long-run sectoral effects of climate change estimated on the panel of the 48 U.S. states over the period 1963-2016 are reported in Table 12. The estimates show that the impact is broad based - each of the 10 sectors is affected by at least one of the four climate variables. Specifically, the agricultural sector is negatively impacted by a rise in temperature

above its historical norm, $\widehat{\theta}_{\Delta\left(\mathcal{T}_{i t}-\mathcal{T}_{i, t-1}^{*}\right)^{+}}<0$. In addition, precipitation above and below the norm also exert negative effects on agricultural output growth. These results are in line with the findings of Burke and Emerick (2016), who consider corn and soy farming in the U.S. over the period 1955-2005, and find that, despite some adaptation efforts by farmers, agricultural output is damaged by extreme heat and excessive precipitation. Note also that the cost of adaptation to climate change is high in the agricultural sector - constructing greenhouses or varying crop mixes involves heftier investments than fitting air conditioning units in offices.

Table 12 also illustrates that deviations of all four climate variables from their historical norms have adverse effects on output growth in the manufacturing sector. While the negative impact of climate change on agricultural production is well studied, the adverse effects on

\footnotetext{
${ }^{23}$ Other reasons for underinvestment include knowledge spillovers and networks externalities.

${ }^{24}$ See Appendix B for further details.
} 


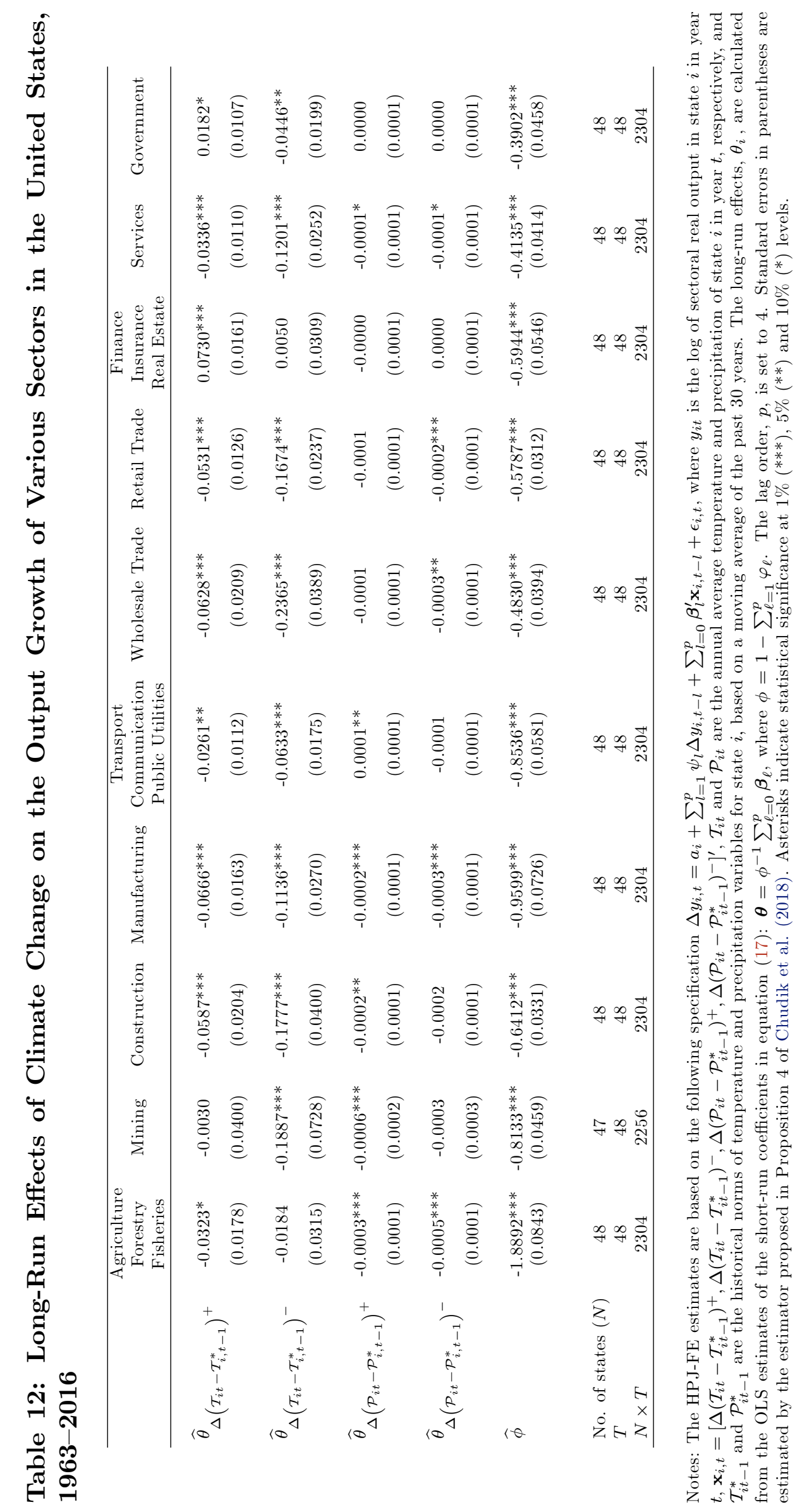


the manufacturing sector in the United States are only being discussed in the new climate economy literature (using micro-data analyses). For example, Cachon et al. (2012) use weekly production data from 64 automobile plants in the U.S. and find that climate variations (extensive periods of rain and snow, high heat, and severe winds), lead to costly production volatility, and have adverse effects on labour productivity, in line with our results. Moreover, our estimates show that output growth in mining, construction, transport, retail trade, wholesale trade, services and government sectors are all negatively affected by unusually cold days in the U.S. as consumer spending falls (households may delay shopping or even cut from spending owing to higher heating costs or home-repair expenses); supply chains are interrupted; ${ }^{25}$ and construction projects are delayed. See also Bloesch and Gourio (2015) for further supporting evidence. Heavy rain can also reduce access to mountainous mining regions, where large deposits are generally found, thereby reducing output growth in the mining sector. Construction and transportation activities are also affected by rain/snow.

Most discussions of climate change focus on the expected increase in average global temperatures over the next century (i.e. global warming). However, the frequency and severity of weather events (such as heat or cold waves, droughts and floods, as well as natural disasters) depend heavily on the variability of temperatures and precipitation as well as their mean. The larger the swings, the more often extremely hot or cold and wet or dry conditions can wreak havoc; see, for instance, Swain et al. 2018. Given current projections of rising average global temperature over the next century, the likelihood that temperatures persistently drift above their historical norm is very high. As we showed above, this could lead to a permanent negative impact on state-level output growth (that is lower production growth in all sectors of the United States economy apart from the mining, government, and finance, insurance and real estate sectors). While persistent deviations of precipitation from its historical norm (either above and below) or below-the-norm temperatures are less likely, the swings (variability) could be unprecedentedly large owing to climate change, and hence, the negative impact on state-level output growth could be sizable and long lasting.

Overall, the industry-level results in Table 12 and the state-level results in Tables 1011, show that deviations of temperature below its historical norms in the U.S. as well as deviations of precipitation from its historical norm are detrimental to long-run state-level and industry-level output growth. When it comes to deviations of temperature above its historical norms, the estimates are negative in the more recent sample for all economic sectors apart from mining, government, and finance, insurance and real estate sectors. In fact $\widehat{\theta}_{\Delta\left(\mathcal{T}_{i t}-\mathcal{T}_{i, t-1}^{*}\right)^{+}}$is positive and statistically significant for government services (at the $10 \%$ level) and finance, insurance and real estate sectors, but most likely this reflects government spending on relief measures and higher insurance premiums in response to climate change.

\footnotetext{
${ }^{25}$ For example, steel production along the coast of Lake Michigan was majorly disrupted during the brutal 2013-14 winter, because frozen Great Lakes meant that cargoes could not be moved via boats as usual.
} 
We acknowledge some resilience building activities in advanced economies, but the evidence from both the cross-country analysis and the U.S. within-country study seems to suggest that while adaptation might have reduced the negative effects in certain sectors, it has not completely offset them at the macro level (see Table 11 and Figure 9). Behrer and Park (2017) note that even the most well-adapted regions in the United States suffer negative production effects from hotter temperatures and Colacito et al. (2019) show that an increase in average summer temperatures will have negative effects on nominal output in various sectors, such as agriculture, construction, retail, services, and wholesale trade.

\section{Concluding Remarks}

Using data on 174 countries over the period 1960 to 2014, and a novel econometric strategy (that differentiates between short-term and long-run effects; accounts for bi-directional feedbacks between economic growth and climate change; and deals with temperature being trended), we showed that persistent changes in climate has long-term negative impacts on economic growth. If temperature deviates from its historical norm by $0.01^{\circ} \mathrm{C}$ annually, longterm income growth will be lower by 0.0543 percentage points per year. Furthermore, in contrast to most of the literature, we illustrated that these negative long-run growth effects are universal, that is they affect all countries, rich or poor, and hot or cold.

We performed a number of counterfactual exercises where we investigated the output effects of annual increases in temperatures under mitigated and unmitigated scenarios during 2015-2100. We showed that keeping the increase in the global average temperature to below 2 degrees Celsius above pre-industrial levels as agreed by 190 parties in Paris in December 2015, will reduce global income by 1.07 percent by 2100. However, an increase in average global temperatures of $0.04^{\circ} \mathrm{C}$ (corresponding to the RCP 8.5 scenario, which assumes higher greenhouse gas emissions in absence of climate change policies) reduces world's real GDP per capita by 7.22 percent by 2100 , with the size of these income effects varying significantly across countries depending on the pace of temperature increases and variability of climate conditions in each country. The estimated global per capita GDP losses under a high-emissions scenario with no policy action (that is RCP 8.5) would almost double if country-specific climate variability were to rise commensurate to temperature increases in each country. Overall, abiding by the Paris Agreement would go a long way in limiting economic losses from climate change across almost all countries.

These effects are somewhat larger than those generally discussed in policy circles. For instance, the integrated assessment models, which have been extensively used to inform climate policy (including by the Obama administration, see Obama 2017) and are the basis

for international negotiations, usually postulate that an increase in temperature only has short-term growth effects (or permanent level effects). However, we showed that persistent 
changes in climate lowers long-term economic growth. We illustrated that while adaptation to climate change could reduce these negative long-run growth effects, it is highly unlikely to offset them entirely. Therefore, our findings call for a more forceful policy response to the threat of climate change, including more ambitious mitigation and adaptation efforts.

We also examined the robustness of our findings, using panel data sets of different economic indicators across 48 U.S. states over the period 1963 to 2016 . Our results provided evidence for the damage climate change causes in the United States using GSP, GSP per capita, labour productivity, and employment as well as output growth in ten economic sectors (such as agriculture, construction, manufacturing, services, retail and wholesale trade). While certain sectors in the U.S. economy might have adapted to higher temperatures, economic activity in the U.S. overall and at the sectoral level continues to be sensitive to deviations of temperature and precipitation from their historical norms.

\section{References}

Agrawala, S., M. Carraro, N. Kingsmill, E. Lanzi, M. Mullan, and G. Prudent-Richard (2011). Private Sector Engagement in Adaptation to Climate Change: Approaches to Managing Climate Risks. OECD Environment Working Papers No 39.

Arguez, A., I. Durre, S. Applequist, R. S. Vose, M. F. Squires, X. Yin, R. R. Heim, and T. W. Owen (2012). NOAA's 1981-2010 U.S. Climate Normals: An Overview. Bulletin of the American Meteorological Society 93(11), 1687-1697.

Barreca, A., K. Clay, O. Deschenes, M. Greenstone, and J. S. Shapiro (2016). Adapting to Climate Change: The Remarkable Decline in the US Temperature-Mortality Relationship over the Twentieth Century. Journal of Political Economy 124(1), 105-159.

Behrer, P. and J. Park (2017). Will We Adapt? Temperature Shocks, Labor and Adaptation to Climate Change. Working Paper.

Binder, M. and M. Pesaran (1999). Stochastic Growth Models and Their Econometric Implications. Journal of Economic Growth 4, 139-183.

Bloesch, J. and F. Gourio (2015). The Effect of Winter Weather on U.S. Economic Activity. Economic Perspectives, Federal Reserve Bank of Chicago 39(1), 1-20.

Brock, W. A. and L. J. Mirman (1972). Optimal Economic Growth and Uncertainty: The Discounted Case. Journal of Economic Theory 4(3), 479 - 513.

Brown, P. T., W. Li, J. H. Jiang, and H. Su (2016). Unforced Surface Air Temperature Variability and Its Contrasting Relationship with the Anomalous TOA Energy Flux at Local and Global Spatial Scales. Journal of Climate 29(3), 925 - 940.

Burke, M. and K. Emerick (2016). Adaptation to Climate Change: Evidence from US Agriculture. American Economic Journal: Economic Policy 8(3), 106-140.

Burke, M., S. M. Hsiang, and E. Miguel (2015). Global Non-Linear Effect of Temperature on Economic Production. Nature 52\%, 235-239. 
Burke, M. and V. Tanutama (2019). Climatic Constraints on Aggregate Economic Output. Working Paper 25779, National Bureau of Economic Research Working Paper 25779.

Cachon, G. P., S. Gallino, and M. Olivares (2012). Severe Weather and Automobile Assembly Productivity. Columbia Business School Research Paper No. 12/37.

Cashin, P., K. Mohaddes, and M. Raissi (2017). Fair Weather or Foul? The Macroeconomic Effects of El Niño. Journal of International Economics 106, 37-54.

Chudik, A., K. Mohaddes, M. H. Pesaran, and M. Raissi (2013). Debt, Inflation and Growth: Robust Estimation of Long-Run Effects in Dynamic Panel Data Models. Federal Reserve Bank of Dallas, Globalization and Monetary Policy Institute Working Paper No. 162.

Chudik, A., K. Mohaddes, M. H. Pesaran, and M. Raissi (2016). Long-Run Effects in Large Heterogeneous Panel Data Models with Cross-Sectionally Correlated Errors. In R. C. Hill, G. Gonzalez-Rivera, and T.H. Lee (Eds.), Advances in Econometrics (Volume 36): Essays in Honor of Aman Ullah, Chapter 4, pp. 85-135. Emerald Publishing.

Chudik, A., K. Mohaddes, M. H. Pesaran, and M. Raissi (2017). Is There a Debt-threshold Effect on Output Growth? Review of Economics and Statistics 99(1), 135-150.

Chudik, A., M. H. Pesaran, and J.-C. Yang (2018). Half-Panel Jackknife Fixed Effects Estimation of Panels with Weakly Exogenous Regressors. Journal of Applied Econometrics 33(6), 816-836.

CIESIN (2016). Gridded Population of the World, Version 4 (GPWv4): Population Density. Columbia University, Palisades, NY: NASA Socioeconomic Data and Applications Center (SEDAC).

Colacito, R., B. Hoffmann, and T. Phan (2019). Temperature and Growth: A Panel Analysis of the United States. Journal of Money, Credit and Banking 51, 313-368.

Dell, M., B. F. Jones, and B. A. Olken (2009). Temperature and Income: Reconciling New Cross-Sectional and Panel Estimates. American Economic Review 99(2), 198-204.

Dell, M., B. F. Jones, and B. A. Olken (2012). Temperature Shocks and Economic Growth: Evidence from the Last Half Century. American Economic Journal: Macroeconomics 4(3), 66-95.

Dell, M., B. F. Jones, and B. A. Olken (2014). What Do We Learn from the Weather? The New ClimateEconomy Literature. Journal of Economic Literature 52(3), 740-798.

Deryugina, T. and S. M. Hsiang (2014). Does the Environment Still Matter? Daily Temperature and Income in the United States. NBER Working Paper No. 20750.

Dhyne, E., C. Fuss, M. H. Pesaran, and P. Sevestre (2011). Lumpy Price Adjustments: A Microeconometric Analysis. Journal of Business 83 Economic Statistics 29(4), 529-540.

Donaldson, J. B. and R. Mehra (1983). Stochastic Growth with Correlated Production Shocks. Journal of Economic Theory 29(2), $282-312$.

Gallup, J. L., J. D. Sachs, and A. D. Mellinger (1999). Geography and Economic Development. International Regional Science Review 22(2), 179-232.

Heal, G. and J. Park (2016). Reflections - Temperature Stress and the Direct Impact of Climate Change: A Review of an Emerging Literature. Review of Environmental Economics and Policy 10(2), 347-362.

Heutel, G., N. Miller, and D. Molitor (2016). Adaptation and the Mortality Effects of Temperature across US Climate Regions. NBER Working Paper No. 23271. 
Hsiang, S. M. (2016). Climate Econometrics. Annual Review of Resource Economics 8(1).

International Monetary Fund, . (2017). The Effects of Weather Shocks on Economic Activity: How Can Low-income Countries Cope? World Economic Outlook Chapter 3, 117-183.

IPCC, . (2013). Climate Change 2013: The Physical Science Basis. Contribution of Working Group I to the Fifth Assessment Report of the Intergovernmental Panel on Climate Change. Cambridge University Press, Cambridge.

IPCC, . (2014). Climate Change 2014: Impacts, Adaptation and Vulnerability. Contribution of Working Group II to the Fifth Assessment Report of the Intergovernmental Panel on Climate Change, Volume 1. Cambridge University Press, Cambridge.

Jones, B. F. and B. A. Olken (2010). Climate Shocks and Exports. American Economic Review 100(2), $454-59$.

Kort, J. R. (2001). The North American Industry Classification System in BEA's Economic Accounts. Survey of Current Business.

Marimon, R. (1989). Stochastic Turnpike Property and Stationary Equilibrium. Journal of Economic Theory $47(2), 282-306$.

Matsuura, K. and C. J. Willmott (2015). Terrestrial Air Temperature and Precipitation: Monthly and Annual Time Series (1900 - 2014), v 4.01.

Mejia, S., M. Mrkaic, N. Novta, E. Pugacheva, and P. Topalova (2018). The Effects of Weather Shocks on Economic Activity: What are the Channels of Impact? IMF Working Paper WP/18/144.

Merton, R. C. (1975). An Asymptotic Theory of Growth Under Uncertainty. The Review of Economic Studies 42(3), 375-393.

Mitchell, J. F. B., K. J. Karoly, G. Hegerl, F. W. Zwiers, M. R. Allen, J. Marengo, and . others (2001). Detection of Climate Change and Attribution of Causes. In J. T. Houghton (Ed.), Climate Change 2001: The Scientific Basis. Contribution of Working Group I to the Third Assessment Report of the Intergovernmental Panel on Climate Change. Cambridge University Press, New York.

Nickell, S. (1981). Biases in Dynamic Models with Fixed Effects. Econometrica 49(6), 1417-1426.

Nordhaus, W. D. (1992). The "DICE" Model: Background and Structure of a Dynamic Integrated ClimateEconomy Model of the Economics of Global Warming. Technical Report 1009, Cowles Foundation Discussion Paper No. 1009.

Nordhaus, W. D. (2006). Geography and Macroeconomics: New Data and New Findings. Proceedings of the National Academy of Sciences of the United States of America 103(10), 3510-3517.

Nordhaus, W. D. (2017). Revisiting the Social Cost of Carbon. Proceedings of the National Academy of Sciences of the United States of America 114(7), 1518-1523.

Obama, B. (2017). The Irreversible Momentum of Clean Energy. Science.

Pacala, S. and R. Socolow (2004). Stabilization Wedges: Solving the Climate Problem for the Next 50 Years with Current Technologies. Science 305(5686), 968-972.

Pesaran, M. H. (1997). The Role of Economic Theory in Modelling the Long Run. Economic Journal 107, 178-191. 
Pesaran, M. H. and Y. Shin (1999). An Autoregressive Distributed Lag Modelling Approach to Cointegration Analysis. In S. Strom (Ed.), Econometrics and Economic Theory in 20th Century: The Ragnar Frisch Centennial Symposium, Chapter 11, pp. 371-413. Cambridge: Cambridge University Press.

Pesaran, M. H. and R. Smith (1995). Estimating Long-run Relationships from Dynamic Heterogeneous Panels. Journal of Econometrics 68(1), 79-113.

Phillips, P. C. B., T. Leirvik, and T. Storelvmo (2019). Econometric Estimates of EarthâẮ́s Transient Climate Sensitivity. Journal of Econometrics, forthcoming.

Sachs, J. D. and A. M. Warner (1997). Sources of Slow Growth in African Economies. Journal of African Economies 6(3), 335-376.

Stern, N. (2007). The Economics of Climate Change: The Stern Review. Cambridge University Press, Cambridge.

Swain, D. L., B. Langenbrunner, J. D. Neelin, and A. Hall (2018). Increasing Precipitation Volatility in Twenty-first-century California. Nature Climate Change 8(5), 427-433.

Tol, R. S. J. (2009). The Economic Effects of Climate Change. Journal of Economic Perspectives 23(2), $29-51$.

Tol, R. S. J. (2014, May). Correction and Update: The Economic Effects of Climate Change. Journal of Economic Perspectives 28(2), 221-26.

Vose, R. S., S. Applequist, M. Squires, I. Durre, M. J. Menne, C. N. Williams, C. Fenimore, K. Gleason, and D. Arndt (2014). Improved Historical Temperature and Precipitation Time Series for U.S. Climate Divisions. Journal of Applied Meteorology and Climatology 53(5), 1232-1251.

Weitzman, M. L. (2009, February). On Modeling and Interpreting the Economics of Catastrophic Climate Change. The Review of Economics and Statistics 91(1), 1-19. 


\section{A Additional Results}

Figure A.1: Global Land-Surface Air and Sea-Surface Water Temperatures (Degrees Celsius, $1960=0$ )
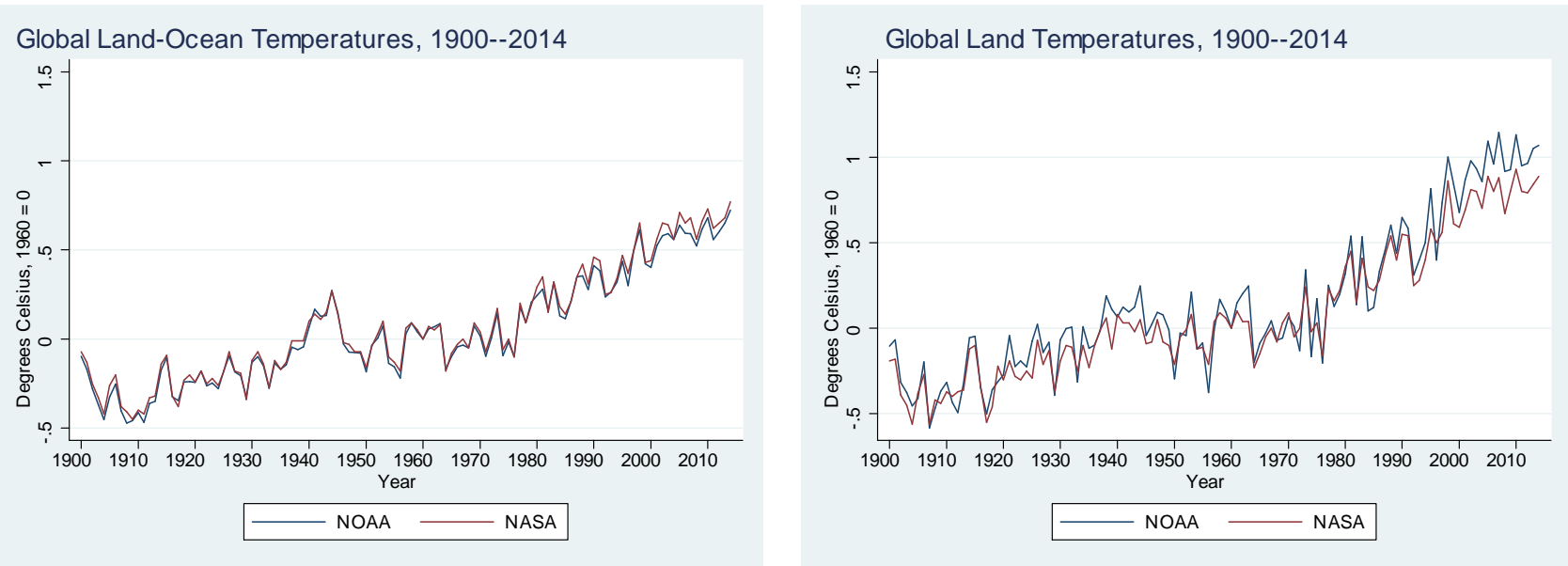

Notes: The left panel shows the global land-surface air and sea-surface water temperatures, and the right panel shows the global land-surface air temperatures, both over the 1900-2014 period. The blue lines show the temperatures observed by the National Centers for Environmental Information (NCEI) at National Oceanic and Atmospheric Administration (NOAA); and the broken red lines show the temperatures observed by the Goddard Institute for Space Studies (GISS) at the National Aeronautics and Space Administration (NASA). The temperatures in 1960 are standardised to zero. 
Table A.1: Individual Country Estimates of the Average Yearly Rise in Temperature Over the Period 1900-2014

\begin{tabular}{|c|c|c|c|c|c|}
\hline Country & $\widehat{b}_{\mathcal{T} i}$ & Country & $\widehat{b}_{\mathcal{T} i}$ & Country & $\widehat{b}_{\mathcal{T} i}$ \\
\hline Afghanistan & $0.0136^{* * *}$ & Georgia & $0.0044^{* *}$ & Oman & $0.0047^{* * *}$ \\
\hline Albania & $0.0036^{* *}$ & Germany & $0.0063^{* * *}$ & Pakistan & $0.0043^{* * *}$ \\
\hline Algeria & $0.0067 * * *$ & Ghana & $0.0035^{* * *}$ & Panama & $0.0060 * * *$ \\
\hline Angola & $0.0099 * * *$ & Greece & -0.0008 & Papua New Guinea & $0.0026^{* *}$ \\
\hline Argentina & $0.0038 * * *$ & Greenland & $0.0110^{* * *}$ & Paraguay & $0.0032^{* *}$ \\
\hline Armenia & $0.0056^{* *}$ & Guatemala & $0.0065^{* * *}$ & Peru & $0.0039 * * *$ \\
\hline Australia & $0.0041^{* * *}$ & Guinea & $0.0028 * * *$ & Philippines & $0.0048 * * *$ \\
\hline Austria & $0.0056^{* * *}$ & Guinea-Bissau & $0.0051^{* * *}$ & Poland & $0.0063^{* * *}$ \\
\hline Azerbaijan & $0.0064 * * *$ & Guyana & $0.0051^{* * *}$ & Portugal & $0.0051 * * *$ \\
\hline Bahamas & $0.0048 * * *$ & Haiti & $0.0190 * * *$ & Puerto Rico & $0.0023^{* * *}$ \\
\hline Bangladesh & $0.0033^{* * *}$ & Honduras & $0.0086 * * *$ & Qatar & $0.0125^{* * *}$ \\
\hline Belarus & $0.0094^{* * *}$ & Hungary & $0.0033^{*}$ & Romania & $0.0043^{* *}$ \\
\hline Belgium & $0.0057 * * *$ & Iceland & $0.0034^{*}$ & Russian Federation & $0.0111^{* * *}$ \\
\hline Belize & $0.0041 * * *$ & India & $0.0029 * * *$ & Rwanda & $0.0050 * * *$ \\
\hline Benin & $0.0032 * * *$ & Indonesia & $0.0025 * * *$ & Saint Vincent and the Grenadines & $0.0050 * * *$ \\
\hline Bhutan & $0.0055 * * *$ & Iran & $0.0072^{* * *}$ & Samoa & $0.0050 * * *$ \\
\hline Bolivia & 0.0011 & Iraq & $0.0083^{* * *}$ & Sao Tome and Principe & $0.0071^{* * *}$ \\
\hline Bosnia and Herzegovina & $0.0106^{* * *}$ & Ireland & $0.0057^{* * *}$ & Saudi Arabia & $0.0070 * * *$ \\
\hline Botswana & $0.0098 * * *$ & Israel & $0.0047^{* * *}$ & Senegal & $0.0074^{* * *}$ \\
\hline Brazil & $0.0061 * * *$ & Italy & $0.0045^{* * *}$ & Serbia & $0.0038 * *$ \\
\hline Brunei Darussalam & 0.0002 & Jamaica & $0.0134^{* * *}$ & Sierra Leone & $0.0031^{* * *}$ \\
\hline Bulgaria & 0.0012 & Japan & $0.0099 * * *$ & Slovakia & $0.0061^{* * *}$ \\
\hline Burkina Faso & $0.0045 * * *$ & Jordan & $0.0032^{*}$ & Slovenia & $0.0062^{* * *}$ \\
\hline Burundi & $0.0075^{* * *}$ & Kazakhstan & $0.0122^{* * *}$ & Solomon Islands & $0.0020^{* *}$ \\
\hline Cabo Verde & $0.0039 * * *$ & Kenya & $0.0026^{* * *}$ & Somalia & $0.0071^{* * *}$ \\
\hline Cambodia & $0.0045 * * *$ & Kuwait & $0.0091^{* * *}$ & South Africa & $0.0051^{* * *}$ \\
\hline Cameroon & $0.0039 * * *$ & Kyrgyzstan & $0.0146 * * *$ & South Korea & $0.0101^{* * *}$ \\
\hline Canada & $0.0110 * * *$ & Laos & $0.0028 * * *$ & South Sudan & $0.0102^{* * *}$ \\
\hline Central African Republic & $0.0020^{* *}$ & Latvia & $0.0094^{* * *}$ & Spain & $0.0080 * * *$ \\
\hline Chad & $0.0048 * * *$ & Lebanon & $0.0030^{*}$ & Sri Lanka & $0.0050 * * *$ \\
\hline Chile & $0.0017^{* *}$ & Lesotho & $0.0026^{* *}$ & Sudan & $0.0102 * * *$ \\
\hline China & $0.0064^{* * *}$ & Liberia & $0.0018^{* *}$ & Suriname & 0.0012 \\
\hline Colombia & $0.0098 * * *$ & Libya & $0.0076^{* * *}$ & Swaziland & $0.0103^{* * *}$ \\
\hline Comoros & $0.0053^{* * *}$ & Lithuania & $0.0080^{* * *}$ & Sweden & $0.0064^{* *}$ \\
\hline Congo & $0.0064^{* * *}$ & Luxembourg & $0.0050^{* * *}$ & Switzerland & $0.0046^{* * *}$ \\
\hline Congo DRC & $0.0051 * * *$ & Macedonia & -0.0000 & Syria & $0.0055^{* * *}$ \\
\hline Costa Rica & $0.0031^{*}$ & Madagascar & $0.0018^{*}$ & Tajikistan & $0.0099 * * *$ \\
\hline Côte d'Ivoire & 0.0013 & Malawi & $0.0162^{* * *}$ & Tanzania & $0.0026^{* * *}$ \\
\hline Croatia & $0.0039^{* *}$ & Malaysia & $0.0014^{*}$ & Thailand & 0.0012 \\
\hline Cuba & $0.0021 * * *$ & Mali & $0.0057 * * *$ & Togo & $0.0023^{* *}$ \\
\hline Cyprus & $0.0080 * * *$ & Mauritania & $0.0083^{* * *}$ & Trinidad and Tobago & $0.0035^{* *}$ \\
\hline Czech Republic & $0.0040 * *$ & Mauritius & $0.0053^{* * *}$ & Tunisia & $0.0087 * * *$ \\
\hline Denmark & $0.0044^{* *}$ & Mexico & $0.0060^{* * *}$ & Turkey & $0.0045^{* *}$ \\
\hline Djibouti & $0.0057 * * *$ & Moldova & $0.0089^{* * *}$ & Turkmenistan & $0.0092^{* * *}$ \\
\hline Dominican Republic & $0.0111^{* * *}$ & Mongolia & $0.0111^{* * *}$ & Uganda & $0.0048 * * *$ \\
\hline Ecuador & $0.0091^{* * *}$ & Montenegro & $0.0070 * * *$ & Ukraine & $0.0089^{* * *}$ \\
\hline Egypt & $0.0056 * * *$ & Morocco & $0.0041^{* * *}$ & United Arab Emirates & $0.0055 * * *$ \\
\hline El Salvador & $0.0050^{* *}$ & Mozambique & $0.0134^{* * *}$ & United Kingdom & $0.0038 * * *$ \\
\hline Equatorial Guinea & $0.0093^{* * *}$ & Myanmar & $0.0051^{* * *}$ & United States & $0.0036^{* * *}$ \\
\hline Eritrea & $0.0046^{* * *}$ & Namibia & $0.0093^{* * *}$ & Uruguay & $0.0064^{* * *}$ \\
\hline Estonia & $0.0093^{* * *}$ & Nepal & $0.0039 * * *$ & US Virgin Islands & $0.0069 * * *$ \\
\hline Ethiopia & $0.0049 * * *$ & Netherlands & $0.0043^{* *}$ & Uzbekistan & $0.0096^{* * *}$ \\
\hline Fiji & $0.0045^{* * *}$ & New Caledonia & 0.0006 & Vanuatu & $0.0043^{* * *}$ \\
\hline Finland & $0.0070 * *$ & New Zealand & $0.0043^{* * *}$ & Venezuela & $0.0152 * * *$ \\
\hline France & $0.0069^{* * *}$ & Nicaragua & $0.0086^{* * *}$ & Vietnam & $0.0015^{*}$ \\
\hline French Polynesia & $0.0062^{* * *}$ & Niger & 0.0009 & Yemen & $0.0154^{* * *}$ \\
\hline Gabon & $0.0074^{* * *}$ & Nigeria & $0.0044^{* * *}$ & Zambia & $0.0033^{* *}$ \\
\hline Gambia & $0.0046^{* * *}$ & Norway & $0.0054^{* *}$ & Zimbabwe & $0.0066 * * *$ \\
\hline
\end{tabular}

Notes: $\widehat{b}_{\mathcal{T} i}$ is the OLS estimate of $b_{\mathcal{T} i}$ in the country-specific regressions $\mathcal{T}_{i t}=a_{\mathcal{T} i}+b_{\mathcal{T} i} t+v_{\mathcal{T}, i t}$, where $\mathcal{T}_{i t}$ denotes the population-weighted average temperature $\left({ }^{\circ} \mathrm{C}\right)$. Asterisks indicate statistical significance at the $1 \%(* * *), 5 \%(* *)$ and $10 \%(*)$ levels. 
Table A.2: Percent Loss in GDP per capita by 2030, 2050, and 2100 under the RCP 2.6 and RCP 8.5 Scenarios

\begin{tabular}{|c|c|c|c|c|c|c|c|c|c|c|c|}
\hline & \multicolumn{5}{|c|}{ Key Variables in Equation (31) } & \multicolumn{6}{|c|}{ Percent Loss in GDP per capita } \\
\hline & \multirow{2}{*}{$\overline{\mathcal{T}} i$} & \multirow{2}{*}{$\widehat{b}_{\mathcal{T} i}^{0}$} & \multirow{2}{*}{$\widehat{\sigma}_{\mathcal{T} i}$} & \multicolumn{2}{|c|}{$d_{i}$} & \multicolumn{3}{|c|}{ RCP 2.6 Scenario } & \multicolumn{3}{|c|}{ RCP 8.5 Scenario } \\
\hline & & & & RCP 2.6 & RCP 8.5 & 2030 & 2050 & 2100 & 2030 & 2050 & 2100 \\
\hline Afghanistan & 12.35 & 0.039 & 0.61 & -0.0005 & 0.0009 & -0.35 & -0.78 & -1.18 & 0.70 & 1.96 & 5.54 \\
\hline Albania & 12.94 & 0.024 & 0.48 & 0.0002 & 0.0014 & 0.15 & 0.42 & 1.22 & 1.03 & 3.13 & 8.86 \\
\hline Algeria & 23.02 & 0.029 & 0.41 & -0.0009 & 0.0004 & -0.59 & -0.94 & 1.33 & 0.34 & 0.92 & 2.56 \\
\hline Angola & 21.90 & 0.019 & 0.34 & -0.0002 & 0.0009 & -0.14 & -0.31 & -0.52 & 0.71 & 2.09 & 5.84 \\
\hline Argentina & 14.14 & 0.007 & 0.29 & 0.0005 & 0.0013 & 0.20 & 0.71 & 2.50 & 0.79 & 2.78 & 8.17 \\
\hline Armenia & 7.82 & 0.014 & 0.82 & 0.0000 & 0.0012 & -0.01 & -0.02 & -0.05 & 0.42 & 1.57 & 6.03 \\
\hline Australia & 21.69 & 0.009 & 0.35 & 0.0002 & 0.0011 & 0.06 & 0.17 & 0.56 & 0.64 & 2.25 & 6.93 \\
\hline Austria & 6.94 & 0.017 & 0.54 & 0.0001 & 0.0013 & 0.06 & 0.16 & 0.46 & 0.71 & 2.39 & 7.58 \\
\hline Azerbaijan & 12.99 & 0.019 & 0.65 & -0.0008 & 0.0004 & -0.21 & -0.23 & 1.25 & 0.18 & 0.54 & 1.80 \\
\hline Bahamas & 25.59 & 0.020 & 0.28 & -0.0008 & -0.0001 & -0.50 & -0.52 & 2.34 & -0.08 & -0.20 & -0.44 \\
\hline Bangladesh & 25.55 & -0.001 & 0.26 & 0.0005 & 0.0014 & 0.06 & 0.42 & 2.15 & 0.55 & 2.68 & 8.59 \\
\hline Belarus & 6.21 & 0.032 & 0.83 & -0.0003 & 0.0009 & -0.12 & -0.28 & -0.54 & 0.52 & 1.58 & 5.04 \\
\hline Belgium & 9.45 & 0.026 & 0.64 & -0.0005 & 0.0004 & -0.23 & -0.47 & -0.29 & 0.25 & 0.71 & 2.17 \\
\hline Belize & 25.54 & 0.011 & 0.27 & -0.0001 & 0.0008 & -0.04 & -0.09 & -0.18 & 0.55 & 1.75 & 5.10 \\
\hline Benin & 27.38 & 0.018 & 0.25 & -0.0003 & 0.0007 & -0.22 & -0.48 & -0.50 & 0.59 & 1.65 & 4.43 \\
\hline Bhutan & 7.84 & 0.014 & 0.36 & 0.0016 & 0.0026 & 1.18 & 3.70 & 10.33 & 2.23 & 6.64 & 17.76 \\
\hline Bolivia & 21.47 & 0.000 & 0.33 & 0.0003 & 0.0015 & 0.02 & 0.15 & 0.90 & 0.53 & 2.64 & 8.82 \\
\hline Bosnia and Herzegovina & 8.96 & 0.037 & 0.58 & 0.0004 & 0.0015 & 0.27 & 0.74 & 2.07 & 1.24 & 3.56 & 9.75 \\
\hline Botswana & 21.96 & 0.026 & 0.62 & -0.0003 & 0.0011 & -0.13 & -0.30 & -0.53 & 0.67 & 2.07 & 6.37 \\
\hline Brazil & 24.45 & 0.016 & 0.24 & 0.0000 & 0.0011 & 0.02 & 0.06 & 0.15 & 0.99 & 2.79 & 7.35 \\
\hline Brunei Darussalam & 26.84 & 0.010 & 0.27 & -0.0005 & 0.0003 & -0.15 & -0.07 & 1.41 & 0.16 & 0.50 & 1.65 \\
\hline Bulgaria & 9.97 & 0.012 & 0.51 & 0.0009 & 0.0021 & 0.39 & 1.39 & 4.84 & 1.24 & 4.41 & 13.16 \\
\hline Burkina Faso & 28.40 & 0.019 & 0.29 & -0.0004 & 0.0007 & -0.26 & -0.53 & -0.26 & 0.60 & 1.72 & 4.71 \\
\hline Burundi & 20.28 & 0.019 & 0.43 & 0.0001 & 0.0012 & 0.08 & 0.21 & 0.59 & 0.81 & 2.56 & 7.46 \\
\hline Cabo Verde & 21.02 & 0.018 & 0.46 & 0.0002 & 0.0009 & 0.10 & 0.27 & 0.80 & 0.57 & 1.80 & 5.54 \\
\hline Cambodia & 26.95 & 0.017 & 0.29 & -0.0007 & 0.0001 & -0.36 & -0.38 & 1.84 & 0.10 & 0.26 & 0.74 \\
\hline Cameroon & 24.43 & 0.012 & 0.29 & -0.0003 & 0.0006 & -0.13 & -0.23 & 0.08 & 0.39 & 1.23 & 3.75 \\
\hline Canada & -6.20 & 0.030 & 0.77 & 0.0004 & 0.0021 & 0.20 & 0.56 & 1.68 & 1.37 & 4.40 & 13.08 \\
\hline Central African Republic & 25.30 & 0.010 & 0.32 & -0.0001 & 0.0008 & -0.05 & -0.11 & -0.15 & 0.49 & 1.65 & 5.12 \\
\hline Chad & 27.57 & 0.018 & 0.46 & -0.0009 & 0.0002 & -0.31 & -0.18 & 2.65 & 0.11 & 0.31 & 0.92 \\
\hline Chile & 8.16 & 0.010 & 0.31 & 0.0008 & 0.0017 & 0.50 & 1.68 & 5.18 & 1.23 & 3.97 & 11.08 \\
\hline China & 6.68 & 0.023 & 0.30 & -0.0006 & 0.0007 & -0.45 & -0.80 & 0.45 & 0.58 & 1.62 & 4.35 \\
\hline Colombia & 24.65 & 0.006 & 0.28 & 0.0000 & 0.0010 & 0.00 & -0.01 & -0.03 & 0.52 & 1.93 & 6.02 \\
\hline Comoros & 25.08 & 0.006 & 0.40 & 0.0004 & 0.0012 & 0.11 & 0.39 & 1.57 & 0.49 & 1.97 & 6.71 \\
\hline Congo & 24.63 & 0.015 & 0.25 & -0.0002 & 0.0008 & -0.12 & -0.27 & -0.40 & 0.62 & 1.81 & 4.99 \\
\hline Congo DRC & 23.92 & 0.015 & 0.26 & -0.0001 & 0.0009 & -0.09 & -0.22 & -0.41 & 0.73 & 2.13 & 5.81 \\
\hline Costa Rica & 23.41 & 0.017 & 0.35 & 0.0007 & 0.0015 & 0.49 & 1.47 & 4.33 & 1.20 & 3.64 & 9.95 \\
\hline Côte d'Ivoire & 26.35 & 0.013 & 0.27 & -0.0003 & 0.0006 & -0.15 & -0.29 & -0.09 & 0.45 & 1.37 & 3.96 \\
\hline Croatia & 11.27 & 0.025 & 0.58 & -0.0002 & 0.0009 & -0.10 & -0.24 & -0.46 & 0.59 & 1.79 & 5.52 \\
\hline Cuba & 25.39 & -0.001 & 0.28 & 0.0005 & 0.0013 & 0.06 & 0.44 & 2.26 & 0.44 & 2.28 & 7.68 \\
\hline Cyprus & 18.67 & 0.015 & 0.48 & -0.0001 & 0.0009 & -0.02 & -0.05 & -0.12 & 0.50 & 1.66 & 5.37 \\
\hline Czech Republic & 7.47 & 0.019 & 0.64 & -0.0002 & 0.0009 & -0.07 & -0.16 & -0.28 & 0.41 & 1.33 & 4.52 \\
\hline Denmark & 7.90 & 0.019 & 0.74 & -0.0005 & 0.0004 & -0.13 & -0.24 & -0.02 & 0.16 & 0.49 & 1.63 \\
\hline Djibouti & 28.00 & 0.013 & 0.35 & -0.0009 & 0.0001 & -0.25 & 0.17 & 3.62 & 0.03 & 0.08 & 0.22 \\
\hline Dominican Republic & 25.19 & 0.015 & 0.37 & -0.0002 & 0.0006 & -0.08 & -0.18 & -0.31 & 0.35 & 1.06 & 3.31 \\
\hline Ecuador & 22.32 & -0.003 & 0.39 & 0.0005 & 0.0014 & 0.00 & 0.19 & 1.49 & 0.27 & 1.94 & 7.70 \\
\hline Egypt & 22.20 & 0.027 & 0.44 & -0.0004 & 0.0008 & -0.29 & -0.61 & -0.69 & 0.63 & 1.79 & 5.06 \\
\hline El Salvador & 24.59 & 0.032 & 0.37 & -0.0001 & 0.0008 & -0.05 & -0.12 & -0.31 & 0.76 & 2.08 & 5.50 \\
\hline Equatorial Guinea & 24.32 & 0.027 & 0.45 & -0.0007 & 0.0002 & -0.40 & -0.76 & -0.02 & 0.14 & 0.36 & 1.00 \\
\hline Eritrea & 25.95 & 0.018 & 0.50 & -0.0002 & 0.0009 & -0.07 & -0.16 & -0.29 & 0.53 & 1.70 & 5.42 \\
\hline Estonia & 5.22 & 0.033 & 0.89 & -0.0007 & 0.0005 & -0.27 & -0.54 & -0.33 & 0.28 & 0.80 & 2.47 \\
\hline Ethiopia & 22.58 & 0.022 & 0.25 & -0.0004 & 0.0006 & -0.30 & -0.66 & -0.72 & 0.56 & 1.52 & 4.00 \\
\hline Fiji & 24.45 & 0.011 & 0.27 & 0.0004 & 0.0011 & 0.25 & 0.77 & 2.39 & 0.81 & 2.54 & 7.12 \\
\hline Finland & 1.47 & 0.030 & 0.96 & -0.0011 & 0.0003 & -0.35 & -0.46 & 1.48 & 0.12 & 0.34 & 1.02 \\
\hline France & 10.55 & 0.022 & 0.50 & -0.0001 & 0.0010 & -0.03 & -0.07 & -0.17 & 0.62 & 1.92 & 5.82 \\
\hline French Polynesia & 23.83 & 0.024 & 0.30 & 0.0005 & 0.0011 & 0.43 & 1.17 & 3.16 & 1.03 & 2.83 & 7.43 \\
\hline Gabon & 24.44 & 0.018 & 0.32 & -0.0002 & 0.0007 & -0.10 & -0.24 & -0.45 & 0.55 & 1.61 & 4.56 \\
\hline Gambia & 26.43 & 0.023 & 0.32 & 0.0002 & 0.0012 & 0.20 & 0.53 & 1.44 & 1.15 & 3.20 & 8.43 \\
\hline
\end{tabular}

Notes: We consider persistent increases in temperatures based on the RCP 2.6 and RCP 8.5 scenarios. The losses are based on $\Delta_{i h}\left(d_{i}\right)$, see equation (31), with $h=16,36$, and 86 (corresponding to the year 2030, 2050, and 2100, respectively) and $m=30$. 
Table A.2: Percent Loss in GDP per capita by 2030, 2050, and 2100 under the RCP 2.6 and RCP 8.5 Scenarios (continued)

\begin{tabular}{|c|c|c|c|c|c|c|c|c|c|c|c|}
\hline & \multicolumn{5}{|c|}{ Key Variables in Equation (31) } & \multicolumn{6}{|c|}{ Percent Loss in GDP per capita } \\
\hline & \multirow[t]{2}{*}{$\overline{\mathcal{T}} i$} & \multirow{2}{*}{$\widehat{b}_{\mathcal{T} i}^{0}$} & \multirow{2}{*}{$\widehat{\sigma}_{\mathcal{T} i}$} & \multicolumn{2}{|c|}{$d_{i}$} & \multicolumn{3}{|c|}{ RCP 2.6 Scenario } & \multicolumn{3}{|c|}{ RCP 8.5 Scenario } \\
\hline & & & & RCP 2.6 & RCP 8.5 & 2030 & 2050 & 2100 & 2030 & 2050 & 2100 \\
\hline Georgia & 8.73 & 0.016 & 0.67 & -0.0004 & 0.0008 & -0.09 & -0.18 & -0.05 & 0.33 & 1.12 & 4.01 \\
\hline Germany & 8.47 & 0.023 & 0.65 & -0.0006 & 0.0004 & -0.22 & -0.39 & 0.08 & 0.21 & 0.61 & 1.92 \\
\hline Ghana & 27.14 & 0.018 & 0.24 & -0.0004 & 0.0005 & -0.31 & -0.61 & -0.10 & 0.43 & 1.18 & 3.17 \\
\hline Greece & 13.82 & 0.011 & 0.49 & 0.0008 & 0.0019 & 0.35 & 1.26 & 4.45 & 1.12 & 4.04 & 12.21 \\
\hline Greenland & -19.71 & 0.038 & 0.73 & -0.0008 & 0.0007 & -0.42 & -0.85 & -0.52 & 0.49 & 1.39 & 4.10 \\
\hline Guatemala & 23.56 & 0.028 & 0.28 & -0.0002 & 0.0008 & -0.16 & -0.40 & -0.89 & 0.80 & 2.12 & 5.48 \\
\hline Guinea & 25.53 & 0.017 & 0.25 & -0.0002 & 0.0008 & -0.12 & -0.28 & -0.50 & 0.71 & 2.03 & 5.45 \\
\hline Guinea-Bissau & 26.74 & 0.024 & 0.28 & -0.0002 & 0.0007 & -0.20 & -0.47 & -0.88 & 0.70 & 1.91 & 5.02 \\
\hline Guyana & 25.98 & 0.003 & 0.33 & 0.0003 & 0.0013 & 0.07 & 0.27 & 1.21 & 0.56 & 2.42 & 7.89 \\
\hline Haiti & 24.55 & 0.016 & 0.53 & 0.0001 & 0.0009 & 0.04 & 0.10 & 0.27 & 0.45 & 1.49 & 4.95 \\
\hline Honduras & 25.27 & 0.021 & 0.35 & -0.0003 & 0.0006 & -0.19 & -0.42 & -0.57 & 0.46 & 1.33 & 3.78 \\
\hline Hungary & 10.33 & 0.016 & 0.64 & -0.0002 & 0.0009 & -0.07 & -0.15 & -0.20 & 0.41 & 1.41 & 4.96 \\
\hline Iceland & 1.10 & 0.021 & 0.65 & -0.0007 & 0.0003 & -0.23 & -0.32 & 0.83 & 0.12 & 0.33 & 1.00 \\
\hline India & 23.99 & 0.009 & 0.25 & 0.0004 & 0.0015 & 0.26 & 0.81 & 2.57 & 1.16 & 3.62 & 9.90 \\
\hline Indonesia & 25.40 & 0.005 & 0.15 & 0.0003 & 0.0011 & 0.19 & 0.61 & 1.92 & 0.91 & 2.79 & 7.51 \\
\hline Iran & 17.33 & 0.023 & 0.52 & -0.0001 & 0.0012 & -0.04 & -0.10 & -0.23 & 0.83 & 2.59 & 7.65 \\
\hline Iraq & 22.11 & 0.024 & 0.67 & -0.0008 & 0.0006 & -0.28 & -0.44 & 0.73 & 0.29 & 0.86 & 2.74 \\
\hline Ireland & 9.34 & 0.015 & 0.41 & 0.0001 & 0.0008 & 0.03 & 0.09 & 0.26 & 0.46 & 1.47 & 4.62 \\
\hline Israel & 20.31 & 0.017 & 0.55 & -0.0004 & 0.0007 & -0.12 & -0.24 & -0.08 & 0.36 & 1.15 & 3.87 \\
\hline Italy & 12.21 & 0.028 & 0.43 & 0.0000 & 0.0011 & 0.01 & 0.02 & 0.05 & 0.89 & 2.56 & 7.01 \\
\hline Jamaica & 25.18 & 0.020 & 0.35 & 0.0000 & 0.0007 & 0.01 & 0.04 & 0.09 & 0.59 & 1.71 & 4.80 \\
\hline Japan & 11.18 & 0.013 & 0.40 & 0.0006 & 0.0017 & 0.33 & 1.06 & 3.47 & 1.12 & 3.72 & 10.70 \\
\hline Jordan & 18.56 & 0.015 & 0.62 & 0.0002 & 0.0015 & 0.08 & 0.22 & 0.70 & 0.72 & 2.61 & 8.69 \\
\hline Kazakhstan & 6.00 & 0.024 & 0.80 & 0.0010 & 0.0023 & 0.46 & 1.48 & 5.02 & 1.35 & 4.65 & 14.33 \\
\hline Kenya & 24.46 & 0.018 & 0.31 & -0.0005 & 0.0004 & -0.29 & -0.48 & 0.50 & 0.29 & 0.82 & 2.39 \\
\hline Kuwait & 25.61 & 0.025 & 0.54 & -0.0008 & 0.0006 & -0.35 & -0.58 & 0.60 & 0.39 & 1.14 & 3.46 \\
\hline Kyrgyzstan & 1.75 & 0.028 & 0.52 & 0.0003 & 0.0017 & 0.18 & 0.48 & 1.36 & 1.31 & 3.91 & 10.85 \\
\hline Laos & 23.20 & 0.009 & 0.39 & -0.0004 & 0.0005 & -0.09 & -0.07 & 0.78 & 0.19 & 0.65 & 2.34 \\
\hline Latvia & 5.82 & 0.030 & 0.85 & -0.0004 & 0.0007 & -0.18 & -0.40 & -0.52 & 0.36 & 1.08 & 3.46 \\
\hline Lebanon & 15.19 & 0.025 & 0.59 & 0.0009 & 0.0019 & 0.53 & 1.63 & 5.06 & 1.36 & 4.30 & 12.35 \\
\hline Lesotho & 11.75 & 0.010 & 0.46 & 0.0008 & 0.0020 & 0.36 & 1.30 & 4.61 & 1.16 & 4.22 & 12.60 \\
\hline Liberia & 25.66 & 0.009 & 0.22 & 0.0001 & 0.0009 & 0.03 & 0.09 & 0.26 & 0.66 & 2.07 & 5.76 \\
\hline Libya & 22.34 & 0.033 & 0.36 & -0.0012 & 0.0000 & -0.91 & -1.31 & 2.50 & 0.03 & 0.07 & 0.19 \\
\hline Lithuania & 6.42 & 0.028 & 0.84 & -0.0003 & 0.0008 & -0.12 & -0.27 & -0.45 & 0.41 & 1.26 & 4.16 \\
\hline Luxembourg & 9.07 & 0.028 & 0.65 & -0.0006 & 0.0003 & -0.29 & -0.56 & -0.12 & 0.19 & 0.54 & 1.60 \\
\hline Macedonia & 10.31 & 0.013 & 0.54 & 0.0007 & 0.0019 & 0.28 & 0.96 & 3.46 & 1.08 & 3.92 & 12.04 \\
\hline Madagascar & 22.87 & 0.021 & 0.28 & -0.0003 & 0.0006 & -0.20 & -0.45 & -0.75 & 0.55 & 1.54 & 4.14 \\
\hline Malawi & 22.26 & 0.023 & 0.34 & -0.0004 & 0.0007 & -0.29 & -0.62 & -0.57 & 0.62 & 1.76 & 4.81 \\
\hline Malaysia & 25.30 & 0.013 & 0.21 & -0.0002 & 0.0006 & -0.15 & -0.31 & -0.34 & 0.53 & 1.51 & 4.12 \\
\hline Mali & 28.70 & 0.021 & 0.38 & -0.0004 & 0.0009 & -0.24 & -0.50 & -0.38 & 0.67 & 1.96 & 5.53 \\
\hline Mauritania & 27.68 & 0.024 & 0.44 & -0.0004 & 0.0008 & -0.26 & -0.54 & -0.47 & 0.63 & 1.86 & 5.33 \\
\hline Mauritius & 23.92 & 0.022 & 0.30 & -0.0005 & 0.0002 & -0.38 & -0.70 & 0.15 & 0.13 & 0.34 & 0.92 \\
\hline Mexico & 20.43 & 0.012 & 0.25 & -0.0002 & 0.0009 & -0.10 & -0.21 & -0.23 & 0.64 & 1.97 & 5.54 \\
\hline Moldova & 9.37 & 0.020 & 0.78 & 0.0004 & 0.0016 & 0.17 & 0.50 & 1.68 & 0.81 & 2.85 & 9.51 \\
\hline Mongolia & 0.15 & 0.028 & 0.66 & -0.0003 & 0.0011 & -0.16 & -0.35 & -0.57 & 0.68 & 2.11 & 6.52 \\
\hline Montenegro & 8.54 & 0.020 & 0.48 & 0.0015 & 0.0026 & 1.05 & 3.33 & 9.64 & 2.09 & 6.42 & 17.50 \\
\hline Morocco & 18.77 & 0.021 & 0.44 & -0.0003 & 0.0009 & -0.18 & -0.38 & -0.44 & 0.65 & 1.97 & 5.80 \\
\hline Mozambique & 24.20 & 0.015 & 0.33 & -0.0004 & 0.0007 & -0.16 & -0.31 & -0.02 & 0.47 & 1.46 & 4.35 \\
\hline Myanmar & 22.98 & 0.020 & 0.30 & -0.0005 & 0.0004 & -0.34 & -0.61 & 0.25 & 0.29 & 0.80 & 2.24 \\
\hline Namibia & 19.57 & 0.026 & 0.50 & 0.0004 & 0.0015 & 0.27 & 0.77 & 2.26 & 1.20 & 3.58 & 9.99 \\
\hline Nepal & 15.13 & 0.018 & 0.38 & 0.0009 & 0.0020 & 0.59 & 1.82 & 5.34 & 1.61 & 4.86 & 13.15 \\
\hline Netherlands & 9.71 & 0.024 & 0.65 & -0.0006 & 0.0003 & -0.24 & -0.43 & 0.13 & 0.15 & 0.42 & 1.27 \\
\hline New Caledonia & 21.43 & 0.012 & 0.36 & 0.0008 & 0.0015 & 0.44 & 1.45 & 4.62 & 1.02 & 3.39 & 9.73 \\
\hline New Zealand & 10.16 & 0.002 & 0.39 & 0.0009 & 0.0017 & 0.23 & 1.17 & 4.78 & 0.70 & 3.18 & 10.35 \\
\hline Nicaragua & 26.18 & 0.029 & 0.34 & -0.0007 & 0.0001 & -0.57 & -1.05 & 0.32 & 0.08 & 0.22 & 0.58 \\
\hline Niger & 27.60 & 0.008 & 0.57 & -0.0007 & 0.0005 & -0.05 & 0.13 & 1.74 & 0.14 & 0.51 & 2.12 \\
\hline Nigeria & 26.87 & 0.016 & 0.30 & -0.0004 & 0.0006 & -0.23 & -0.42 & 0.08 & 0.42 & 1.24 & 3.56 \\
\hline Norway & 1.35 & 0.023 & 0.75 & -0.0008 & 0.0004 & -0.23 & -0.36 & 0.62 & 0.19 & 0.56 & 1.80 \\
\hline
\end{tabular}

Notes: We consider persistent increases in temperatures based on the RCP 2.6 and RCP 8.5 scenarios. The losses are based on $\Delta_{i h}\left(d_{i}\right)$, see equation (31), with $h=16,36$, and 86 (corresponding to the year 2030, 2050, and 2100, respectively) and $m=30$. 
Table A.2: Percent Loss in GDP per capita by 2030, 2050, and 2100 under the RCP 2.6 and RCP 8.5 Scenarios (continued)

\begin{tabular}{|c|c|c|c|c|c|c|c|c|c|c|c|}
\hline & \multicolumn{5}{|c|}{ Key Variables in Equation (31) } & \multicolumn{6}{|c|}{ Percent Loss in GDP per capita } \\
\hline & \multirow[t]{2}{*}{$\overline{\mathcal{T}} i$} & \multirow[t]{2}{*}{$\widehat{b}_{\mathcal{T} i}^{0}$} & \multirow[t]{2}{*}{$\widehat{\sigma}_{\mathcal{T} i}$} & \multicolumn{2}{|c|}{$d_{i}$} & \multicolumn{3}{|c|}{ RCP 2.6 Scenario } & \multicolumn{3}{|c|}{ RCP 8.5 Scenario } \\
\hline & & & & RCP 2.6 & RCP 8.5 & 2030 & 2050 & 2100 & 2030 & 2050 & 2100 \\
\hline Oman & 26.79 & 0.008 & 0.31 & 0.0002 & 0.0013 & 0.08 & 0.26 & 0.87 & 0.81 & 2.83 & 8.31 \\
\hline Pakistan & 20.43 & 0.010 & 0.40 & 0.0002 & 0.0015 & 0.08 & 0.26 & 0.88 & 0.88 & 3.16 & 9.55 \\
\hline Panama & 25.12 & 0.017 & 0.31 & 0.0000 & 0.0008 & 0.01 & 0.02 & 0.05 & 0.63 & 1.87 & 5.27 \\
\hline Papua New Guinea & 23.80 & 0.007 & 0.19 & 0.0003 & 0.0011 & 0.15 & 0.45 & 1.44 & 0.82 & 2.55 & 6.99 \\
\hline Paraguay & 23.72 & 0.005 & 0.50 & 0.0003 & 0.0014 & 0.06 & 0.23 & 1.02 & 0.49 & 2.21 & 8.01 \\
\hline Peru & 19.96 & 0.007 & 0.32 & 0.0002 & 0.0012 & 0.05 & 0.16 & 0.55 & 0.66 & 2.46 & 7.61 \\
\hline Philippines & 25.42 & 0.007 & 0.20 & 0.0005 & 0.0013 & 0.29 & 0.98 & 3.05 & 0.98 & 3.09 & 8.46 \\
\hline Poland & 7.84 & 0.026 & 0.76 & -0.0003 & 0.0008 & -0.12 & -0.27 & -0.43 & 0.38 & 1.16 & 3.83 \\
\hline Portugal & 15.20 & 0.010 & 0.42 & 0.0002 & 0.0013 & 0.07 & 0.22 & 0.72 & 0.68 & 2.46 & 7.75 \\
\hline Puerto Rico & 23.53 & 0.006 & 0.30 & 0.0006 & 0.0013 & 0.24 & 0.89 & 3.16 & 0.71 & 2.62 & 7.92 \\
\hline Qatar & 26.79 & 0.027 & 0.51 & -0.0004 & 0.0008 & -0.25 & -0.54 & -0.62 & 0.60 & 1.77 & 5.15 \\
\hline Romania & 8.91 & 0.019 & 0.62 & 0.0002 & 0.0014 & 0.10 & 0.27 & 0.83 & 0.77 & 2.64 & 8.47 \\
\hline Russian Federation & -5.96 & 0.035 & 0.68 & -0.0002 & 0.0014 & -0.14 & -0.34 & -0.71 & 1.03 & 3.08 & 8.93 \\
\hline Rwanda & 19.93 & 0.016 & 0.35 & 0.0001 & 0.0011 & 0.06 & 0.15 & 0.42 & 0.80 & 2.49 & 7.12 \\
\hline St. Vincent \& Grenadines & 26.69 & 0.012 & 0.29 & -0.0005 & 0.0002 & -0.19 & -0.26 & 0.70 & 0.13 & 0.38 & 1.16 \\
\hline Samoa & 26.24 & -0.004 & 0.28 & 0.0008 & 0.0014 & 0.02 & 0.66 & 3.64 & 0.31 & 2.31 & 8.31 \\
\hline Sao Tome and Principe & 25.69 & 0.024 & 0.29 & -0.0001 & 0.0007 & -0.04 & -0.11 & -0.27 & 0.69 & 1.88 & 4.97 \\
\hline Saudi Arabia & 25.51 & 0.021 & 0.55 & -0.0007 & 0.0006 & -0.26 & -0.38 & 0.78 & 0.34 & 1.05 & 3.35 \\
\hline Senegal & 28.29 & 0.026 & 0.35 & -0.0004 & 0.0006 & -0.31 & -0.67 & -0.73 & 0.53 & 1.46 & 4.01 \\
\hline Serbia & 9.96 & 0.016 & 0.54 & 0.0002 & 0.0014 & 0.09 & 0.25 & 0.78 & 0.79 & 2.74 & 8.66 \\
\hline Sierra Leone & 26.20 & 0.016 & 0.24 & -0.0004 & 0.0005 & -0.25 & -0.47 & -0.03 & 0.41 & 1.16 & 3.22 \\
\hline Slovakia & 7.64 & 0.020 & 0.61 & 0.0001 & 0.0013 & 0.06 & 0.17 & 0.50 & 0.71 & 2.36 & 7.54 \\
\hline Slovenia & 7.80 & 0.030 & 0.59 & 0.0003 & 0.0015 & 0.22 & 0.61 & 1.76 & 1.10 & 3.33 & 9.50 \\
\hline Solomon Islands & 26.85 & 0.010 & 0.18 & 0.0002 & 0.0009 & 0.12 & 0.35 & 1.04 & 0.77 & 2.23 & 5.98 \\
\hline Somalia & 26.65 & 0.021 & 0.32 & -0.0006 & 0.0003 & -0.37 & -0.65 & 0.41 & 0.22 & 0.59 & 1.66 \\
\hline South Africa & 17.52 & 0.007 & 0.33 & 0.0001 & 0.0012 & 0.04 & 0.11 & 0.35 & 0.67 & 2.46 & 7.56 \\
\hline South Korea & 11.07 & 0.008 & 0.49 & 0.0008 & 0.0019 & 0.30 & 1.15 & 4.34 & 0.96 & 3.73 & 11.68 \\
\hline South Sudan & 27.35 & 0.031 & 0.43 & -0.0008 & 0.0004 & -0.52 & -0.98 & 0.05 & 0.32 & 0.87 & 2.40 \\
\hline Spain & 13.31 & 0.026 & 0.45 & -0.0001 & 0.0010 & -0.08 & -0.19 & -0.43 & 0.77 & 2.26 & 6.39 \\
\hline Sri Lanka & 27.11 & 0.011 & 0.21 & -0.0001 & 0.0006 & -0.07 & -0.17 & -0.27 & 0.50 & 1.51 & 4.23 \\
\hline Sudan & 27.34 & 0.029 & 0.38 & -0.0009 & 0.0002 & -0.63 & -1.04 & 1.21 & 0.19 & 0.51 & 1.38 \\
\hline Suriname & 26.21 & 0.004 & 0.34 & 0.0003 & 0.0012 & 0.07 & 0.26 & 1.06 & 0.54 & 2.26 & 7.42 \\
\hline Swaziland & 20.33 & 0.017 & 0.43 & -0.0008 & 0.0002 & -0.29 & -0.23 & 2.14 & 0.09 & 0.24 & 0.71 \\
\hline Sweden & 2.27 & 0.021 & 0.89 & -0.0005 & 0.0007 & -0.14 & -0.24 & 0.07 & 0.24 & 0.76 & 2.67 \\
\hline Switzerland & 4.88 & 0.018 & 0.49 & 0.0008 & 0.0019 & 0.46 & 1.45 & 4.60 & 1.32 & 4.27 & 12.24 \\
\hline Syria & 17.88 & 0.022 & 0.65 & -0.0005 & 0.0007 & -0.19 & -0.37 & -0.07 & 0.37 & 1.12 & 3.67 \\
\hline Tajikistan & 3.08 & 0.000 & 0.57 & 0.0003 & 0.0017 & 0.01 & 0.06 & 0.38 & 0.43 & 2.38 & 9.35 \\
\hline Tanzania & 22.65 & 0.010 & 0.31 & -0.0003 & 0.0008 & -0.09 & -0.17 & 0.02 & 0.46 & 1.54 & 4.73 \\
\hline Thailand & 26.22 & 0.005 & 0.31 & -0.0002 & 0.0007 & -0.03 & -0.05 & 0.06 & 0.29 & 1.12 & 3.98 \\
\hline Togo & 26.41 & 0.018 & 0.25 & -0.0001 & 0.0008 & -0.07 & -0.18 & -0.41 & 0.76 & 2.13 & 5.64 \\
\hline Trinidad and Tobago & 25.62 & 0.024 & 0.30 & -0.0005 & 0.0003 & -0.36 & -0.76 & -0.56 & 0.24 & 0.64 & 1.74 \\
\hline Tunisia & 20.08 & 0.037 & 0.43 & -0.0011 & 0.0001 & -0.82 & -1.40 & 1.21 & 0.08 & 0.21 & 0.53 \\
\hline Turkey & 11.24 & 0.014 & 0.70 & 0.0002 & 0.0014 & 0.07 & 0.20 & 0.64 & 0.60 & 2.26 & 7.98 \\
\hline Turkmenistan & 15.67 & 0.025 & 0.67 & 0.0000 & 0.0012 & 0.00 & -0.01 & -0.01 & 0.72 & 2.30 & 7.19 \\
\hline Uganda & 22.84 & 0.020 & 0.31 & -0.0004 & 0.0005 & -0.28 & -0.56 & -0.17 & 0.42 & 1.19 & 3.32 \\
\hline Ukraine & 8.17 & 0.026 & 0.81 & 0.0002 & 0.0014 & 0.08 & 0.22 & 0.63 & 0.73 & 2.39 & 7.82 \\
\hline United Arab Emirates & 27.22 & 0.016 & 0.48 & 0.0002 & 0.0015 & 0.08 & 0.22 & 0.65 & 0.92 & 3.10 & 9.31 \\
\hline United Kingdom & 8.69 & 0.013 & 0.46 & -0.0001 & 0.0007 & -0.02 & -0.05 & -0.11 & 0.34 & 1.16 & 3.97 \\
\hline United States & 6.94 & 0.015 & 0.36 & 0.0004 & 0.0016 & 0.20 & 0.60 & 1.88 & 1.20 & 3.77 & 10.52 \\
\hline Uruguay & 17.49 & 0.015 & 0.35 & 0.0002 & 0.0009 & 0.09 & 0.24 & 0.70 & 0.65 & 2.05 & 6.00 \\
\hline US Virgin Islands & 26.79 & 0.023 & 0.45 & -0.0009 & -0.0002 & -0.41 & -0.50 & 1.89 & -0.13 & -0.30 & -0.54 \\
\hline Uzbekistan & 12.84 & 0.021 & 0.69 & 0.0007 & 0.0019 & 0.30 & 0.93 & 3.11 & 1.11 & 3.79 & 11.72 \\
\hline Vanuatu & 24.75 & 0.028 & 0.33 & -0.0005 & 0.0002 & -0.38 & -0.83 & -0.87 & 0.21 & 0.55 & 1.48 \\
\hline Venezuela & 25.00 & 0.016 & 0.30 & 0.0000 & 0.0010 & 0.00 & 0.00 & -0.01 & 0.82 & 2.45 & 6.74 \\
\hline Vietnam & 23.20 & 0.005 & 0.32 & 0.0000 & 0.0009 & 0.00 & 0.01 & 0.02 & 0.38 & 1.51 & 5.15 \\
\hline Yemen & 24.56 & 0.035 & 0.60 & -0.0007 & 0.0004 & -0.40 & -0.82 & -0.61 & 0.27 & 0.74 & 2.12 \\
\hline Zambia & 21.17 & 0.019 & 0.47 & 0.0003 & 0.0015 & 0.18 & 0.51 & 1.56 & 1.06 & 3.40 & 9.82 \\
\hline Zimbabwe & 21.24 & 0.014 & 0.47 & 0.0001 & 0.0013 & 0.04 & 0.12 & 0.35 & 0.76 & 2.62 & 8.15 \\
\hline
\end{tabular}

Notes: We consider persistent increases in temperatures based on the RCP 2.6 and RCP 8.5 scenarios. The losses are based on $\Delta_{i h}\left(d_{i}\right)$, see equation $(31)$, with $h=16,36$, and 86 (corresponding to the year 2030, 2050, and 2100 , respectively) and $m=30$. 


\section{Table B.1: Division (SIC) and Sector (NAICS) Classifications}

\begin{tabular}{ll}
\hline Division (SIC) & Sector (NAICS) \\
\hline Agriculture, Forestry, Fisheries & Agriculture, Forestry, Fishing \& Hunting \\
Mining & Mining \\
Construction & Construction \\
Manufacturing & Manufacturing \\
& Transportation \& Warehousing \\
Transport, Communication, and Public Utilities & Information \\
& Utilities \\
Wholesale Trade & Wholesale Trade \\
Retail Trade & Retail Trade \\
Finance, Insurance, and Real Estate & Finance/Insurance/Real Estate/Rental/Leasing \\
& Professional \& Business Services \\
Services & Educational Services/Health Care/Social Assistance \\
& Arts/Entertainment/Recreation/Accommodation/Food Services \\
Government & Other Services, Ex Government \\
\hline
\end{tabular}

\section{B U.S. Data Appendix}

We obtain state-level economic activity data from the Bureau of Economic Analysis (BEA). Real Gross State Product (GSP) data is available from 1977, but nominal GSP data is available from 1963. We deflate the nominal GSP series using the consumer price index (CPI) for each state, and splice the resulting data over 1963-1977 with the real GSP from 1977 using annual growth rates, to construct a real GSP series for 1963-2016.

BEA provides output by sector at the state level from 1963. However, there are two issues with this database. Firstly, there was a change in industrial classifications in 1997: from 1963 to 1997, the Standard Industrial Classification (SIC) consists of ten divisions, while from 1997 onwards, the North American Industry Classification System (NAICS) gradually replaces the SIC, further branching the ten divisions into fifteen sectors. ${ }^{26}$ Secondly, as with the GSP data, only nominal sectoral output data (by SIC divisions) is available before 1977. Real sectoral output is available in both SIC and NAICS classification in 1997. This allows us to construct the real sectoral output series from 1963-2016. Specifically, building a series over the period 1963 to 2016 involves two steps: (i) reconciling SIC and NAICS classifications (see Table B.1), and (ii) splicing the most recent real series (1997-2016) backwards using growth rates from the deflated nominal series (1963-1997).

We use BEA's producer price index (PPI) data to deflate the nominal industry outputs under SIC for the years 1963-1976. As the PPI data is constructed based on NAICS, we use the SICNAICS matching in Table B.1 for the PPI deflator. Where there is more than one NAICS sector matched to a SIC division, we take a simple arithmetic average of the PPI of all matched NAICS sectors. From 1997 onwards, real output by sector is available based on NAICS classification. We, therefore, aggregate the NAICS real output by industry to SIC divisions using our matching scheme, and splice these series backwards using the growth rates of real sectoral output under SIC in 1963-1997. This gives us real output by sector and state for the period 1963 to $2016{ }^{27}$

\footnotetext{
${ }^{26}$ See Kort (2001) for more details.

${ }^{27}$ Note that "Agriculture, Forestry, Fishing \& Hunting" and "Mining" data is not available for Rhode
} 
We collect monthly state-level, area-weighted climate data from the NOAA's National Centres for Environmental Information (NCEI). The NCEI reports monthly average temperature and precipitation $^{28}$ for each state from aggregates of climate readings across weather stations, adjusting for the distribution of stations and terrain. Temperature is measured in degrees Fahrenheit and precipitation in inches. We convert them into degrees Celsius and millimeters, respectively (to match our cross-country data). The monthly averages in each year within the sample period are then used to obtain annual averages.

Finally, we obtain U.S. employment data from the Bureau of Labor Statistics (BLS). We take annual, state-level number of employed persons that encompasses "persons 16 years and over in the civilian noninstitutional population" under a wide range of employment conditions.

Island in 2016 and agricultural data in 2016 is also unavailable for Delaware. Moreover, the mining industry of Delaware is excluded from our sample due to multiple irregular missing entries.

${ }^{28}$ Snow is included as melted precipitation in rain gauges under NOAA methodology. 